\title{
Disparités socio-ethniques et hiérarchies de la terre en perspectives : du poste de Détroit aux cantons de Malden et de Sandwich, comté d'Essex (1871)
}

\section{Fernand Ouellet}

Volume 5, 2002

URI : https://id.erudit.org/iderudit/1039351ar

DOI : https://doi.org/10.7202/1039351ar

Aller au sommaire du numéro

Éditeur(s)

Société Charlevoix

Presses de l’Université d'Ottawa

ISSN

1203-4371 (imprimé)

2371-6878 (numérique)

Découvrir la revue

Citer cet article

Ouellet, F. (2002). Disparités socio-ethniques et hiérarchies de la terre en perspectives : du poste de Détroit aux cantons de Malden et de Sandwich, comté d'Essex (1871). Cahiers Charlevoix, 5, 47-139.

https://doi.org/10.7202/1039351ar
Résumé de l'article

Allant à l'encontre des thèses égalitaristes (Dechêne, Greer) ou partiellement égalitaristes (Paquet et Wallot, Courville) qui ont cours pour expliquer les sociétés nouvelles, Fernand Ouellet examine les " disparités socio-ethniques " et les " hiérarchies de la terre " qu'il constate avant 1871 dans les cantons de Malden et de Sandwich, dans le sud-ouest ontarien. Cet article fait suite à son analyse de la population de Hawkesbury et d'Alfred, dans l'est ontarien, où il avait spécifiquement abordé cette question. Parmi les nombreux facteurs qui sont au coeur de sa discussion et qui permettent de rendre compte des écarts entre les groupes ethniques, le moment de l'arrivée dans la région a une importance substantielle. Si les Canadiens français avaient été les derniers venus dans l'Est, ils furent les premiers dans le Sud-Ouest, ce qui leur donna une prépondérance certaine. Mais d'autres facteurs jouent aussi un rôle important, notamment l'âge et le lieu d'origine, la religion et l'alphabétisation. Sans négliger aucun de ces éléments, mais en considérant en outre les pratiques antérieures de distribution des terres, à partir de sources diverses aveux et dénombrements, terriers, recensements -, Fernand Ouellet montre que les inégalités sont structurelles, que la thèse égalitariste « relève beaucoup plus du mythe que de la réalité », car l'évolution du Québec, comme celle de Malden et de Sandwich avant 1871, n'est « qu'un aspect de la prolifération des inégalités socio-économiques et socioculturelles à tous les niveaux ».
Ce document est protégé par la loi sur le droit d'auteur. L’utilisation des services d’Érudit (y compris la reproduction) est assujettie à sa politique d'utilisation que vous pouvez consulter en ligne.

https://apropos.erudit.org/fr/usagers/politique-dutilisation/ 


\section{DisPARITÉS SOCIO-ETHNIQUES}

ET HIÉRARCHIES DE LA TERRE EN

PERSPECTIVES: DU POSTE DE DÉTROIT

auX Cantons de Malden et de Sandwich, COMTÉ D’ESSEX (1871)*

Fernand Ouellet

Département d'histoire

Université York, Toronto

* Ce texte a été rédigé grâce à l'appui du programme Killman.

Cahiers Charlevoix 5, 2002, pp. 47-139 


\section{SOMMAIRE}

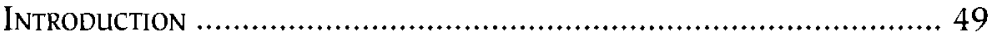

I - De la Nouvelle-France au Sud-Ouest ontarien ....................... 55

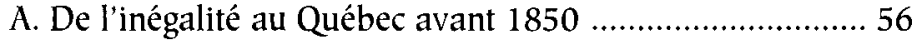

B. De la société de Détroit en 1701

à celle de Malden et de Sandwich en 1871 ................. 75

II - LE PROFIL SOCIO-ETHNIQUE ET CULTUREL DES HABITANTS

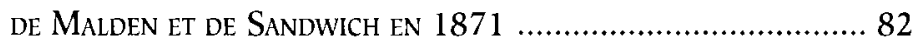

III - HiÉRARCHIES SOCIALES ET HIÉRARCHIES

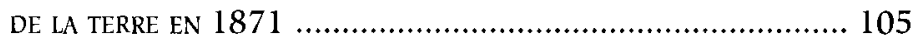

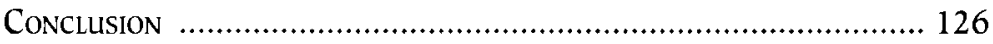




\section{DISPARITÉS SOCIO-ETHNIQUES}

\section{ET HIÉRARCHIES DE LA TERRE EN}

PERSPECTIVES: DU POSTE DE DÉTROIT

\section{aux cantons de Malden et de Sandwich, COMTÉ D’ESSEX (1871)}

\section{INTRODUCTION}

Longtemps, les historiens ont eu tendance à présenter les sociétés nouvelles créées du XVII ${ }^{\mathrm{e}}$ au XIX $\mathrm{X}^{\mathrm{e}}$ siècle le long du Saint-Laurent, y compris leurs paysanneries, comme des communautés égalitaires. Cette façon de voir les choses obnubilait le fait que les métropoles qui leur avaient donné naissance étaient tout à fait hiérarchisées et que l'environnement nord-américain était beaucoup plus accueillant que ces historiens ne le prétendent à l'enracinement de ces divisions sociales. Ainsi, l'implantation en Nouvelle-France du régime seigneurial, pour ne nommer que cette institution, avait été un essai réussi pour refléter, par le biais de la répartition inégale du sol et des droits seigneuriaux, la hiérarchie sociale dont les diverses catégories d'immigrants et les grands commis de la métropole et de l'État colonial étaient eux-mêmes imbus. Les distributions massives ${ }^{1}$ et

${ }^{1}$ Avant 1663,14521734 arpents de terre furent concédés à titre de fiefs, d'arrières-fiefs et d'arrières-arrières-fiefs à environ 64 personnages éminents de 
inégales de seigneuries aux nobles, aux clercs et aux bourgeois, faites avant 1663, alors que la population était encore peu nombreuse, n'avaient été que l'amorce d'un processus qui engloba aussi les censives. Cette façon de répartir la terre avait des racines si lointaines et si profondes qu'elle fut réactivée durant la dernière décennie du XVIII siècle à l'intention d'une autre clientèle et avec un autre système, juste avant que le terroir seigneurial ne commence à être encombré.

Ainsi, lorsque vint le moment de mettre en place un cadre pour la distribution des terres situées en dehors des seigneuries bas-canadiennes et des terres situées dans le Haut-Canada, le système du franc et commun soccage fut choisi. L'État aurait pu, par ce moyen, répartir la terre en toute égalité à qui en ferait la demande. Mais il l'utilisa moins avec l'idée d'échapper aux écueils du féodalisme qu'avec le désir de susciter l'émergence d'une aristocratie foncière locale en tant que barrière contre les aspirations démocratiques. Comme le dit si bien Joy Parr:

The first land grants in the Colony to Loyalists and military settlers varied in size to reflect the rank and social situation of the recipients. Through time a hierarchy in holding sizes was maintained through differential access to capital and patronage, and by the vagaries of inheritance and family fortune ${ }^{2}$.

Cette façon, parmi d'autres, d'instaurer les inégalités sociales se traduisit concrètement par des octrois gratis de terre de 200 ou 300 acres aux simples soldats et aux Loyalistes ordinaires et de 1000 ou 5000 acres $^{3}$ en faveur des officiers militaires, des hauts fonctionnaires et des mar-

la colonie, soit 226902 arpents par individu. Marcel Trudel, Le Terrier du SaintLaurent en 1663, Ottawa, Éditions de l'Université d'Ottawa, 1973, p. 529.

${ }^{2}$ Joy Parr, "Hired Men: Ontario Agricultural Wage Labour in Historical Perspective $»$, Labour/Le Travail, 15, 1985, p. 91.

${ }^{3}$ Leo Johnson, «Land Policy, Population Growth, and Social Structure in Historical Perspective», J.K. Johnson (dir.), Historical Essays on Upper Canada, Toronto, McCelland and Stewart, 1975, pp. 32-73. 
chands. Dans les deux Canadas ${ }^{4}$, les aspects abusifs de ce système, notamment l'absentéisme de nombreux grands propriétaires, le coût élevé des honoraires exigés par les officiers gouvernementaux, ainsi que les réserves de la couronne et du clergé anglican, furent de plus en plus dénoncés. Dès lors, le mouvement pour libérer la terre de ces entraves ne cessa de progresser. En 1826, le gouvernement introduisit, ce qui n'était pas un avantage pour les plus pauvres, la vente avec paiements échelonnés, système qui, en 1837 , fut remplacé par celui de la vente au comptant. Au sujet des procédés en vigueur de 1810 à 1840, David Gagan écrit: "The result of this system in Peel, as elsewhere in Upper Canada, was the distortion of the settlement process to the detriment of the ordinary settler ${ }^{5} . »$

Les immigrants, qui désiraient avant tout avoir accès à la terre, particulièrement à la propriété, et qui se présentaient dans une contrée où la terre était en grande abondance, ne pouvaient que se sentir limités par une structure qui, à l'origine, tenait compte de leur rang, de leur degré de richesse et de leur niveau d'instruction. Ceux qui en souffrirent le plus furent les immigrants les plus pauvres, obligés de se reclasser, pour un temps ou pour toujours, comme locataires ou journaliers. En se référant à des études américaines sur ces questions, William L. Marr écrivait en 1984:

\footnotetext{
${ }^{4}$ Même si les normes et leur interprétation changèrent au cours des ans, la concentration des terres aux mains d'une petite élite se poursuivit, mais beaucoup moins, semble-t-il, dans le Haut-Canada que dans la colonie voisine. Ainsi, dans le Bas-Canada, de 1795 à 1817, 1705940 acres de terre furent concédées à 74 individus dans 62 cantons, soit une moyenne de 19453 acres pour le chef du canton et de 200 acres pour chacun de ses 18 associés. Compilation faite à partir des informatons contenues dans Ivanhoë Caron, $\mathrm{La}$ Colonisation de la province de Québec, Les cantons de l'Est, 1791-1815, Québec, s.n. d'éditeur, 1927, pp. 86-188, 211-236.

${ }^{5}$ David Gagan, Hopeful Travelers, Families, Land, and Social Change in MidVictorian Peel County, Canada West, Toronto, University of Toronto Press, 1981, p. 23.
} 
farmers climb a ladder, with the bottom rung representing someone who hires himself out for wages; on the second rung is a tenant (cash or share); and on the top rung is an owner-operator. The latter have several advantages which are scarce to those on the other two rungs - namely, savings, a credit standing, knowledge of the agricultural techniques used in the area, capital (including livestock), and market contacts. These can all be acquired, but they take time and some effort; thus a person starts as a labourer or tenant and moves to being an owner-operator after he has acquired the necessary assets ${ }^{6}$.

Déjà, à travers ce processus, se dessine l'image d'une paysannerie très tôt divisée entre propriétaires et locataires, entre cultivateurs, excédentaires à des degrés divers, et petits producteurs forcés, afin de joindre les deux bouts, de se livrer à des travaux saisonniers tant en agriculture qu'ailleurs.

Pour apercevoir cette réalité plus complètement, il est nécessaire de rappeler que l'immigration n'était pas seulement le fait de familles et d'individus inscrits dans certaines occupations, comme certains historiens veulent bien le faire savoir, mais aussi de groupes ethniques et religieux. En effet, ces derniers, aussi bien que les premiers, eurent tendance à se regrouper en certains lieux plutôt qu'en d'autres. Ils virent ainsi définir leur place en fonction de leur nombre relatif dans chacune des catégories sociales et de leur héritage culturel. Remettant en question cette perspective qui fait fi de la question ethnique, Ken Lockwood fait remarquer dans son étude du canton de Montague que: «Hence a work as David Gagan's study of Peel county, in which the Irish came to comprise half the population, does not deign to list them in its index ${ }^{7}$." Avec raison, puisque les Irlandais de Montague, plus pauvres que les autres immigrants et arri-

\footnotetext{
${ }^{6}$ William L. Marr, «Tenant vs. Owner Occupied Farms in York County, Ontario, $1871 »$, Donald Akenson (ed.), Canadian Papers in Agricultural History, 4, Gananoque, Langdale Press, 1984, p. 54.

${ }^{7}$ Ken Lockwood, «Irish Immigrants and the "Critical Years" in Eastern Ontario: The Case of Montague Township, 182 1-1881", Canadian Papers in Agricultural History, 4, 1984, pp. 154, 167.
} 
vés après eux, avaient, dit Lockwood, été obligés, contrairement à leurs devanciers, d'acheter leurs terres au lieu de les recevoir gratuitement. Ce qui signifie que leur arrivée tardive dans ce canton avait certainement eu de sérieux effets sur leur localisation et sur la qualité des sols qu'ils eurent en partage. De là, des disparités plus ou moins définitives, non seulement à l'intérieur de chacune des ethnies, mais aussi entre les ethnies elles-mêmes.

Ce sont là des considérations dont nous avons déjà vérifié la pertinence dans deux cantons de l'Est ontarien, Hawkesbury et Alfred, où des émigrants canadiens-français catholiques, pauvres et peu alphabétisés, parvinrent, entre 1860 et 1871 , à former une communauté majoritaire stable $^{8}$. Arrivés les derniers dans cette région, ils s'y trouvèrent, pour cette raison et autrement, fortement surreprésentés parmi les catholiques, les analphabètes, les journaliers, les locataires et les cultivateurs qui dépendaient davantage du travail en forêt pour survivre. Qu'ils aient éprouvé plus de difficultés à accéder à la propriété foncière et qu'ils aient été grandement sous-représentés parmi les classes dirigeantes et les cultivateurs les plus productifs allait presque de soi en l'occurrence.

C'est à partir de ces mêmes préoccupations que notre attention se porte maintenant sur le Sud-Ouest ontarien, région au sol plus riche que ne l'était celui de l'est de la province. Car, en ces lieux, les Canadiens français avaient été, dès 1708, les initiateurs de la colonisation agricole et s'y étaient maintenus en se concentrant de plus en plus sur le territoire des comtés actuels d'Essex et de Kent. Mais, en 1851 , ils avaient été tellement submergés par l'immigration anglophone qu'ils ne comptaient plus que pour $4,8 \%$ de la population du Sud-Ouest. Par la suite, ils améliorèrent un peu leur représentation, passant à 5,4\% en 1911. Dans le

${ }^{8}$ F. Ouellet, «Inégalités ethniques, disparités socio-culturelles et hiérarchie de la terre à Hawkesbury et à Alfred en 1871 ", Cahiers Charlevoix, 4, 2000, pp. 51-148. 
comté d'Essex où, en 1851 , résidaient $74 \%$ des Canadiens français du Sud-Ouest et $21 \%$ de ceux de la province, leur croissance fut très rapide jusqu'en 1881 , multipliant alors leurs effectifs par 2,6. Dès lors, leur progression ralentit considérablement. Bien loin de doubler leur nombre sans immigration en 25 ans, ils ne l'accrurent que de $41 \%$ en 30 ans. Essex perdit donc du terrain par rapport aux autres concentrations canadiennes-françaises de la province puisque, à cette date, seulement $10 \%$ des éléments d'origine française y étaient regroupés. Cependant, à l'intérieur d'Essex, leur situation resta tout à fait confortable. Car, pendant toutes ces années, leurs effectifs se stabilisèrent à un peu moins du tiers de la population. Même si leur taux d'urbanisation resta toujours inférieur à celui des autres, ils n'en suivirent pas moins, quoiqu'à un rythme plus lent, ce mouvement presque universel: $8,1 \%$ pour eux et $10,9 \%$ pour les autres en $1851 ; 37 \%$ pour eux et $53 \%$ pour les autres en 1911.

La population des cantons de Malden et de Sandwich se chiffrait à 10059 habitants en 1871 , soit $31 \%$ de celle du comté d'Essex. Celle de Malden, moins de la moitié de celle de Sandwich, était concentrée dans la ville d'Amherstburg dans une proportion de 56\%. Le canton de Sandwich, bien que le plus peuplé, était, au contraire, rural à $84 \%$. Dans l'ensemble des deux cantons, les Canadiens français étaient les plus ruraux par une marge considérable, alors que les Anglais et les Noirs étaient les plus urbains. Les chefs de maisonnée y étaient au nombre de 1861 , dont 815 anglophones, 863 Canadiens français et 183 Noirs. Parmi les anglophones, les Irlandais surpassaient à peine les Anglais. Pour leur part, les Canadiens français y représentaient la moitié de la population et $46 \%$ des chefs de maisonnée. Étant donné la grande variété des profils socio-ethniques présents dans ces communautés,il ne fait pas de doute que les cantons de Malden et de 
Sandwich, comme ceux de Hawkesbury et d'Alfred, constituaient des endroits privilégiés pour l'étude des inégalités ethniques, économiques et sociales. Avec une différence majeure, cependant: en 1871, les chefs de maisonnée canadiens-français de l'Est ontarien étaient en grande majorité presque fraîchement arrrivés du Québec, alors que ceux du Sud-Ouest étaient les descendants de ceux qui avaient fréquenté le poste de Détroit, fondé en 1701, et avaient persisté dans cette région en dépit de tout les changements d'allégeance et de territoire. En 1871, à Hawkesbury et à Alfred, la proportion des chefs de maisonnée canadiens-français nés en Ontario se chiffrait à seulement $14 \%$, alors qu'à Malden et Sandwich, elle s'élevait à $76 \%$. Ici, les éléments d'origine afro-américaine, parmi lesquels seulement $10 \%$ étaient nés en Ontario, étaient les plus défavorisés.

\section{I - De la Nouvelle-France au Sud-Ouest ontarien}

Cette histoire est donc celle d'une communauté qui s'était formée sur un territoire qui se rattachait à la NouvelleFrance, en un lieu dominé par la traite et à une époque où les rapports agriculture-pelleteries s'exprimaient avec une intensité maximale. Après le début du $\mathrm{XIX}^{\mathrm{e}}$ siècle, ces Canadiens français participèrent à leur façon au développement du Haut-Canada autour de l'agriculture et de l'exploitation de la forêt, étant aussi présents dans les industries et les villes lorsque celles-ci virent le jour. Leur communauté devait beaucoup à la société inégalitaire qui l'avait fondée. Tout autant, d'ailleurs, que celles que les Canadiens français iront, après 1840 , créer dans les villes de la Nouvelle-Angleterre, ainsi qu'à Hawkesbury et à Alfred. 


\section{A. De L'INÉGALITÉ Au QuéBEC AVANT 1850}

En 1987, Christian Dessureault ${ }^{9}$ écrivait que l'égalitarisme paysan était "en grande partie un mythe frontiériste». Pourtant, bien avant l'Américain Turner $^{10}$ qui publia sa thèse en 1893, les historiens canadiens-français de la survivance nationale avaient reconstruit le passé de la nation en termes d'homogénéité et d'égalitarisme. Aussi la paysannerie était-elle, en tant que lieu privilégié où fermentaient les valeurs nationales, homogène par la race, la religion et ses rapports à la terre. Bien sûr, des classes dirigeantes existaient dans cette société, mais, ajoutentils, loin d'être possédées par l'esprit de classe, elles étaient surtout les servantes attentives des aspirations et des intérêts collectifs.

Plus d'un siècle après Garneau, l'idée d'une paysannerie égalitaire animait encore le discours des historiens néonationalistes et même de certains nationalistes touchés par le marxisme qui utilisèrent le modèle de la classe ethnique pour redire ces choses ${ }^{11}$. Avec Louise Dechêne, l'idée d'une paysannerie homogène et égalitaire prit une importance d'autant plus capitale que cette historienne dessinait une frontière à peu près étanche entre la ville et la campagne. Une telle coupure tendait à confiner le colonial, le hiérarchisé et l'inégalitaire au milieu urbain qui n'avait, ajoute-t-elle, que «des attaches nominales avec le monde rural ${ }^{12}$ ». La paysannerie assise sur «l'uniformité

\footnotetext{
${ }^{9}$ Christian Dessureault, «L'Égalitarisme paysan dans l'ancienne société rurale de la vallée du Saint-Laurent: éléments pour une ré-interprétation", $R H A F$, 40, 1987, p. 406.

${ }^{10}$ Frederick Jackson Turner, The Frontier in American History, New York, Holt, Rinehart and Winston, 1962, 375 p.

${ }^{11}$ Gilles Bourque, Classes sociales et question nationale au Québec, 1760-1840, Montréal, Éditions Parti pris, 1970, pp. 9-55; Denis Monière, Le Développement des idéologies au Québec des origines à nos jours, Montréal, Éditions QuébecAmérique, 1977, pp. 13-156.

${ }^{12}$ Louise Dechêne, Habitants et marchands de Montréal au XVII siècle, Paris et Montréal, Plon, 1974, p. 489.
} 
des exploitations ${ }^{13}$ " était donc "la seule catégorie durable» d'une nation en formation ${ }^{14}$.

On pourrait croire que des historiens aux perspectives plus marxistes que nationalistes ${ }^{15}$ auraient abandonné cette idée d'une paysannerie homogène. Mais s'ils l'avaient fait, comment auraient-ils pu soutenir qu'une paysannerie affligée de sérieuses divisions internes aurait pu s'unir en 1837 et mener sans flancher le bon combat contre les féodaux et les colonisateurs? C'est le dilemme auquel Allan Greer fut confronté dans son étude de trois seigneuries de la vallée du Richelieu. Là, il s'agissait, selon lui, de paysans exploités par des seigneurs nobles, par des clercs et des marchands qui, en 1765, ne possédaient pas tous des étendues égales de terres. Cependant, Greer les décrit ainsi: «a largely homogeneous class of cultivators living in selfsufficient households, each possessing enough land to live on but not enough to dominate others ${ }^{16} "$. Mais, entre 1765 et 1831 , cette société se diversifie davantage, la paysannerie devient de plus en plus inégale, un prolétariat rural émerge ${ }^{17}$, des pressions démographiques apparaissent, la proportion des occupants de terres de moins de 100 arpents augmente substantiellement et, dès la fin du XVIII siècle, nombre de personnes quittent les lieux chaque année. Néanmoins, Greer maintient son diagnostic antérieur: "However, a closer look at evolving social structures reveals that these divisions were still quite limited ${ }^{18}$."

${ }^{13}$ Ibid., p. 487 . Voir aussi p. 486.

${ }^{14}$ Ibid., pp. 487-488.

${ }^{15}$ Lise Pilon-Lêe, «Le Régime seigneurial au Québec: contribution à une analyse de la transition du féodalisme au capitalisme", Cahiers du socialisme, 6, 1980, pp. 133-168; Gilles Bourque et Anne Légaré, Le Québec. La question nationale, Paris, Maspéro, 1979, $232 \mathrm{p}$.

${ }^{16}$ Allan Greer, Peasant, Lord and Merchant. Rural Society in Three Quebec Parishes, 1740-1840, Toronto, UTP, 1985, p. 21.

${ }^{17}$ Dans les townships de Hawkesbury et d'Alfred, en 1871 , le nombre de chefs de maisonnée journaliers est de 362 et le nombre de journaliers résidant dans les maisonnées sans en être les chefs est de 300, pour un total de 662 . La différence est importante.

${ }^{18}$ Ibid. , p. 218. 
Pour Gilles Paquet et Jean-Pierre Wallot, la paysannerie reste homogène et autosuffisante jusqu'au début du XIX ${ }^{e}$ siècle. C'est alors que se produit l'intrusion soudaine et fracassante de l'économie de marché, qu'ils décrivent un peu comme s'il s'agissait de l'origine de la mondialisation des marchés ${ }^{19}$. Car, en plus d'avoir des effets régénérateurs à tous les niveaux de la société, cet événement aurait marqué l'avènement d'une paysannerie dynamique, diversifiée et habitée par un nombre croissant de producteurs de plus en plus riches. Tout cela n'était que la conséquence normale et presque universellement bénéfique de la modernisation par le marché ${ }^{20}$.

L'accroissement de la richesse, disent-ils, se répartit aussi inégalement entre les groupes sociaux et à l'intérieur de chacun d'eux. . Cette transformation de la structure de la richesse traduit en plus une grande différenciation sociale sous la pression du marché: les riches deviennent plus riches, la moyenne des habitants accroissent leurs biens, les moins riches se trouvent de plus en plus distancés par les plus favorisés ${ }^{21}$.

Pour décortiquer cette mutation, les auteurs s'en remettent à une source unique, fort utile à certains égards, mais qui soulève, comme telle, des questions de fond, notamment le fait que les individus les plus pauvres n'avaient guère recours à cette pratique. Bien plus, leur échantillon de 924 inventaires après décès, retenus pour les années 1791-1835, était biaisé en faveur des villes de Québec et de Montréal. En effet, 39\% des inventaires, soit 357, portent sur elles, quand la population urbaine représentait moins de $13 \%$ de celle de la province. D'ailleurs, de la première à la dernière tranche chronologique, le nombre d'inventaires

\footnotetext{
${ }^{19}$ Gilles Paquet, Oublier la révolution tranquille. Pour une nouvelle socialité, Montréal, Liber, 1999, 159 p.

${ }^{20}$ Gilles Paquet et Jean-Pierre Wallot, «Structures sociales et niveaux de richesse dans les campagnes du Québec, 1792-1812", Material History Bulletin, Ottawa, National Museum of Man,1983, 17, pp. 35, 43.

${ }^{21}$ Idem, "Stratégie foncière de l'habitant: Québec (1790-1835)", RHAF, 1986, 39 , p. 559.
} 
retenus ne s'accroît que du double, alors que la population catholique de la province se multiplie par trois ${ }^{22}$. Christian Dessureault qui a recueilli tous les inventaires dressés dans la seigneurie de Saint-Hyacinthe de 1795 à 1835, en a trouvé un par 14 habitants dans la première tranche chronologique et seulement un par 43 habitants dans la seconde. Ce qui voudait dire que le nombre d'inventaires aurait décliné au XIX ${ }^{\mathrm{e}}$ siècle en même temps que le nombre de pauvres aurait augmenté. Aussi, dans sa conclusion à propos des inventaires après décès, Dessureault est beaucoup moins enthousiaste que ses collègues d'Ottawa:

les données du recensement de 1831 montrent que l'utilisation des inventaires après décès minimise fortement le nombre réel de petits propriétaires, surtout ceux de moins de 60 arpents, et grossit quelque peu celui des grands propriétaires de 300 arpents et plus ${ }^{23}$.

Cette thèse de la modernisation de la société par le déblocage soudain de l'agriculture a été reprise par Serge Courville. Avant ce moment décisif, dit-il, le paysan était le porte-parole silencieux mais agissant de la culture. À cause de son rapport à la famille, à l'établissement des enfants, à la survie du patrimoine, il était davantage, aux XVII et $\mathrm{XVIII}^{\mathrm{e}}$ siècles, lié à la terre «non pas pour sa valeur d'échange, mais pour sa valeur d'usage ${ }^{24} »$. C'est de cette façon qu'il apparaissait comme le véritable créateur d'un nouveau pays. Mais, à partir de 1815 , ce même paysan se serait animé et transformé en être de marché ${ }^{25}$. Grâce à son dynamisme et à l'appui de la bourgeoisie rurale, les villages

\footnotetext{
${ }^{22}$ Jean-Pierre Hardy, Gilles Paquet, David Thiery Ruddel et Jean-Pierre Wallot, Culture matérielle et société au Québec, 1792-1835, Material History Bulletin, Ottawa, National Museum of Man, 1983, 17, p. 12.

${ }^{23}$ Christian Dessureault, "Crise et modernisation. La société rurale maskoutène durant le premier tiers du XIX ${ }^{e}$ siècle», RHAF, 42, 1987, pp. 363, 379.

${ }^{24}$ Serge Courville, "Conclusion", dans Peuplement colonisateur aux XVII et XVIII ${ }^{e}$ siècles, 1987, Cahiers du Célat, 8, p. 287.

${ }^{25}$ Serge Courville, Entre ville et campagne. L'essor du village dans les seigneuries du Bas-Canada, Québec, PUL, 1990, pp. 24, 34, 59.
} 
et les petites industries se seraient multipliées d'une façon spectaculaire dans la province. En disant cela, l'auteur voulait démontrer qu'il existait une voie spécifiquement canadienne-française vers l'urbanisation et l'industrialisation du Québec. Pour illustrer son propos sur la modernité, Courville affirme, dans un premier temps, que le nombre de villages, qui ne s'était accru que de 25 à 53 de 1762 à 1815 , s'éleva brusquement à 210 en 1831 et à 306 en 1851. À vrai dire, son argumentation repose sur un seul chiffre: les 53 villages de 1815 tirés de la Description topographique du Bas-Canada de Joseph Bouchette. Si cette donnée était exacte, il y aurait eu un village par 2321 habitants en 1762, un par 5623 habitants en 1815 , un par 2137 en 1831 et un par 2539 en $1851^{26}$. Autrement dit, le nombre d'habitants par village aurait augmenté dramatiquement de la conquête à 1815 , pour ensuite revenir, de 1831 à 1851 , au niveau où il était en 1762 .

TABLEAU 1

Évolution du nombre de villages au Québec, au Bas-Canada et au Canada-Est de 1762 à 1851 par rapport à la population rurale

\begin{tabular}{|c|c|c|c|c|c|c|c|}
\hline & 1762 & $1762-1815$ & 1815 & $1815-1831$ & 1831 & $1831-1851$ & 1851 \\
\hline villages ( $\left.\mathrm{n}^{\text {bre }}\right)^{*}$ & * 25 & & 53 & & 210 & & 306 \\
\hline augm. (\%) & & 112 & & 296 & & 46 & \\
\hline $\begin{array}{l}\text { pop. rurale** } \\
\text { augm. (\%) }\end{array}$ & 58030 & & 298000 & & 448866 & & 776847 \\
\hline $\begin{array}{l}\text { augm. (\%) } \\
\text { pop. rur./ }\end{array}$ & & 413 & & 31 & & 73 & \\
\hline villages $\left(\mathrm{n}^{\mathrm{bre}}\right)$ & 2321 & & 5623 & & 2137 & & 2539 \\
\hline
\end{tabular}

sources: ${ }^{*}$ nombre de villages, voir $\mathrm{n} .23 ;{ }^{* *}$ population rurale d'après Courville, 1815, 1831 et 1851: «Un Monde rural en mutation: le BasCanada dans la première moitié du XIX ${ }^{e}$ siècle", Histoire sociale/Social History, 20, p. 244.

S'il y eut transfert de la population vers les villes, ce ne fut bien faiblement qu'entre 1831 et 1851 , d'après les chiffres de Courville relatifs à la population des villes et

${ }^{26}$ Ibid., pp. 24, 34, 38. 
villages de 1000 habitants et plus. En effet, les taux d'urbanisation évoluent alors de $12,2 \%$ en 1784 , à $12,1 \%$ en 1831 et à $12,7 \%$ en 1851 .

Ceci dit, n'est-on pas en droit de se demander comment une maigre récolte de 269 minots de céréales et de pommes de terre par producteur, en 1831, dans la région la plus productive de la province, aurait pu, à elle seule, alimenter cette révolution villageoise et la protoindustrialisation dont il parle? D'autant plus que cette moisson était composée de seulement $22 \%$ de blé, de $24 \%$ d'avoine et de $41 \%$ de pomme de terre ${ }^{27}$. En effet, Courville affirme qu'en 1831 les deux tiers des industries rurales étaient localisées dans les seigneuries rurales, mais sans dire que $84 \%$ de la population de la province y était concentrée. Il ne précise pas non plus que la population des cantons du district de Montréal, où $40 \%$ des moulins et des fabriques étaient situés, ne représentait que $15 \%$ de celle de cette région ${ }^{28}$. On aimerait aussi apprendre que $41 \%$ de ces activités étaient localisées dans le district de Québec, alors que seulement $32 \%$ de la population s'y trouvait. En vérité, ces industries étaient surreprésentées dans les régions où l'industrie forestière tenait le plus de place dans la structure économique.

Ainsi, jusqu'à tout récemment, le discours historien québécois a surtout mis en valeur le caractère égalitaire de la paysannerie de la vallée du Saint-Laurent. Afin de tester la validité de cette tradition historiographique et de mieux rattacher les premières étapes du peuplement canadienfrançais dans le comté d'Essex au contexte québécois, nous avons misé sur certaines sources, peu utilisées jusqu'à maintenant. Il s'agit d'ensembles de documents qui décrivent

\footnotetext{
${ }^{27}$ Serge Courville, «Le Marché des subsistances. L'exemple de la plaine de Montréal au début des années 1830: une perspective géographiquen, RHAF, 42, 1988, pp. 2 I 4 s.

${ }^{28}$ Idem, "La seigneurie canadienne à l'époque de Durham: Éléments d'une problématique», Annali Academici Canadesi, 8, 1991, pp. 66s.; Fernand Ouellet, "Féodalité, régime seigneurial et modernisation dans l'historiographie québécoise des années $1980 »$, ibid., 8, 1991, pp. 37s.
} 
les avoirs fonciers des individus: à savoir les Aveux et dénombrements, les Terriers et les recensements. Deux seigneuries, en particulier, nous ont servi de guide: celles de Beaupré et de Laprairie.

Parce que la Nouvelle-France était coloniale, les métropolitains y jouaient un rôle primordial par les représentants civils et militaires du monarque et par les clercs et les nobles venus de France. Dans la hiérarchie sociale, la bourgeoisie venait après ces derniers, donc avant les artisans et les paysans. Il est vrai qu'il existait un dualisme entre le monde agricole et celui de la traite des pelleteries. Mais, assez vite, certains rapports furent aménagés entre eux par le biais de la main-d'œuvre saisonnière originaire des campagnes et, éventuellement, par la commercialisation du blé. Aussi longtemps que le blé n'eut pas de marché à l'extérieur de la colonie, la participation à la traite ou aux pêcheries était pratiquement le seul moyen d'acquérir le numéraire et le crédit nécessaires à l'achat des produits importés. Vers 1720 s'ouvrit le marché des Antilles ${ }^{29}$, mais le travail saisonnier demeura quand même une nécessité pour les ruraux qui ne disposaient pas de surplus agricoles ou qui n'avaient pas assez de terre pour en générer ${ }^{30}$. En effet, la commercialisation de l'agriculture, simplement mesurée par les exportations de blé, atteignit, pendant la seconde moitié du XVIII ${ }^{e}$ siècle, un sommet inégalé par la suite: 479710 minots en 1774 (4,6 per capita), 611153 en 1794 (3,6 per capita), 1151000 en 1802 (5,7 per capita), 732360 en 1825 ( 1,9 per capita) et 665000 ( 1,3 per capita) en $1831^{31}$. Notons qu'après 1831 le Bas-Canada, dont les

\footnotetext{
${ }^{29}$ Jacques Mathieu, Le Commerce entre la Nouvelle-France et les Antilles au XVIII ${ }^{e}$ siècle, Montréal, Fides, 1981, 276 p.; Louise Dechêne, Le Partage des subsistances au Canada sous le régime français, Montréal, Boréal, 1994, pp. 203-206.

${ }_{30}$ Fernand Ouellet, «Dualité économique et changement technologique au Québec (1760-1790)», Histoire sociale/Social History, 9, 1976, pp. 256-296. ${ }^{31}$ Idem, Le Bas-Canada, 1791-1840. Changements structuraux et crise, Ottawa, PuO, 1976, p. 179.
} 
exportations de blé avaient décliné depuis le début du siècle, était devenu déficitaire et importait annuellement environ 500000 minots de blé pour ses propres besoins. Paquet et Wallot, comme Courville, ont donc grandement exagéré l'autosuffisance des habitants au XVIII ${ }^{e}$ siècle et l'ampleur de leur articulation au marché au siècle suivant. $S$ 'il y eut d'importantes transformations après le début du $\mathrm{XIX}^{\mathrm{e}}$ siècle, il faut les attribuer en premier lieu à l'énorme expansion de l'économie forestière et au déplacement de la colonisation agricole à l'ouest du Bas-Canada.

C'est en conséquence de la commercialisation de l'agriculture, surtout après 1760 , que se précisa peu à peu la diversification de la population rurale, la création de villages et d'industries rurales. Et cela, sans compter un accroissement du nombre des marchands de campagne et de membres des professions libérales. Même Allan Greer montre que Samuel Jacob, un de ces marchands opérant dans la vallée du Richelieu, expédia, de 1763 à 1773, 60412 minots de blé vers le marché. Dans une de ses notes en fin d'ouvrage, il signale en plus que, vers 1774, chacun des 48 fournisseurs de Jacob aurait apporté à son magasin 207 minots de blé en moyenne ${ }^{32}$. De Louis Michel, qui a analysé les transactions faites entre Gaspard Massue, marchand de Varennes, et les paysans du lieu, provient le même son de cloche. De 1784 à 1792, chacun des 54 producteurs de la seigneurie, qui se ravitaillaient chez lui, lui aurait fourni 74 minots de blé en moyenne par an. Michel en conclut que:

Ainsi, conjugués avec la distribution du sol, les rapports marchands semblent bien engendrer une ligne de partage essentielle au sein de la population rurale. D'un côté des gens bien pourvus en terres et capables de dégager de leurs récoltes un surplus relativement substantiel. En le vendant, ils acquièrent un pouvoir d'achat qui fait d'eux les principaux consommateurs de marchandises importées. . Àl'inverse, d'autres individus, d'autres

${ }^{32}$ Allan Greer, op. cit., pp. 162, 286 n. 61. 


\section{FERNAND OuelLet}

familles, voient leurs ressources accaparées presque entièrement par les nécessités de la subsistance. Ils manquent de moyens d'échange. Ils fréquentent pourtant le magasin du marchand

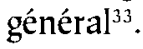

L'auteur aurait pu ajouter que les paysans non excédentaires et déficitaires, ou leurs fils, pouvaient rembourser, en tout ou en partie, leurs dettes à l'endroit du marchand, du seigneur et du curé en se livrant au travail saisonnier dans la traite, l'exploitation forestière ou les pêcheries ${ }^{34}$.

Disons que les marchands de blé et de pelleteries misaient sur l'inégalité foncière existante et ne l'ont pas créée. Car elle existait à l'origine et s'étendait aussi bien aux seigneurs laïcs et ecclésiastiques qu'aux censitaires de toutes conditions. En effet, dès les débuts de la colonie, les nobles avaient été favorisés par rapport au clergé et à la bourgeoisie dans l'attribution des seigneuries. En 1663, leur part respective du sol concédé se situait à $70 \%, 16 \%$ et $14 \%$. Même si, après ce départ fulgurant, la part de la noblesse se normalisa à environ $50 \%$, sa suprématie se maintint à ce dernier niveau jusqu'en $1781^{35}$. C'est alors que s'accélérèrent les achats de fiefs et de portions de fiefs par les bourgeois francophones et anglophones ${ }^{36}$. Dans ce contexte, il n'est pas étonnant que, dès les débuts de la colonie, la dimension des seigneuries ait aussi varié considérablement d'un fief à un autre, ainsi que d'un arrière-fief et d'un arrière-arrière-fief à un autre. Par exemple, la seigneurie de Beaupré (Séminaire de Québec) s'étendait sur 684300 arpents, celle de NotreDame-des-Anges (jésuites) sur 25200 , celle de Sillery (autochtones convertis) sur 10584 , celle de Gaudarville

${ }^{33}$ Louis Michel, «Le Livre de compte (1784-1792) de Gaspard Massue, marchand à Varennes", Histoire sociale/Social History, 13, 1980, pp. 395ss.

${ }^{34}$ Colin M. Coates, The Metamorphoses of Landscape and Community in Early Quebec, Montreal and Kingston, McGill-Queen's UP, 2000, pp. 126-129.

${ }^{35}$ Marcel Trudel, Les Débuts du régime seigneurial au Canada, Montréal, Fides, 1974, pp. $51-78$.

${ }^{36}$ Fernand Ouellet, "Propriété seigneuriale et groupes sociaux dans la vallée du Saint-Laurent (1663-1840)", Revue de l'université d'Ottawa, 47, 1977, pp. 183-213. 
(Louis de Lauson) sur 14 784, celle de Lauzon (Jean de Lauson) sur 254016 et celle de lîle de Montréal (Sulpiciens) sur 296272.

Comme les seigneurs étaient les premiers responsables des concessions de terres à l'intérieur de leurs seigneuries, les censives elles-mêmes n'échappèrent pas à l'emprise de l'inégalitaire. En 1663, l'étendue moyenne de la roture était de 271 arpents dans le district de Québec, de 72 arpents dans celui de Trois-Rivières et de 25 sur l'île de Montréal. À l'intérieur de chaque district, ces dimensions variaient de seigneurie en seigneurie: 534 arpents en moyenne dans celle de Beaupré, 243 dans Notre-Dame-des-Anges, 55 dans Sillery, 93 dans Gaudarville et 184 dans Lauzon ${ }^{37}$. Avec le temps et la multiplication des concessions de terres aux individus à l'échelle du territoire, les différences interrégionales s'atténuèrent. Selon les Aveux et dénombrements ${ }^{38}$ faits de 1723 à 1745 , la superficie moyenne des censives dans chacun des trois districts s'établissait à 157, 138 et 107 arpents respectivement.

Cela ne signifie pas pour autant qu'un vent égalitaire avait soufflé sur la colonie depuis 1663. Car, déjà avant cette date, dans la seigneurie de Beaupré où les censitaires avaient été très bien pourvus en terres au départ, des individus avaient commencé à ajouter des parcelles à leur concession originelle. En 1663, ces gens représentaient $8 \%$ des occupants de terres, mais ils accaparaient maintenant $20 \%$ du sol. Cette pratique se maintint jusqu'en 1732,

${ }^{37}$ Marcel Trudel, Le Terrier du Saint-Laurent, Ottawa, Éuo, 1973, pp. 533571 . Il ne s'agit pas, à proprement parler, d'un terrier, mais d'un recensement réalisé par l'auteur des seigneuries et des censives indiquant le nom de leurs propriétaires et la dimension de leurs possessions foncières en 1663. Ce document ne mentionne pas s'il y eut ou non partage égal de la terre à la mort du propriétaire précédent.

${ }^{38}$ Jacques Mathieu et Alain Laberge, L'Occupation des terres dans la vallée du Saint-Laurent. Les aveux et dénombrements, 1723-1745, Sillery, Septentrion, 1991,413 p. Ce document est un recensement des terres qui ressemble au terrier constitué par Marcel Trudel: le nom du propriétaire, la dimension de la terre et, en plus, la description des bâtiments. 
date où $6 \%$ des habitants possédaient $20 \%$ du sol. Notons ici qu'un siècle plus tard, l'étendue moyenne de la roture dans Beaupré aura fondu, passant entre-temps de 575 arpents en 1731 à 156 en 1831 , alors que le pourcentage de ceux qui possédaient des terres de 201 arpents et plus y déclina de $90 \%$ à $30 \%$.

On ne saurait donc croire que les concessions originelles faites par le Séminaire de Québec aux colons de Beaupré avaient été de dimensions égales. Disons que la faible mesure d'égalité, qui aurait pu exister à ce moment s'en est trouvée vite réduite à la suite de la double intervention du seigneur et des censitaires. Ce qui devait se produire partout et, plus spécifiquement, dans la seigneurie de Laprairie, octroyée aux jésuites en 1647. En 1733, au moment de l'Aveu et dénombrement, il y avait 160 censitaires dans la seigneurie. Quatre-vingt-deux d'entre eux n'avaient qu'une seule parcelle de terre, d'une étendue moyenne de 77 arpents. L'égalité était loin de régner parmi ces gens puisque le tiers d'entre eux possédait moins de 50 arpents et que $12 \%$ seulement avaient 100 arpents et plus. Les 78 autres censitaires se partageaient, d'une façon tout aussi inégale, 245 parcelles d'une superficie moyenne de 152 arpents, soit le double de celles des premiers. Le résultat de ce brassage échelonné sur quatre cinquièmes de siècle depuis 1647, animé parfois par le seigneur, mais, le plus souvent, par les pratiques successorales et les actes d'acheter et de vendre des censitaires, est que, dans l'ensemble, la concession initiale en fut substantiellement augmentée. La propriété moyenne eut alors une superficie de 113 arpents, répartis fort inégalement, puisque $61 \%$ des censitaires de l'endroit possédaient moins de 100 arpents de terre. Par contre, une vingtaine de paysans, soit $12 \%$ des occupants de terres, monopolisaient le tiers du sol concédé.

Analysé dans cette perspective de longue durée, le terrier de la seigneurie, dressé entre 1837 et 1841 , prend une importance capitale. Car il éclaire à nouveau pendant un 
autre siècle la structure d'inégalité en marche depuis les origines et stimulée en plus par l'apparition des pressions démographiques et les transformations socio-économiques. En effet, en 1837, les occupants de terres de Laprairie, au nombre de 827, se partageaient 1523 parcelles dont la superficie moyenne était de 37 arpents, soit 19 arpents de moins qu'en 1723. Comme 462 d'entre eux ne possédaient qu'une parcelle, les 365 individus qui monopolisaient de 2 à 16 parcelles se trouvaient à en contrôler 1053 , d'une dimension moyenne de 92 arpents. Cette prolifération des parcelles s'explique en premier lieu par le recours, sans doute de plus en plus fréquent et stimulé par la saturation progressive du territoire, au partage égal de la terre entre les descendants. Dans la seigneurie de Laprairie, 774 parcelles, soit $51 \%$ d'entre elles, avaient été générées de cette façon. Notons aussi qu'en plus des veuves, les filles célibataires et mariées avaient été effectivement admises au partage. Ce qui nuance considérablement la thèse, actuellement très à la mode, qui valorise au plus haut point la démarche des pères de famille qui remettaient, par donation entre vifs, la terre à l'un des fils, quitte à prévoir des compensations pour les autres ayants droit. Cette multiplication des parcelles au cours des ans reflétait en plus l'endettement d'un grand nombre d'individus et le zèle acquisitif de bien des autres. Ainsi, la proportion de ceux qui occupaient des terres de 100 arpents et plus déclina de $39 \%$, qu'elle était en 1732, à 19\% en 1837. En 1732, la superficie moyenne de la censive était de 113 arpents; un siècle plus tard elle n'était plus que de 62 arpents. 
TABLEAU 2

Le mouvement de la propriété foncière dans la seigneurie de Laprairie

(1733-1837)

\begin{tabular}{|c|c|c|c|c|c|c|c|c|}
\hline & \multicolumn{4}{|c|}{ parcelles } & \multicolumn{4}{|c|}{ propriétaires } \\
\hline & \multicolumn{2}{|c|}{1733} & \multicolumn{2}{|c|}{1837} & \multicolumn{2}{|c|}{1733} & \multicolumn{2}{|c|}{1837} \\
\hline & nombre & $\%$ & nombre & $\%$ & nombre & $\%$ & nombre & $\%$ \\
\hline 49 et - & 157 & 48,0 & 1118 & 73,3 & 31 & 19,4 & 425 & 51,4 \\
\hline $50-99$ & 146 & 44,6 & 330 & 21,7 & 66 & 41,2 & 242 & 29,3 \\
\hline 100 et + & 24 & 7,4 & 75 & 4,9 & 63 & 39,4 & 160 & 19,3 \\
\hline total & 327 & 100 & 1523 & 99,9 & 160 & 100 & 827 & 100 \\
\hline
\end{tabular}

Sources: ANQ 1733: Aveux et dénombrements de la Nouvelle-France; Terrier de la seigneurie de Laprairie, 1837-1841. Ce terrier, contrairement à celui de Trudel et à l'Aveu de 1723, fournit, en plus, des informations sur le partage égal de la terre à la mort du précédent propriétaire.

À la vue de ces chiffres, on pourrait croire que l'élite agricole identifiée en 1732 avait plus ou moins sombré sous le poids des forces irrésistibles du démembrement de la propriété foncière. D'autant plus que, dans la seigneurie de Laprairie, $85 \%$ des censitaires, les pauvres et les mieux nantis, étaient largement endettés auprès du seigneur $\mathrm{r}^{39}$. À Sorel, la dette des censitaires, raconte Greer, n'avait cessé d'augmenter depuis 1809 et se chiffrait alors à 92000 livres. À Saint-Ours, la situation n'était pas différente ${ }^{40}$. Tout cela, sans compter les dettes contractées chez le marchand et le curé. Il faut dire que ces chiffres recouvraient des réalités fort différentes: celles du paysan qui s'endettait inexorablement, de celui qui voulait agrandir sa terre pour survivre et de celui qui désirait cumuler des parcelles. En somme, une tension constante entre les forces du morcellement de la propriété et celles de la concentration.

En effet, les $19 \%$ de censitaires qui possédaient 100 arpents et plus de terre contrôlaient $51 \%$ du sol dans la seigneurie. Ce qui veut dire que l'élite agricole d'autrefois

${ }^{39}$ Fernand Ouellet, «La Répartition de la propriété foncière et types d'exploitation agricole dans la seigneurie de Laprairie durant les années 1830 », dans F. Ouellet, Mélanges d'histoire sociale du Bas-Canada, Montréal, HMH, 1972 , p 130.

${ }^{40}$ Allan Greer, op. cit., pp. 126s. 
avait persisté non seulement grâce à ses avoirs fonciers, mais aussi grâce à ses surplus de production écoulés à Montréal et aux revenus tirés des locations de terres et d'emplacements. En 1831, dans la paroisse de Laprairie, cette élite regroupait seulement $4 \%$ des producteurs de céréales et de pommes de terre qui étaient responsables de $20 \%$ de la récolte. Le cultivateur moyen produisait 280 minots, mais celui qui appartenait à l'élite en comptait 1545. D'ailleurs, ce petit groupe se trouvait élargi par l'apport de ceux, soit $35 \%$ des censitaires, dont les troupeaux comprenaient entre 20 et 100 bêtes. Enfin, comme les locataires de terres et d'emplacements représentaient $43 \%$ des chefs de maisonnée de la paroisse, il faut en conclure que les locations constituaient en plus une source appréciable de revenus pour cette élite qui s'apparentait davantage à la petite bourgeoisie qu'au reste de la paysannerie.

À cet égard, les Canadiens français étaient avantagés puisque, presque partout dans les seigneuries, ils s'étaient établis longtemps avant les anglophones. La paroisse de Laprairie ne faisait pas exception à la règle. Dans cette localité, les anglophones représentaient $22 \%$ des chefs de maisonnée, mais seulement $14 \%$ des propriétaires fonciers, $19 \%$ des cultivateurs et $11 \%$ des travailleurs non qualifiés. Par contre, ils étaient surreprésentés parmi les artisans (32\%), ainsi que dans les affaires et les professions (34\%). Les différences étaient également substantielles au plan de l'alphabétisation. Seulement $8 \%$ des cultivateurs et $20 \%$ des artisans canadiens-français savaient signer leur nom, alors que les deux tiers des cultivateurs et tous les artisans d'origine britannique étaient alphabétisés ${ }^{41}$.

Comme le démontre la situation dans Laprairie, les inégalités résultant de la présence des Britanniques dans les campagnes seigneuriales ont été fortement sous-estimées.

${ }^{41}$ Fernand Ouellet, Mélanges d'histoire sociale..., pp. 114-149, 153-173. 
Pourtant, c'était eux qui contrôlaient en grande partie le commerce, les industries et les institutions financières dans les villes. À Québec et à Montréal, ils constituaient $45 \%$ et $52 \%$ respectivement de la population, dont $45 \%$ des artisans et des journaliers. Il va de soi qu'ils dominaient en plus le commerce international, en particulier celui, en grande expansion, du bois, ainsi que le trafic dans les deux directions avec le Canada et les États-Unis. Ainsi leur poids en milieu rural, surtout dans la région de Montréal, était d'autant plus significatif qu'ils y possédaient, en tout ou en partie, un grand nombre de seigneuries et la grande majorité des cantons où leurs compatriotes étaient majoritaires. Dans les cinq seigneuries Christie étudiées par Françoise Noël ${ }^{42}$ et dans celle de la Petite-Nation décrite par Claude Baribeau ${ }^{43}$, il apparaît que des anglophones, parfois agents du seigneur, étaient devenus à la fois grands propriétaires fonciers, agriculteurs sur une grande échelle, constructeurs ou locataires de moulins et entrepreneurs forestiers, jouant alors un rôle prépondérant dans l'économie locale. Ce fut aussi le cas dans la région de SaintEustache étudiée par Monique Benoît. Dans les seigneuries Christie et la région de Saint-Eustache, mises ensemble, les anglophones étaient surreprésentés parmi les hommes de professions, les gens d'affaires et même parmi les cultivateurs. Par contre, ils étaient sous-représentés parmi les travailleurs non qualifiés. Dans la région de Saint-Eustache, ils étaient également beaucoup plus alphabétisés dans la paroisse irlandaise catholique de Saint-Colomban, la plus pauvre de la région, que dans les paroisses à très grande majorité canadienne-française de Saint-Jérôme et de SaintEustache. Les signatures au baptême se répartissaient ainsi:

\footnotetext{
${ }^{42}$ Françoise Noël, The Christie Seigneuries. Estate Management and Settlement in the Upper Richelieu Valley, 1760-1854, Montreal-Kingston, McGill-Queen's University Press, 1992, pp. 121-128.

${ }^{43}$ Claude Baribeau, La Seigneurie de la Petite-Nation. Le rôle économique et social du seigneur, Hull, Asticou, 1983, pp. 101-108, 134-137.
} 
Saint-Colomban, 46,5\%; Saint-Jérôme, paroisse plus pauvre que Saint-Eustache, 10,9\%; Saint-Eustache, 23,1\%.

TABLEAU 3

La présence des Britanniques dans les seigneuries Christie* et dans la région de Saint-Eustache en 1831

\begin{tabular}{lrcrrrrr}
\hline & \multicolumn{2}{c}{ Canadiens français } & \multicolumn{2}{c}{ Britanniques } & \multicolumn{2}{c}{ Total } \\
nombre & $\%$ & nombre & $\%$ & nombre & $\%$ \\
$\begin{array}{l}\text { h. de profession } \\
\text { et affaires }\end{array}$ & 88 & 49,7 & 89 & 50,3 & 177 & 100 \\
artisans & 331 & 77,0 & 99 & 23,0 & 430 & 100 \\
cultivateurs & 2316 & 73,5 & 835 & 26,5 & 3151 & 100 \\
non qualifiés & 866 & 88,7 & 110 & 11,3 & 976 & 100 \\
divers & 139 & 92,0 & 12 & 8,0 & 151 & 100 \\
total & 3740 & 76,6 & 1145 & 23,4 & 4885 & 100 \\
\hline
\end{tabular}

Source: APC, Recensement nominatif de $1831 .^{*}$ Les seigneuries Christie étaient Bleury, Sabrevois, Noyan, de Léry et Lacolle. Monique Benoît, «La Formation d'une région: la marche du peuplement de Saint-Eustache à Saint-Jérôme et le problème des subsistances», thèse de M.A., Université d'Ottawa, 1980, $172 \mathrm{p}$.

La participation sur place des Britanniques au développement de nombreuses localités dans les campagnes seigneuriales témoigne, dira-t-on, de la marche inexorable de la commercialisation de l'agriculture. Pourtant, démontre Monique Benoît, la population catholique ne s'accrut dans la région de Saint-Eustache, entre 1831 et 1851 , que de $71 \%$, soit un déficit de $21 \%$ par rapport au surplus des naissances sur les décès. Pendant ce temps, la production de céréales et de pommes de terre n'augmenta que de $39 \%$, alors que le nombre d'animaux sur les fermes ne crût que de $10 \%$. Bien plus, en 1851, la moitié des hommes de profession et des gens d'affaires anglophones avait quitté la région ${ }^{44}$. Il est vrai qu'il existait une élite agricole, mais elle était si peu nombreuse (occupants de plus de 100 arpents de terre: seulement $15,5 \%$ ) qu'elle n'aurait pu entraîner derrière elle le reste de la paysannerie. La région

${ }^{44}$ Monique Benoît, ibid., pp. 50, 87, 145, 149. 
de Saint-Eustache n'était pas un cas isolé. Car, sur le territoire de Laprairie, quatre paroisses, chevauchant la frontière seigneuriale, s'étaient développées. Mais, de 1831 à 1846 , leur population avait augmenté de $30 \%$, ce qui était beaucoup moins que leur croissance naturelle, alors que leur récolte de céréales et de pommes de terre ne s'était accrue que de $21 \%$. Pendant ce temps, la production de blé avait diminué de $73 \%$ et le nombre d'animaux sur les fermes de $13 \%{ }^{45}$.

À l'échelle de la province en 1831 , le tiers des chefs de maisonnée ruraux était composé de locataires ${ }^{46}$ et le pourcentage des journaliers s'y chiffrait à $21 \%$. Depuis le début du siècle, la hiérarchie traditionnelle des cultures, dominée par le blé dans une proportion d'environ $70 \%$, avait été renversée, passant à $22 \%$ en 1831 , puis à $15 \%$ en 1851. Pendant ces deux décennies, la récolte moyenne de céréales et de pommes de terre avait même décliné de $25 \%$.

Cette évolution que nous venons de décrire avait abouti en 1831 à une acccumulation des pressions démographiques sur le territoire seigneurial et, peu de temps après, au débordement des surplus de population vers les régions périphériques de la province et les États-Unis et le HautCanada. Ainsi, la région de Saint-Eustache était un territoire où la colonisation avait été déclenchée par les surplus démographiques des paroisses plus anciennes de l'île Jésus, de Terrebonne et d'ailleurs. Vers 1815, la paroisse de Saint-Eustache, fondée en 1769 , avait déjà les traits d'une paroisse saturée. Car, entre 1790 et 1822 , sa population n'avait augmenté que de $88 \%$, alors que, par sa seule croissance naturelle, ses effectifs avaient doublé en moins de 25 ans. Il y avait done eu déplacement de personnes vers l'intérieur de la région. Comme la population, dans les

\footnotetext{
${ }^{45} \mathrm{APC}$, Recensement nominatif des paroisses en question.

${ }^{46}$ Fernand Ouellet, Le Bas-Canada, 1791-1840. Changements structuraux et crise, Ottawa, PLIO, 1976, pp. 186-190, 284-290.
} 
quatre paroisses nées de ce processus, ne s'était accrue que de $12 \%$ entre 1822 et 1842 , il semblait évident que les pressions démographiques étaient responsables de ce mouvement continu ${ }^{47}$.

Cette interprétation a été confirmée en 1980 par Monique Benoît qui s'est employée à suivre la marche du peuplement dans les dix localités de la région. Et cela, en comparant la croissance de la population selon les recensements et selon les données de la croissance naturelle de 1831 à $1851^{48}$. Ce qu'elle dégage, c'est avant tout un mouvement d'occupation du sol dicté d'une part par les pressions sur la terre et mené d'autre part à partir des meilleures terres vers les moins bonnes. Au terme de ces déplacements, 2844 personnes de religion catholique avaient quitté la région: les unes se retrouvant à la Petite-Nation, les autres en Ontario ou aux États-Unis. De 1851 à 1861, la situation devient même tragique puisque la population totale de la région décline de 27925 individus à 26396, soit une perte absolue de 1529 habitants.

${ }^{47}$ Ibid., p. 243.

${ }^{48}$ Serge Gagnon ignore cette étude. Serge Gagnon, Le Passé composé. De Ouellet à Rudin, Montréal, VLB, 1999, pp. 76-80. 


\section{TABLEAU 4}

Migrations nettes dans les paroisses de la région de Saint-Eustache selon les recensements et selon la croissance naturelle (1831-1851)

\begin{tabular}{lcccrr}
\hline population catholique & $(1)$ & \multicolumn{1}{c}{$(2)$} & \multicolumn{1}{c}{$(3)$} & \multicolumn{1}{c}{$(4)$} & \multicolumn{1}{c}{$(5)$} \\
Saint-Eustache & 4759 & 2195 & 6954 & 3955 & -2999 \\
Sainte-Thérèse & 2609 & 1780 & 4389 & 2856 & -1533 \\
Saint-Benoît & 4373 & 2082 & 6455 & 2565 & -3890 \\
Sainte-Scholastique & 3663 & 3251 & 6914 & 4603 & -2311 \\
Saint-Jérôme & & 2393 & 2393 & 5201 & 2808 \\
Saint-Colomban & & 343 & 343 & 857 & 514 \\
Saint-Augustin & & 824 & 824 & 2204 & 1380 \\
Saint-Hermas & & 816 & 816 & 1689 & 873 \\
Saint-Janvier & & 341 & 341 & 1530 & 1189 \\
Saint-Placide & & 94 & 94 & 1219 & 1125 \\
total & 15404 & 14119 & 29523 & 26679 & -2844 \\
\hline
\end{tabular}

Source: nous avons composé ce tableau à partir de deux tableaux de Monique Benoît, op. cit., pp. 78, 87: (1) recensement de 1831, (2) croissance naturelle 1831-1851, (3) population attendue en 1851, (4) recensement de 1851 , (5) solde = migration nette.

Ce type de pressions démographiques, qui accentue la parcellisation du sol et trouve sa soupape dans les migrations internes et externes, a aussi été décrit par Alain Laberge dans le collectif sur la région de la Côte-du-Sud. Dans les 23 paroisses de cette aire, la plupart anciennes, la population ne fit que doubler du recensement de 1790 à celui de 1831 , alors qu'elle l'avait déjà fait en 1815 par la seule force de sa croissance naturelle. Pendant les trente années suivantes, elle ne s'accrut que de $45 \%$. Donc, selon Laberge:

À partir de la fin du XVIII siècle et particulièrement dans les premières décennies du XIX ${ }^{c}$, la Côte-du-Sud connaît une période de pressions démographiques résultant essentiellement du renversement du rapport favorable entre la population régionale et l'espace disponible qui avait existé jusqu'à ce moment. Durant la première moitié du XIX ${ }^{e}$ siècle, la région voit ainsi se mettre en place une réalité brutale: la région devient un espace saturé, un monde plein ${ }^{49}$.

${ }^{49}$ Alain Laberge et al., Histoire de la Côte-du-Sud, Québec, IQRC, 1993, pp. 79ss. Dans la RHAF, 48, 1994, p. 262, Serge Gagnon s'en est pris, sans trop de succès, à Laberge à ce sujet. 
Comme la société qui s'était constituée à Détroit était héritière de la Nouvelle-France et du Québec à de nombreux égards, qu'en sera-il de la marche de l'égalité en ces lieux éloignés?

\section{B. De la Société De Détroit en 1701 à celle de MALDEN ET DE SANDWICH EN 1871}

Les Canadiens français d'Essex n'étaient donc pas, comme ceux de Hawkesbury et d'Alfred, le produit des conditions défavorables qui prévalaient dans leur milieu d'origine durant les années 1830-1870. Car la majorité d'entre eux descendait de ceux qui, à une époque éloignée, avaient habité les environs du poste de Détroit, qui n'était guère plus qu'un des relais commerciaux d'une NouvelleFrance en expansion constante vers le sud et vers l'ouest. Dans les années 1780 , certains disaient que les cultivateurs de Détroit étaient paresseux et ignorants. Mais, en 1871 , ils étaient encore là, et leur production de céréales et de pommes de terre égalait celle de l'occupant moyen de terre de l'Ontario, surpassant même celle du Bas-Canadien moyen par un pourcentage de $66 \%$.

La fondation de Détroit en 1701 par Antoine Laurent de Lamothe Cadillac avait fait partie d'une stratégie à la fois militaire et commerciale destinée à contrer la progression des habitants de la Nouvelle-Angleterre vers le nord et à préserver l'influence française auprès des Amérindiens, ces pourvoyeurs de pelleteries. Il y avait donc eu à Détroit, en plus des indigènes, une population sans cesse en mouvement formée de commerçants de pelleteries, d'engagés pour la traite, de militaires et de gens venus s'établir comme colons. Les éléments les plus stables, à part les esclaves panis et noirs, se recrutaient en majorité dans les paroisses de la vallée du Saint-Laurent. En effet, selon le registre des mariages de Détroit, les conjoints étaient originaires de quarante-deux paroisses de la vallée du Saint-Laurent. 
TABLEAU 5

L'origine géographique des conjoints mariés

à Détroit de 1760 à 1781

\begin{tabular}{lrrrrrr}
\hline & \multicolumn{2}{c}{ Époux } & \multicolumn{2}{c}{ Épouses } & \multicolumn{2}{c}{ Total } \\
& nombre & nombre $\%$ & nombre & $\%$ \\
$\begin{array}{l}\text { Québec } \\
\text { villes (Q. T.-R., M) }\end{array}$ & 8 & 10,0 & 7 & 8,7 & 15 & 9,4 \\
& & & & & & \\
paroisses rurales & 21 & 1 & 22 & & & \\
$\begin{array}{l}\text { D. de Québec } \\
\text { D. de Trois-Rivières }\end{array}$ & 4 & 1 & 5 & & & \\
$\begin{array}{l}\text { D. de Montréal } \\
\text { total }\end{array}$ & 16 & 9 & 25 & & & \\
& 41 & 51,2 & 11 & 13,7 & 52 & 32,5 \\
autres & & & & & & \\
France & 5 & 0 & 5 & & & \\
Détroit & 19 & 55 & 74 & & & \\
inconnue & 7 & 7 & 14 & & & \\
total & 31 & 38,7 & 62 & 77,5 & 93 & 58,1 \\
grand total & 80 & 99,9 & 80 & 99,9 & 160 & 100 \\
\hline
\end{tabular}

Source: Ernest Lajeunesse, The Windsor Border Region. Canada's Southermost Frontier. A Collection of Documents, Toronto, The Champlain Society, 1960, pp. 344-354.

Cette population, estimée à une soixantaine de personnes en 1708, s'accrut, sans compter la garnison, à 483 en 1750, dont 33 esclaves, à 1357 en 1773 , dont 75 esclaves, et à 2191 en 1782 , dont 179 esclaves.

Comme il en coûtait cher au roi pour ravitailler ce poste en produits de toutes sortes et que le sol de la région était, en général, fertile, les autorités de la Nouvelle-France eurent toujours en tête un projet agricole. Même si la traite des pelleteries exerçait un grand attrait sur ceux qui fréquentaient le poste, il était possible de combiner, comme cela se faisait à l'est, la traite et l'agriculture. D'autant plus, comme le disait le lieutenant-gouverneur Hamilton en 1776, que: "The soil is so good that great crops are raised by careless and very ignorant farmers. Wheat, Indian Corn, Barley, Oats, Pease, Buck Wheat yield a great increase ${ }^{50}$." Déjà,

${ }^{50}$ Ernest Lajeunesse, op. cit., p. 85. 
en 1708, des colons avaient amorcé des gestes en ce sens. Par la suite, grâce à l'encouragement du gouvernement qui, en plus d'accorder des terres aux résidents intéressés, avait fait venir des familles en leur fournissant des lots de 120 arpents, des animaux et de l'outillage, une activité agricole se développa. Selon le recensement de 1750, environ $20 \%$ des 53 cultivateurs de l'endroit pratiquaient, si l'on en juge par les quantités de blé récoltées et le nombre d'animaux entretenus, une agriculture assez commercialisée. Ainsi le troupeau moyen était de 11,3 animaux, mais certains individus en comptaient entre 25 et 60 sur leurs fermes. En 1768, le nombre d'animaux dans le troupeau moyen avait augmenté dans une proportion de $67 \%{ }^{51}$.

Après 1760, le mouvement des concessions de terres se poursuivit selon les pratiques établies par les commandants de l'époque française. Autrefois, les commandants du poste, agissant au nom du roi, avaient accordé aux simples habitants des terres dont la dimension se chiffrait, le plus souvent, à 120 arpents. Les concessions de 80 arpents paraissent aussi avoir été fréquentes. Évidemment, ces normes ne valaient pas pour les personnes de qualité, puisqu'en 1750 le chevalier de Longueuil avait demandé et reçu une terre de 480 arpents. En 1768, le général Gage, afin de protéger les autochtones contre les abus des Blancs, annula les concessions faites depuis 1760 par les officiers militaires Picoté de Belestre, Galdwin et Bruce. Il rejeta aussi les achats de terres appartenant aux indigènes et non validés au préalable par le gouverneur. Par contre, il confirma les concessions faites aux colons avant 1760 et il limita, semble-t-il, les nouvelles à 120 arpents. Ainsi, en 1792, 67\% des habitants de la Petite-Côte possédaient des censives d'environ 120 arpents $^{52}$.

La véritable intrusion de l'inégalité foncière dans la région eut lieu à la suite de l'intervention des Amérindiens dans

\footnotetext{
${ }^{1}$ Ibid., pp. 54-56, 63-64.

52 Ibid., p. 75.
} 
ce processus. En effet, de 1765 à 1788, ceux-ci accordèrent à des officiers militaires et civils, ainsi qu'à des marchands de pelleteries et autres personnes d'énormes quantités de terre, difficiles à estimer avec précision, «in consideration of good will, love and affection». Le plus souvent, ces dons se situaient entre 80 et 1000 arpents de terre. Par contre, la concession faite à Jacob Shieffelin recouvrait une superficie de sept milles carrés, alors que celle attribuée à James Abbott et à Isaac Williams comprenait trois lieues de large. Il en fut ainsi de la concession faite à William McComb. Enfin, Thomas McKee se fit accorder l'île Pelée pour 99 ans, alors que James Allan et les Caldwell, William et James, reçurent un domaine de 66 milles carrés pour 99 ans. Les Britanniques furent les grands bénéficiaires de ces dons dans une proportion d'au moins $90 \%{ }^{53}$.

Cette tendance inégalitaire se poursuivit avec l'arrivée des Loyalistes et le licenciement des officiers et des soldats, à qui le gouvernement distribua des terres, en ayant soin de mettre les officiers dans une catégorie spéciale. Ainsi le capitaine Elliott se fit attribuer 3000 acres qu'il exploita d'abord avec des esclaves importés de Virginie. Évidemment, le nombre des concessions de 200 acres augmenta considérablement avec l'arrivée des colons et avec la décision d'attribuer des suppléments de terre à ceux dont la propriété mesurait moins de 200 acres. En 1794, le nombre de Britanniques ainsi récompensés pour leur loyauté et leur service égalait presque celui des Canadiens français, soit 125 pour les premiers, 134 pour les seconds et 2 pour les Noirs. Lorsque Détroit passa effectivement aux Américains en 1796, on distribua des terres à plus d'une centaine de chefs de maisonnée passés en terre canadienne ${ }^{54}$. Ce fut d'ailleurs le moment où les villes de Sandwich et d'Amherstburg furent créées pour assumer le rôle que Détroit avait joué jusque-là.

53 Ibid., pp. 313-322.

${ }^{54}$ Ibid., pp. 357-359. 
L'inégalité fut enfin assurée par les transactions quotidiennes des habitants de la région consignées dans les actes notariés passés entre 1765 et 1795 . De cette façon, si on exclut de cette liste les 23 dons de terres faits par les Amérindiens, 119 parcelles d'une superficie de 19480 arpents de terre furent mises sur le marché et vendues. Pour l'essentiel, les paiements furent réalisés en argent pour une somme totale de 349957 livres courantes françaises. Seulement quatre transactions impliquèrent des paiements en blé et en farine et six autres furent simplement des échanges de terres. Même si chacune de ces transactions ne portait que sur de petites quantités de terre, 156 arpents en moyenne chez les Canadiens français et $190 \mathrm{chez}$ les Britanniques, elles ne firent rien pour enrayer la marche de l'inégalité foncière entre les deux groupes ethniques et à l'intérieur de chacun d'eux.

Notons ici, afin de mieux comprendre la suite des choses, qu'il existait une différence capitale entre le régime seigneurial et le franc et commun soccage. En effet, la concession d'une terre neuve par le seigneur était, en principe, gratuite, mais le censitaire était, même lorsque la terre lui était vendue légalement ou illégalement, sujet à perpétuité à un enchevêtrement d'obligations financières et autres qui limitaient son droit de propriété. Ainsi, quand le régime seigneurial fut, en 1854, condamné à s'éteindre, les seigneurs, contrairement aux censitaires, devinrent propriétaires absolus des terres non concédées. Ce qui représentait pour un assez grand nombre d'entre eux, parmi lesquels le Séminaire de Québec et Papineau figuraient en bonne place, de grandes étendues de terres couvertes de forêts. Bien plus, les seigneurs furent non seulement largement indemnisés pour les droits les plus onéreux, mais ils eurent désormais les mains libres pour réclamer les arrérages accumulés et pour continuer à recevoir le paiement des droits non rachetés par les censitaires. Il ne fait pas de doute que les seigneurs furent les principaux bénéficiaires de la législation 
de 1854, eux qui, dans les décennies précédentes, avaient vu leurs revenus stagner ou décliner ${ }^{55}$ à cause de conditions économiques défavorables. Ainsi, quoique condamné à mort, le régime seigneurial continua à survivre sous une forme mitigée pendant un demi-siècle. Dans la région de Détroit, la situation était différente puisque ceux qui avaient reçu des terres avant 1792, étaient les censitaires du roi. Quand les cantons de Malden et de Sandwich furent créés, à la même date, ces individus furent automatiquement reconnus comme de simples propriétaires.

Sous le système du franc et commun soccage, au contraire, la terre, qu'elle ait été accordée gratuitement ou vendue, se trouvait libérée de toutes entraves lorsque son acquéreur avait rempli les conditions du transfert. En 1799, la plupart des hauts fonctionnaires et les grands noms du commerce des pelleteries dans la région apparaissaient parmi ceux qui avaient reçu de substantielles quantités de terre. Les Bird, Elliott, Reynold, Meldrum, Park, Forsyth, Mackenzie, Duff et Caldwell figuraient dans ce groupe. Par la suite, d'autres noms s'ajoutèrent, tels ceux de John Richardson, d'Edward Ellice, d'Alexander Grant et de Thomas Smith. La majorité de ces privilégiés n'était pas forcément intéressée à mettre ses terres en valeur en utilisant une main-d'œuvre immigrante. Aussi son avenir paraissait-il problématique.

Grâce à l'enquête menée par John Clark dans les Abstracts Index to Deeds ${ }^{56}$, nous avons pu suivre le mouvement de la propriété foncière dans la partie rurale du canton de Malden jusqu'en 1852. Comme partout ailleurs dans la province, l'émission des lettres patentes y avait été rapide au départ, 44 de 1790 à 1799, et s'était ralentie

\footnotetext{
${ }^{55}$ Sur cette question, voir Fernand Ouellet, «Féodalité, régime seigneurial et modernisation dans l'historiographie québécoise des années 1980», Annali Academici Canadesi, 7, Ottawa, 1991, pp. 24-28.

${ }^{56}$ John Clark, «Land and Law in Essex County. Malden Township and the Abstract Index to Deeds", Histoire sociale/Social History, 11, 1978, pp. 475-493.
} 
par la suite: seulement 65 en 70 ans. Par contre, les transactions faites au jour le jour sur ce bloc initial, au nombre de 624 avant 1852 , avaient augmenté lentement jusqu'en 1825 pour ensuite s'accroître à un rythme plus prononcé avec l'accroissement de l'immigration.

En 1825, même si le commerce des pelleteries avait décliné radicalement, l'aristocratie de la terre qui s'était formée dans la région depuis l'époque de la Révolution américaine avait néanmoins tenu le coup malgré certaines pertes encourues. Au sommet de la hiérarchie, il y avait Matthew Elliott, la famille Caldwell, R. Reynold, John Richardson et Edward Ellice. Vingt-cinq ans plus tard, les Caldwell, les Elliott et les Reynold avaient conservé leur importance, mais les principaux marchands de fourrures étaient disparus après avoir divisé et liquidé leurs avoirs fonciers. En 1871, il se trouvait encore des Elliott et des Caldwell à Malden et à Sandwich. Bien malin qui aurait pu les distinguer de la masse des propriétaires de terres de ces lieux: 87 acres en moyenne pour les neuf personnages en question apparaissant au recensement et 87 acres pour l'ensemble des propriétaires de ces deux cantons. Les Meikle, les Reynold et les Lockart avaient aussi été bien dotés de terres dans le passé. Pourtant, les sept personnes ainsi identifiées ne possédaient en moyenne que 71 acres de terre. Malden, Sandwich, Hawkesbury et Alfred étaient peut-être exemplaires à cet égard. Dans ce cas, on pourrait dire qu'en Ontario, contrairement à ce qui se passait au Québec où la grande propriété seigneuriale était restée relativement intacte même après 1854 , il y aurait eu déclin de l'élite foncière constituée après 1760 à la faveur de l'expansion du commerce des pelleteries et des événements politico-militaires. On pourrait en conclure que, sans pour autant faire disparaître les inégalités, cette transformation radicale avait surtout fait passer la propriété foncière aux mains de ceux qui cultivaient le sol et des classes inférieures. Il est vrai qu'ailleurs les entrepreneurs forestiers avaient 
établi leur contrôle sur de grandes étendues de terre, mais, en agissant ainsi, ils avaient surtout misé sur l'accumulation de réserves dans les forêts privées et publiques plutôt que sur des terres à potentiel agricole.

\section{II - LE PROFIL SOCIO-ETHNIQUE ET CULTUREL DES HABITANTS De Malden et de Sandwich en 1871}

Les Canadiens français de Malden et de Sandwich n'avaient donc pas été plongés soudainement, comme ceux de Hawkesbury et d'Alfred, dans une société multiethnique et pluriconfessionnelle. Car ils avaient occupé ce territoire bien avant d'amorcer, dans la seconde moitié du XVIII ${ }^{\mathrm{e}}$ siècle, tout contact régulier avec les anglophones d'origine américaine et britannique et avec les colons d'origine germanique. Étant installés depuis si longtemps en ces lieux et n'ayant reçu depuis 1790 que peu d'immigrants de leur propre origine du Québec et d'ailleurs, leur population s'était accrue, pour l'essentiel, sous l'effet de leur haute natalité. Aussi, contrairement aux Écossais, aux Anglais et aux Allemands, leur pourcentage était-il plus élevé dans la population que parmi les chefs de maisonnée. En 1871, leur profil était celui d'une population enracinée depuis longtemps: $76 \%$ de leurs chefs de maisonnée, $79 \%$ de leurs épouses, $85 \%$ de leurs fils adultes résidant dans les maisonnées et $91 \%$ de leurs enfants étaient nés en Ontario. En effet, les chefs de maisonnée nés en Ontario habitaient la province depuis 42 ans en moyenne, alors que la minorité née ailleurs n'y était que depuis une décennie.

Leur profil contrastait avec celui des anglophones qui devaient la majeure partie de leur croissance à l'immigration des années 1850-1860. En effet, 77\% des chefs de maisonnée anglophones, $65 \%$ de leurs épouses, 58\% de leurs fils adultes résidant dans la maisonnée et $86 \%$ de leurs enfants étaient nés dans les îles Britanniques et, parfois, aux États-Unis, au Québec et dans les Maritimes. 
Leur âge moyen était de 48 ans. Parmi eux, les Écossais, les Allemands, les Anglais et les Irlandais étaient, dans l'ordre, les derniers venus. Ces anglophones étaient âgés de 37 ans en moyenne au moment de leur arrivée en Ontario, les Canadiens français de 34 ans et les Noirs de 50 ans. Les premiers et les derniers se trouvaient donc, en ce qui concerne le moment de l'arrivée dans la région, dans une situation semblable à celle des Canadiens français lors de leur arrivée à Hawkesbury et à Alfred.

Le contraste était encore plus marqué avec la petite minorité d'origine afro-américaine dont l'existence était ancienne, mais dont le parcours avait été sujet à bien des accidents depuis l'époque de la Nouvelle-France. Marcel Trudel y a dénombré la présence, de 1690 à 1782, de 3604 esclaves, dont 1095 Noirs et 2509 Amérindiens. Presque six d'entre eux sur dix se trouvaient, selon l'expression de Trudel, dans les paroisses du Pays du Saint-Laurent et les autres vivaient dans les postes de traite. Détroit, le poste le mieux pourvu à cet égard, en eut 656 , dont $128 \mathrm{Noirs}^{57}$. En fait, entre 1750 et 1782 , les esclaves avaient représenté environ $8 \%$ de la population à cet endroit. Nous savons aussi qu'à la fin du siècle, le capitaine Elliott d'Amherstburg avait importé des esclaves de Virginie pour cultiver le tabac sur ses terres. Qu'est-il advenu de ces individus et des descendants de ceux qui les avaient précédés? L'historien Robin Wincks, qui a tenté d'en rédiger l'histoire continue, ne mentionne ${ }^{58}$ que la présence d'esclaves fugitifs à Amherstburg dans les années 1820. Ceux-ci, dit-il, s'intégrèrent assez bien dans la communauté jusqu'à l'arrivée des Irlandais vers 1850 , époque qui coïncidait avec une contraction de l'emploi dans la région. En 1846, ajoute-t-il, on avait même créé The Refugee Home Society, dont l'objectif

\footnotetext{
${ }^{57}$ Marcel Trudel, Dictionnaire des esclaves et de leurs propriétaires au Canada français, Montréal, HMH, 1990, pp. XII-XIX.

${ }_{58}$ Robin W. Wincks, The Blacks in Canada. A History, Montreal-Kingston, McGill-Queen's UP, 1997, pp. 142s., 144, 148, 204-210.
} 
était de faciliter l'accès des Noirs à la propriété foncière. Pendant quelques années, la société réussit à procurer des lots de 25 acres à 150 individus. Mais, bientôt, elle aurait elle-même été rongée par des dissensions idéologiques et autres. Toujours est-il qu'en 1871, la communauté noire ne représentait toujours que $11 \%$ de la population à Malden et $5 \%$ à Sandwich, soit seulement $7 \%$ de la population totale. Bien plus, elle était constituée de personnes nées aux États-Unis dans une proportion de 90\% et arrivées au Canada depuis seulement sept années en moyenne. On peut aisément en conclure que, malgré l'abolition de l'esclavage dans les Canadas, les Noirs n'avaient pas été encouragés à s'y perpétuer et à y prospérer.

\section{TABLEAU 6}

Les chefs de maisonnée à Malden et à Sandwich en 1871: nombre, âge, années de résidence

\begin{tabular}{|c|c|c|c|c|c|c|c|c|}
\hline \multirow[b]{2}{*}{ nombre } & \multicolumn{2}{|c|}{ Écossais Anglais } & \multicolumn{2}{|c|}{ Allem. * Irlandais } & \multicolumn{3}{|c|}{$\begin{array}{l}\text { Anglo- Canadiens Noirs } \\
\text { phones français }\end{array}$} & \multirow{2}{*}{$\begin{array}{r}\text { total } \\
1861\end{array}$} \\
\hline & 133 & 295 & 61 & 326 & 815 & 863 & 183 & \\
\hline âge moyen & 46,2 & 45,1 & 42,0 & 48,0 & 46,2 & 43,4 & 47,3 & 45,0 \\
\hline années de résidence & 18,9 & 16,6 & 18,4 & 17,1 & 17,3 & 35,2 & 9,8 & 24,9 \\
\hline nés en Ontario (\%) & 33,1 & 23,4 & 32,8 & 17,2 & 23,3 & 76,0 & 10,4 & 46,4 \\
\hline âge moyen & 39,1 & 38,2 & 38,0 & 49,0 & 41,6 & 42,3 & 34,2 & 42,5 \\
\hline nés ailleurs (\%) & 66,9 & 76,6 & 67,2 & 82,8 & 76,8 & 24,0 & 89,6 & 53,6 \\
\hline âge moyen & 49,7 & 47,2 & 44,0 & 47,8 & 47,6 & 44,7 & 56,8 & 48,5 \\
\hline années de résidence & 8,9 & 10,0 & 8,8 & 10,5 & 10,0 & 10,4 & 7,0 & 9,6 \\
\hline
\end{tabular}

Source: ANC, recensement nominatif de 1871 , comté d'Essex, bobines 9888-9889. ${ }^{*}$ Dans ce groupe, il y a quelques familles d'origine hollandaise. Cette mention ne sera pas rappelée.

À Malden et à Sandwich, comme ailleurs, la grande majorité des maisonnées avaient été constituée de couples avec enfants. Les immigrants qui étaient arrivés seuls, ou veufs avec leurs enfants, avaient souvent trouvé une conjointe en terre d'accueil. Aussi, dans tous les groupes ethniques, à l'exception des Anglais, le pourcentage des épouses nées en Ontario était-il supérieur à celui des chefs 
de maisonnée par une marge qui approchait les $15 \%$. D'une façon générale, celles-ci étaient plus jeunes que leurs conjoints. Les seules unions parmi lesquelles cette différence dépassait les six années, mettaient en cause les chefs de maisonnée irlandais avec une marge de 7,5 ans et les Canadiens français avec une marge de 8,8 années. Parmi les maris non francophones nés à l'extérieur de la province, l'écart moyen avec leurs épouses était inférieur à 7 ans, bien que s'élevant à 9 années chez les Écossais et à 16 ans chez les Noirs. Enfin, à la naissance de leur premier enfant, les femmes anglophones étaient âgées de 24,3 ans, les Canadiennes françaises de 22 ans et les Noires de 24,1 années. Les taux de natalité étaient de $24,6^{\circ / 00} \mathrm{chez}$ les anglophones, de $30,5^{0 / 00}$ chez les Canadiens français et de $27,2{ }^{0 / 00} \mathrm{chez}$ les Noirs. Les maisonnées des anglophones étaient composées de 5,3 personnes, celles des Canadiens français de 5,8 et celles des Noirs de 4,1 . Il y avait donc plus de personnes extérieures à la famille dans les maisonnées d'anglophones que dans les deux autres.

TABLEAU 7

Le profil des épouses à Malden et à Sandwich en 1871

\begin{tabular}{lrrrrrrrr}
\hline & \multicolumn{1}{c}{ Écossais Anglais } & \multicolumn{6}{c}{ Allem. Irlandais Anglo- Canadiens Noirs } & total \\
& & & \multicolumn{5}{c}{ phones } & français \\
nombre & 113 & 254 & 59 & 262 & 688 & 759 & 133 & 1580 \\
âge moyen & 41,0 & 39,1 & 37,0 & 40,5 & 39,8 & 38,5 & 40,4 & 39,2 \\
âge: 1 $^{\text {cr }}$ enfant & 25,5 & 24,6 & 24,6 & 23,5 & 24,3 & 22,0 & 24,1 & 23,2 \\
enfants, nombre & 2,9 & 3,3 & 2,8 & 3,8 & 3,4 & 4,0 & 2,9 & 3,6 \\
& & & & & & & & \\
nées en Ontario (\%) & 27,4 & 38,2 & 47,4 & 31,7 & 34,7 & 78,8 & 15,0 & 54,2 \\
âge moyen & 41,2 & 33,0 & 35,1 & 32,2 & 34,0 & 38,3 & 31,2 & 36,9 \\
nées ailleurs (\%) & 72,6 & 61,8 & 52,6 & 68,3 & 65,3 & 21,2 & 85,0 & 45,7 \\
âge moyen & 41,0 & 42,9 & 38,6 & 44,4 & 42,8 & 39,3 & 42,0 & 41,9 \\
\hline
\end{tabular}

Source: ANC, recensement nominatif de 1871, comté d'Essex, bobines 9888-9889. 


\section{FERnAND OUELLET}

Dans la plupart des maisonnées, il existait une catégorie de résidents qui n'étaient ni chefs de maisonnée, ni propriétaires, ni occupants d'une terre. Il s'agissait, le plus souvent, de membres masculins de la famille, non mariés, qui avaient déclaré une occupation assez souvent différente de celle du chef de maisonnée. Parmi ces jeunes adultes, les anglophones de Malden et de Sandwich étaient plus âgés que ceux du même rang à Hawkesbury et à Alfred, soit 26 ans contre 24,5, alors que les Canadiens français étaient à peine différents de ceux de l'est de la province, soit 23,5 ans contre 23,6 . Il va de soi que la proportion de ces fils de famille nés en Ontario était substantiellement plus élevée qu'elle ne l'était parmi les chefs de maisonnée et les épouses. Ce qui veut dire que le processus d'enracinement progressait normalement, mais plus rapidement parmi les derniers venus dans la région que chez les Canadiens français. C'est d'ailleurs dans le groupe de ceux qui étaient nés à l'extérieur de la province que la moyenne d'âge dépassait le plus souvent l'âge moyen habituel des garçons au mariage. L'âge de ces individus qui avaient immigré avec leurs parents était de 28,9 ans chez les anglophones, de 26,6 ans chez les Canadiens français et de 26,3 ans chez les Noirs. 
DisPaRITÉS SOCIO-ETHNIQUES, COMTÉ D'ESSEX (1871)

TABLEAU 8

Membres de la maisonnée qui, sans être chefs de maisonnée, ont déclaré des occupations à Malden et à Sandwich en 1871

\begin{tabular}{|c|c|c|c|c|c|c|c|c|}
\hline \multirow[b]{2}{*}{ nombre } & \multicolumn{2}{|c|}{ Écossais Anglais } & \multirow{2}{*}{$\begin{array}{c}\text { Allem. } \\
22\end{array}$} & \multirow[t]{2}{*}{ Irlandais } & \multicolumn{3}{|c|}{$\begin{array}{l}\text { Anglo- Canadiens Noirs } \\
\text { phones français }\end{array}$} & \multirow{2}{*}{$\begin{array}{l}\text { total } \\
916\end{array}$} \\
\hline & 70 & 155 & & & 420 & 449 & 47 & \\
\hline âge moyen & 21,4 & 26,6 & 29,5 & 26,9 & 26,0 & 23,5 & 24,3 & 24,7 \\
\hline Dntario (\%) & 45,7 & 56,8 & 63,6 & 62,4 & 57,6 & 85,5 & 53,2 & 71,1 \\
\hline wen & 26,5 & 23,5 & 28,3 & 22,9 & 23,9 & 23,0 & 22,6 & 23,3 \\
\hline nés : & 54,3 & 43,2 & 36,4 & 37,6 & 42,4 & 14,5 & 46,8 & 28,9 \\
\hline âge moyen & 17,1 & 30,8 & 31,5 & 33,6 & 28,9 & 26,6 & 26,3 & 28,1 \\
\hline
\end{tabular}

Source: ANC, recensement nominatif de 1871, comté d'Essex, bobines 9888-9889.

Les Canadiens français de Malden et de Sandwich étaient les plus ruraux de tous. Leur taux d'urbanisation était de $18,6 \%$, soit la moitié de celui des anglophones et $40 \%$ de celui des Noirs. Dans Malden, leur taux s'élevait à $45 \%$, mais il était quand même inférieur d'environ $28 \%$ à celui des anglophones et de 30 à $35 \%$ à celui des Noirs et des Irlandais. Dans Sandwich, leur taux était la moitié de celui des anglophones, le tiers de celui des Noirs et à peine le quart de celui des Allemands. En milieu urbain, la proportion des chefs de maisonnée canadiens-français nés en Ontario était inférieure à ce qu'elle était dans l'ensemble des deux cantons: $67 \%$ contre $76 \%$. Ce qui laisse supposer que nombre d'entre eux, surtout les journaliers, entretenaient encore le rêve d'un établissement agricole. On peut en dire autant des Irlandais, des Allemands et des Noirs. Il est certain que ces différences entre les groupes ethniques quant au rapport à la ville avaient leurs racines dans des disparités socio-économiques et autres. 


\section{TABLEAU 9}

Taux d'urbanisation des groupes ethniques à Malden et à Sandwich en 1871: la population urbaine de chaque groupe par rapport à sa population totale dans chacun de ces cantons

\begin{tabular}{lccc}
\hline & Amherstburg/ & Sandwich*/ & \\
& Malden & Sandwich & Ensemble \\
Écossais (nombre) & $176 / 346$ & $47 / 333$ & $223 / 679$ \\
$\%$ & 50,9 & 14,1 & 32,9 \\
Anglais (nombre) & $397 / 621$ & $326 / 967$ & $723 / 1538$ \\
$\%$ & 54,7 & 35,5 & 47,0 \\
Allemands (nombre) & $43 / 106$ & $94 / 206$ & $137 / 312$ \\
$\%$ & 40,6 & 45,6 & 43,7 \\
Irlandais (nombre) & $431 / 627$ & $125 / 1155$ & $556 / 1782$ \\
$\%$ & 68,7 & 10,8 & 31,2 \\
Anglophones (nombre) & $1047 / 1700$ & $592 / 2611$ & $1639 / 4311$ \\
$\%$ & 61,5 & 22,7 & 38,0 \\
Canadiens français (nombre) & $539 / 1204$ & $400 / 3847$ & $939 / 5051$ \\
$\%$ & 55,2 & 10,4 & 18,6 \\
Afro-Américains (nombre) & $235 / 373$ & $96 / 324$ & $331 / 697$ \\
$\%$ & 63,0 & 29,6 & 47,5 \\
grand total (nombre) & $1821 / 3277$ & $1088 / 6782$ & $2909 / 10059$ \\
$\%$ & 55,6 & 16,1 & 28,9 \\
\hline
\end{tabular}

Source: ANC, recensement nominatif de 1871, comté d'Essex, bobines 9888-9889. * il s'agit de la ville de Sandwich.

En somme, la société de Malden et de Sandwich, tout autant que celle de Hawkesbury et d'Alfred, était divisée en communautés ethniques, numériquement inégales, installées à des époques différentes dans la région et réparties inégalement entre les campagnes et les villes. Les Canadiens français, arrivés les premiers, les surpassaient toutes individuellement en nombre, surclassant même tous les anglophones pris ensemble. Les communautés d'origine irlandaise, anglaise, afro-américaine, écossaise et germanique étaient, dans l'ordre, les moins nombreuses.

À cette complexité introduite par le facteur ethnique et par les rapports ville-campagne, il faut ajouter celle, encore plus grande, apportée par les appartenances aux Églises. Disons d'abord que le groupe qui se distançait le plus des autres, par son association étroite avec une seule confes- 
sion religieuse, était celui des Canadiens français. En effet, être canadien-français, c'était pratiquement, comme à Hawkesbury et à Alfred, être catholique. Non seulement les chefs de maisonnée canadiens-français étaient-ils catholiques dans une proportion de $99,3 \%$, mais ils constituaient $76 \%$ des chefs de maisonnée catholiques de ces cantons. Après eux, venaient les Irlandais qui étaient davantage associés au catholicisme que ceux que nous avons rencontrés à Hawkesbury et à Alfred: 67,3\% l'étaient dans le premier cas et $44,2 \%$ dans l'autre. À cet égard, ils se situaient sur un pied d'égalité avec les Anglais parmi lesquels $67 \%$ des chefs de maisonnée se réclamaient de l'Église anglicane ou épiscopalienne. Les Afro-Américains se tenaient au quatrième rang en ce qui concerne l'appartenance à une seule Église. En effet, $51,4 \%$ d'entre eux se rattachaient à l'Église baptiste et $35 \%$ à l'Église méthodiste. Ils étaient suivis des Écossais dont la moitié des chefs de maisonnée adhéraient à l'Église presbytérienne. Les Allemands constituaient sans doute le groupe le moins polarisé par une seule croyance: $26 \%$ étaient des méthodistes, $25 \%$ des catholiques et $23 \%$ des anglicans. Notons aussi que 32 individus, dont 13 Noirs, s'étaient déclarés sans croyance religieuse. Pour tout dire, l'Église catholique obtenait le premier rang pour le nombre des fidèles parmi les chefs de maisonnée, soit $61 \%$ des effectifs. À sa suite, venaient dans l'ordre l'Église anglicane avec $16,5 \%$, l'Église méthodiste avec $7,3 \%$, l'Église baptiste avec $5,9 \%$ et l'Eglise presbytérienne avec $4,6 \%$. 
TABLEAU 10

La religion des chefs de maisonnée à Malden et à Sandwich en 1871

Écossais Anglais Allem. Irlandais Anglo- Canadiens Noirs total

Églises (\%)

\begin{tabular}{lrrrrrrrr} 
Église catholique & 6,9 & 7,3 & 24,6 & 67,3 & 33,2 & 99,3 & 1,6 & 61,1 \\
Église anglicane & 21,4 & 67,0 & 22,9 & 21,9 & 37,5 & 0,5 & 1,1 & 16,5 \\
Église presbytérienne & 49,6 & 3,3 & 3,3 & 1,5 & 10,3 & 0 & 1,6 & 4,6 \\
Église d'Écosse & 4,6 & 0 & 0 & 0 & 0,7 & 0 & 0 & 0,3 \\
Église méthodiste & 5,3 & 10,6 & 26,2 & 5,5 & 8,9 & 0 & 34,8 & 7,3 \\
Église baptiste & 2,0 & 1,8 & 3,3 & 1,2 & 1,8 & 0,1 & 51,4 & 5,9 \\
Autres & 6,9 & 7,7 & 11,5 & 1,2 & 5,2 & 0 & 2,2 & 2,4 \\
"None» & 3,0 & 2,2 & 8,2 & 1,2 & 2,4 & 0 & 7,2 & 1,7 \\
Total & 99,7 & 99,9 & 100 & 99,8 & 100 & 99,9 & 99,9 & 99,8 \\
\hline
\end{tabular}

Source: ANC, recensement nominatif de 1871, comté d'Essex, bobines 9888-9889.

On pourrait s'attendre à ce que les affiliations religieuses des épouses aient été un simple reflet de celles des chefs de maisonnée parmi lesquels se recrutaient leurs conjoints. Pourtant, comme nous l'avons déjà observé en ce qui concerne Hawkesbury et Alfred, la réalité était sensiblement différente. Ainsi, le pourcentage des épouses écossaises et anglaises de religion catholique faisait plus que doubler celui des chefs de maisonnnée catholiques de même origine ethnique. Quant aux épouses catholiques d'origine allemande, elles surpassaient de $40 \%$ les effectifs des chefs de maisonnée de même origine qui se déclaraient catholiques. Au contraire, parmi les catholiques irlandais et canadiens-français, les différences d'appartenance religieuse entre les conjoints de même origine ethnique étaient minimes. Quant à l'Église anglicane, elle paraissait beaucoup plus répandue parmi les chefs de maisonnée d'origine anglaise que parmi les épouses de même origine: des taux respectifs de $67 \%$ et de $51,7 \%$. Entre les chefs de maisonnée écossais presbytériens et les épouses de même allégeance, on observe des écarts plus modestes: 49,6\% contre $44,2 \%$. 
DisPARITÉS SOCIO-ETHNIQUES, COMTÉ D'ESSEX (1871)

TABLEAU 11

La religion des épouses à Malden et à Sandwich en 1871

\begin{tabular}{lrrrrrrrr}
\hline & Écossais Anglais & \multicolumn{3}{c}{ Allem. Irlandais Anglo- Canadiens Noirs } & total \\
phones & français \\
Églises (\%) & & & \multicolumn{6}{c}{. } \\
Église catholique & 15,0 & 15,8 & 34,4 & 67,9 & 37,1 & 98,0 & 0 & 63,1 \\
Église anglicane & 21,2 & 51,7 & 26,2 & 22,1 & 33,2 & 1,4 & 4,4 & 15,5 \\
Église presbyt. & 44,2 & 5,5 & 8,2 & 1,5 & 10,6 & 0 & 0,7 & 4,7 \\
Église d'Écosse & 2,6 & 0 & 0 & 0 & 0,4 & 0 & 0 & 0,2 \\
Église méthodiste & 5,3 & 18,6 & 22,9 & 5,7 & 11,9 & 0 & 37,5 & 8,4 \\
Église baptiste & 2,6 & 2,4 & 1,6 & 1,5 & 2,0 & 0,4 & 52,2 & 5,5 \\
Autres & 7,1 & 4,7 & 4,9 & 0,8 & 3,6 & 0,1 & 2,2 & 1,8 \\
«None» & 1,8 & 1,2 & 1,6 & 0,4 & 1,0 & 0 & 2,9 & 0,7 \\
Total & 99,8 & 99,9 & 99,8 & 99,9 & 99,8 & 99,9 & 99,9 & 99,9 \\
\hline
\end{tabular}

Source: ANC, recensement nominatif de 1871, comté d'Essex, bobines 9888-9889.

Cette diversité des appartenances confessionnelles entre les maris et les épouses reflétait un marché matrimonial fort actif. À Hawkesbury et à Alfred, nous avions relevé 199 unions dans lesquelles les époux était différents, soit par l'origine ethnique, soit par l'appartenance religieuse. $\grave{A}$ Malden et à Sandwich, leur nombre était encore plus considérable: 336 au total, dont 194 interethniques, 51 interconfessionnelles et 91 à la fois interethniques et interconfessionnelles, sur un total de 1580 unions possibles, soit un pourcentage de $21,3 \%$. Les groupes ethniques les moins nombreux, c'est-à-dire les Allemands, les Écossais, les Noirs et les Anglais, avaient franchi beaucoup plus aisément que les Canadiens français la barrière ethnique et les interdits cléricaux. Ainsi, comme l'indique le TABLEAU 12, le pourcentage de couples mixtes était douze fois plus élevé chez les Allemands que chez les Canadiens français. Disons aussi que, dans l'ensemble, les ruraux s'étaient montrés plus réticents à cet égard que les urbains. Ainsi, chez les anglophones, le pourcentage d'unions de cette nature contractées en milieu urbain était de $47,3 \%$, alors que leur taux d'urbanisation était de $38 \%$. Chez les Canadiens français, ces pourcentages respectifs étaient de $45,9 \%$ et de 
$18,6 \%$. En cela, les Noirs se distinguaient radicalement des autres. Car 76,5\% de leurs couples mixtes résidaient en milieu rural, alors que leur taux de ruralité était de $52,5 \%$.

TABLEAU 12

Nombre d'unions mixtes à Malden et à Sandwich par rapport au nombre total de couples de même origine ethnique 1871

\begin{tabular}{|c|c|c|c|c|c|c|c|c|}
\hline \multirow[b]{2}{*}{ Interethniques } & \multicolumn{2}{|c|}{ Écossais Anglais } & \multirow[t]{2}{*}{ Allem. } & \multirow[t]{2}{*}{ Irlandais } & \multicolumn{3}{|c|}{$\begin{array}{l}\text { Anglo- Canadiens Noirs } \\
\text { phones français }\end{array}$} & \multirow[t]{2}{*}{ total } \\
\hline & & & & & & & & \\
\hline unions mixtes ( $\mathrm{n}^{\text {bre }}$ ) & 26 & 62 & 21 & 41 & 150 & 28 & 16 & 194 \\
\hline couples ( $\mathrm{n}^{\text {bre }}$ total) & 113 & 254 & 59 & 262 & 688 & 759 & 133 & 1580 \\
\hline$\%$ & 23,0 & 24,4 & 35,6 & 15,6 & 21,8 & 3,7 & 14,9 & 12,3 \\
\hline \multicolumn{9}{|l|}{ Interconfessionnelles } \\
\hline unions mixtes $\left(\mathrm{n}^{\text {bre }}\right)$ & 2 & 21 & 2 & 11 & 36 & 1 & 14 & 51 \\
\hline couples ( $\mathrm{n}^{\text {bre }}$ total) & 113 & 254 & 59 & 262 & 688 & 759 & 133 & 1580 \\
\hline$\%$ & 1,8 & 8,3 & 3,4 & 4,2 & 5,2 & 0,1 & 10,5 & 3,2 \\
\hline \multicolumn{9}{|l|}{$\begin{array}{l}\text { Interethniques et } \\
\text { interconfessionnelles }\end{array}$} \\
\hline unions mixtes ( $\mathrm{n}^{\text {bre }}$ ) & 20 & 31 & 15 & 11 & 77 & 7 & 7 & 91 \\
\hline couples ( $\mathrm{n}^{\text {bre }}$ total) & 113 & 254 & 59 & 262 & 688 & 759 & 133 & 1580 \\
\hline$\%$ & 17,7 & 12,2 & 25,4 & 4,2 & 11,2 & 0,9 & 5,3 & 5,7 \\
\hline \multicolumn{9}{|l|}{ Total } \\
\hline unions mixtes ( $\mathrm{n}^{\text {bre }}$ ) & 48 & 114 & 38 & 63 & 263 & 36 & 37 & 336 \\
\hline couples ( $\mathrm{n}^{\text {bre }}$ total) & 113 & 254 & 59 & 262 & 688 & 759 & 133 & 1580 \\
\hline$\%$ & 42,5 & 44,9 & 64,4 & 24,0 & 38,2 & 4,7 & 27,8 & 21,3 \\
\hline
\end{tabular}

Source: ANC, recensement nominatif de 1871, comté d'Essex, bobines 9888-9889.

En ce domaine, les différences de croyances religieuses étaient plus significatives que celles liées à l'appartenance ethnique. Aussi les contrastes entre les catholiques et les protestants étaient-ils particulièrement frappants. En effet, le taux d'interconfessionnalité des couples, quand le mari était protestant, s'élevait à $20,6 \%$, et à $1,7 \%$ lorsqu'il était catholique. Cette résistance des catholiques aux mariages interconfessionnels était particulièrement marquée chez les maris canadiens-français catholiques: seulement 8 de leurs 
33 épouses choisies en dehors de leur communauté n'étaient pas catholiques. Par contre, soixante filles canadiennesfrançaises, parmi lesquelles 48 catholiques et 12 protestantes, avaient épousé des hommes d'une autre origine ethnique. Des couples ainsi formés, 29 étaient homogènes catholiques, 19 incluaient des Canadiennes françaises catholiques et des protestants, et une seule protestante canadienne-française sur douze avait un mari catholique.

\section{TABLEAU 13}

Mariages mixtes: la religion des épouses quand les maris étaient protestants et la religion des épouses, quand les maris étaient catholiques

à Malden et à Sandwich en 1871

\begin{tabular}{|c|c|c|c|c|c|c|c|c|}
\hline & Écossais & Anglais & Allem. & Irlandais & $\begin{array}{l}\text { Anglo- } \\
\text { phones }\end{array}$ & $\begin{array}{c}\text { Canadiens } \\
\text { français }\end{array}$ & Noirs & total \\
\hline \multicolumn{9}{|l|}{$\begin{array}{l}\text { Religion des épouses } \\
\text { avec maris protestants } \\
\text { ou «nones»* }\end{array}$} \\
\hline catholiques $\left(\mathrm{n}^{\mathrm{bre}}\right)$ & 10 & 27 & 9 & 6 & 52 & 0 & 1 & 53 \\
\hline anglicanes $\left(\mathrm{n}^{\mathrm{bre}}\right)$ & 13 & 36 & 10 & 18 & 77 & 3 & 6 & 86 \\
\hline presbytériennes ( $\mathrm{n}^{\text {bre }}$ ) & 10 & 8 & 3 & 1 & 22 & 0 & 0 & 22 \\
\hline méthodistes ( $\mathrm{n}^{\text {bre }}$ ) & 6 & 19 & 7 & 10 & 42 & 0 & 18 & 60 \\
\hline baptistes $\left(\mathrm{n}^{\mathrm{bre}}\right)$ & 2 & 4 & 1 & 3 & 10 & 0 & 7 & 17 \\
\hline Autres ( $\left.\mathrm{n}^{\text {bre }}\right)$ & 2 & 1 & 0 & 0 & 3 & 0 & 3 & 6 \\
\hline «None» $\left(\mathrm{n}^{\mathrm{brc}}\right)$ & 2 & 1 & 0 & 0 & 3 & 0 & 0 & 3 \\
\hline Total $\left(\mathrm{n}^{\mathrm{bre}}\right)$ & 45 & 96 & 30 & 38 & 209 & 3 & 35 & 247 \\
\hline \multicolumn{9}{|l|}{ religion des épouses } \\
\hline $\begin{array}{l}\text { avec maris catholiques } \\
\text { catholiques }\left(\mathrm{n}^{\text {bre }}\right)\end{array}$ & 3 & 14 & 5 & 19 & 41 & 25 & 0 & 66 \\
\hline anglicanes ( $\left.\mathrm{n}^{\text {bre }}\right)$ & 0 & 1 & 2 & 6 & 9 & 6 & 0 & 15 \\
\hline presbytériennes $\left(\mathrm{n}^{\text {bre }}\right)$ & 0 & 0 & 1 & 0 & 1 & 0 & 0 & 1 \\
\hline méthodistes ( $\mathrm{n}^{\text {bre}}$ ) & 0 & 1 & 0 & 1 & 0 & 1 & 2 & 2 \\
\hline baptistes ( $\mathrm{n}^{\text {bre }}$ ) & 0 & 1 & 0 & 0 & 1 & 2 & 1 & 4 \\
\hline Autres $\left(n^{\text {bre }}\right)$ & 0 & 1 & 0 & 0 & 1 & 0 & 0 & 1 \\
\hline «None» $\left(\mathrm{n}^{\text {bre }}\right)$ & 0 & 0 & 0 & 0 & 0 & 0 & 0 & 0 \\
\hline Total $\left(n^{\text {bre }}\right)$ & 3 & 18 & 8 & 25 & 54 & 33 & 2 & 89 \\
\hline Grand total & 48 & 114 & 38 & 63 & 263 & 36 & 37 & 336 \\
\hline
\end{tabular}

Source: ANC, recensement nominatif de 1871, comté d'Essex, bobines 9888-9889. *none = sans attachement à une religion. 
Tout cela ne veut pas dire que l'origine ethnique et la race n'étaient pas des facteurs décisifs dans le choix d'une épouse. Notons, à cet égard, que seulement trois chefs de maisonnée anglophones et francophones sur 1447, en l'occurrence trois Anglais, avaient épousé une fille d'origine afro-américaine. Ce qui s'explique en partie par le fait que les filles noires à marier étaient relativement peu nombreuses. Pourtant les Allemandes étaient encore moins nombreuses et quinze d'entre elles avaient trouvé des maris anglophones ou canadiens-français. Par contre, les chefs de maisonnée noirs avaient choisi dans les autres ethnies 22 de leurs 37 épouses, dont 11 parmi les Anglaises et seulement deux parmi les Canadiennes françaises, toutes deux d'allégeance méthodiste.

TABLEAU 14

Mariages mixtes: l'ethnicité des épouses selon celle des chefs de maisonnée masculins de Malden et de Sandwich en 1871

\begin{tabular}{|c|c|c|c|c|c|c|c|c|}
\hline & Écossai & Anglais & Allem. & Irlandais & $\begin{array}{l}\text { Anglo- } \\
\text { phones }\end{array}$ & $\begin{array}{l}\text { Canadiens } \\
\text { français }\end{array}$ & s Noirs & total \\
\hline Écossaises ( $\mathrm{n}^{\text {bre }}$ ) & 3 & 20 & 12 & 8 & 43 & 2 & 1 & 46 \\
\hline Anglaises ( $\left.\mathrm{n}^{\text {bre }}\right)$ & 16 & 21 & 6 & 25 & 68 & 13 & 11 & 92 \\
\hline Allemandes ( $\left.\mathrm{n}^{\text {bre }}\right)$ & 1 & 9 & 3 & 3 & 16 & 1 & 1 & 18 \\
\hline Irlandaises ( $n^{\text {bre }}$ ) & 15 & 39 & 5 & 11 & 70 & 19 & 4 & 93 \\
\hline Anglophones ( $\mathrm{n}^{\text {bre }}$ ) & 35 & 89 & 26 & 47 & 197 & 35 & 17 & 249 \\
\hline C. françaises $\left(n^{\text {bre }}\right)$ & 12 & 19 & 11 & 16 & 0 & 1 & 2 & 61 \\
\hline Noires $\left(\mathrm{n}^{\text {bre }}\right)$ & 0 & 3 & 0 & 0 & 0 & 0 & 15 & 18 \\
\hline inconnues $\left(\mathrm{n}^{\text {bre }}\right)$ & 1 & 3 & 1 & 0 & 6 & 0 & 3 & 8 \\
\hline Total $\left(\mathrm{n}^{\text {bre }}\right)$ & 48 & 115 & 38 & 63 & 264 & 36 & 37 & 336 \\
\hline
\end{tabular}

Source: ANC, recensement nominatif de 1871, comté d'Essex, bobines 9888-9889.

Le nombre élevé de ces alliances a-t-il eu seulement pour effet de résoudre les problèmes temporaires de croissance de certains groupes peu nombreux? Ou bien a-t-il eu des conséquences plus lointaines et plus profondes sur le développement des relations entre les diverses communautés anglophones et protestantes au Canada? Le fait est que, des chefs de maisonnée aux adultes masculins vivant 
avec eux, on peut déceler un recul des anglicans anglais et des presbytériens écossais au profit des méthodistes qui, le plus souvent, dominaient numériquement en dehors des concentrations canadiennes-françaises où les catholiques surpassaient tous les autres groupes. Cepedant, les polarisations entre protestants et catholiques n'ont jamais été assez fortes pour faire taire les oppositions entre les évêques catholiques d'origine française et ceux d'origine irlandaise, supportés qu'ils étaient par leurs clergés et, jusqu'à un certain point, par leurs fidèles respectifs ${ }^{59}$.

\section{TABLEAU 15}

La religion des membres de la maisonnée qui, sans être chefs de maisonnée, ont déclaré des occupations à Malden et à Sandwich en 1871

\begin{tabular}{|c|c|c|c|c|c|c|c|c|}
\hline \multirow[b]{2}{*}{$(\%)$} & \multicolumn{2}{|c|}{ Écossais Anglais } & \multirow[t]{2}{*}{ Allem. } & \multirow[t]{2}{*}{ Irlandais } & \multirow[t]{2}{*}{$\begin{array}{l}\text { Anglo- } \\
\text { phones }\end{array}$} & \multicolumn{2}{|c|}{$\begin{array}{l}\text { Canadiens Noirs } \\
\text { français }\end{array}$} & \multirow[t]{2}{*}{ total } \\
\hline & & & & & & & & \\
\hline Église catholique & 14,3 & 11,5 & 29,2 & 71,4 & 37,5 & 94,5 & 0 & 61,0 \\
\hline Église anglicane & 25,7 & 52,8 & 45,8 & 16,6 & 33,0 & 1,1 & 2,3 & 15,3 \\
\hline Église presbyt. & 34,2 & 5,1 & 8,3 & 1,1 & 8,4 & 0,9 & 0 & 4,1 \\
\hline Église d'Écosse & 7,1 & 0 & 0 & 0 & 1,2 & 0 & 0 & 0,5 \\
\hline Église méthodiste & 10,0 & 16,6 & 12,5 & 8,0 & 11,7 & 1,1 & 38,4 & 9,1 \\
\hline Église baptiste & 2,8 & 4,4 & 0 & 1,7 & 2,8 & 2,0 & 52,3 & 6,8 \\
\hline Autres & 5,7 & 8,3 & 0 & 0,6 & 4,4 & 0,4 & 2,3 & 2,3 \\
\hline «None» & 0 & 1,3 & 4,2 & 0,6 & 0,9 & 0 & 4,6 & 0,8 \\
\hline Total & 99,8 & 100 & 100 & 100 & 99,9 & 100 & 99,9 & 99,9 \\
\hline
\end{tabular}

Source: ANC, recensement nominatif de 1871, comté d'Essex, bobines 9888-9889.

La société de Malden et de Sandwich, comme celle de Hawkesbury et d'Alfred, toutes deux à l'image de l'Ontario, était donc multiethnique et multiconfessionnelle. Les Canadiens français se distinguaient de la plupart des anglophones par leur ancienneté dans la région, leur caractère rural, leur natalité plus élevée et leur unique association avec le catholicisme. Les Noirs s'en séparaient aussi par leur arrivée plus tardive, par leur statut minoritaire, par

${ }^{59}$ Robert Choquette, L'Église catholique dans l'Ontario français du XIX $X^{e}$ siècle, Ottawa, PUO, 1984, pp. 91-138. 
leur physionomie plus urbaine et leur expérience antérieure de l'esclavage en terre américaine. On ne saurait donc s'étonner qu'ils aient été, au même titre que les Canadiens français, différents des autres par leur taux exceptionnellement élevé d'analphabétisme.

À la suite de leur étude sur l'analphabétisme en Ontario, basée sur un échantillon de 5386 adultes masculins tirés du recensement de 1871, Gordon Darroch et Lee Soltow font observer que

the chance of a man's being illiterate was directly affected by his age, religious affiliation, city residence, and ethnic origin, when the effects of all other measured variables are taken into account. . ethnicity made the greatest contribution, followed by religion, after the two, in diminishing order of importance, are age, residence and the five economic variables. . More generally, the Scottish men of all religious persuasions, except Catholics, had very low illiteracy rates, averaging around 4 per cent. Once again, by contrast, we see the highest male illiteracy rate in Ontario en 1871 was among French-origin Catholics: well over half the group was illiterate ${ }^{60}$.

Ces disparités avaient une origine ancienne. Avant 1760 , des écarts entre les Canadiens nés au pays et les Français de la métropole et, il va sans dire, avec les habitants de la Nouvelle-Angleterre, s'étaient creusés progressivement en ce domaine. Après 1760 , ces polarisations s'étaient accentuées avec l'arrivée au Québec d'immigrants des colonies américaines et des îles Britanniques. Elles s'étaient maintenues et perpétuées même après que, dans les deux Canadas, l'État eut décidé d'intervenir efficacement pour assurer la diffusion de l'enseignement élémentaire ${ }^{61}$. Ainsi, selon les adresses de loyauté à la reine (1838-1839) dépouillées par Allan Greer, $80 \%$ des ruraux et $55 \%$ des

${ }^{60}$ Gordon Darroch and Lee Soltow, Property and Inequality in Victorian Ontario. Structural Patterns and Cultural Communilies in the 1871 Census, Toronto, UTP, 1994, pp. 147, 150, 152 s.

${ }^{61}$ Fernand Ouellet, "Fréquentation scolaire, alphabétisation et société au Québec et en Ontario jusqu'en 1911: les francophones et les autres», Cahiers Charlevoix, 2, Sudbury, Prise de parole et Société Charlevoix, 1995, pp. 280, 295. 
urbains bas-canadiens étaient incapables de signer leur nom $^{62}$. Ces chiffres sont comparables à ceux que nous avons obtenus en examinant les dépositions et les examens volontaires des 2539 personnages reliés aux insurrections de 1837-1838: un taux total d'analphabétisme de $71 \%$ chez ces Canadiens français et de $13 \%$ chez les anglophones. Parmi les cultivateurs des deux origines, il se situait à $86 \%$ et à $20 \%$ respectivement ${ }^{63}$.

Les habitants du poste éloigné de Détroit n'avaient donc pas été plus négligés par l'Église catholique et par l'État que ceux des paroisses situées à distance moyenne des villes de la Nouvelle-France, même si celle de l'Assomption (Sandwich), établie en 1767, n'eut son école qu'en 1786. En effet, en cette année, les demoiselles Adhémar et Papineau, de Montréal, vinrent dispenser leur enseignement dans une école construite à leur intention qui, en 1792 , n'avait encore que 12 pensionnaires et 5 ou 6 externes $^{64}$. On ignore encore ce qu'il advint de cette école. Toujours est-il qu'en 1828 trois religieuses de la congrégation de l'Enfant-Jésus vinrent prendre charge d'une école qui dispensait l'enseignement à une cinquantaine d'enfants. Il est curieux de constater que, pour cette école, on fut immédiatement obligé de chercher une enseignante laïque «bien versée dans la grammaire française et la géographie $^{65}$ ». À cette date, en plus de cette école bilingue, il n'existait, semble-t-il, dans la région qu'une grammar school. On aurait donc attendu la réforme des années 1840 , accomplie sous la direction d'Egerton Ryerson qui voulait déconfessionnaliser le système, pour qu'un élan fût donné à la fréquentation scolaire dans la province. Ainsi, en 1851, il y avait autant d'élèves dans les écoles élémentaires du

${ }^{62}$ Ibid., p. 299.

${ }^{63}$ Ibid., p. 300.

${ }^{64}$ Ernest Lajeunesse, op. cit., pp. XV-C1, 274-309; Jack D. Cecillon, « Turbulent Times in the Diocese of London : Bishop Fallon and His French Canadian Flock, 1910-1918 ", M.A. Thesis, University of Windsor, 1989, pp. 1-12. ${ }^{65}$ R. Choquette, op. cit., p. 292. 
Sud-Ouest ontarien que dans l'ensemble de la province en 1842. Au sujet de l'intensité de la participation des Canadiens français à ce mouvement, on ignore presque tout. Sauf l'incident provoqué par l'instituteur Gigon, unilingue français appelé à prendre charge d'une école publique établie selon les normes nouvelles, qui amena le conseil régional de l'éducation à reconnaître, en 1851 , le français et l'allemand, en plus de l'anglais, comme langues d'enseignement $^{66}$. Sauf aussi la construction par les jésuites du collège de l'Assomption en 1856.

Les contrastes entre Canadiens français et anglophones étaient donc bien antérieurs à l'année 1844. Les chefs de maisonnée canadiens-français de Hawkesbury et d'Alfred, qui, en 1871, étaient nés au Québec dans une proportion de $85 \%$ et qui habitaient l'Ontario depuis moins de 10 ans, étaient aux trois quarts analphabètes, alors que ceux de Malden et de Sandwich qui étaient nés en Ontario dans une proportion de $76 \%$ et y résidaient depuis 42 ans en moyenne, ne l'étaient qu'à moitié. Leur taux était de $8 \%$ plus bas que celui des habitants du comté des DeuxMontagnes, dont le taux d'analphabétisme était le double de celui du comté à majorité anglophone d'Argenteuil. Le moment de l'arrivée dans une région, très important dans leur cas, l'était beaucoup moins pour les anglophones. En effet, entre les Écossais, les Anglais et les Irlandais de ces deux régions, les différences étaient minimes, même si les deux premiers groupes avaient été les pionniers de Hawkesbury et d'Alfred: pour eux, un taux d'analphabétisme d'environ $10 \%$ dans les deux endroits. Il y avait donc une tradition canadienne-française et catholique d'analphabétisme qui avait ses racines en Nouvelle-France et en Acadie, et qui s'était propagée en Ontario avec l'immigration d'origine française. Â côté d'elle, coexistait une tradition d'alphabétisme, dont les racines étaient anglophones,

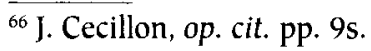


protestantes, britanniques et américaines. Aussi les taux d'analphabétisme des chefs de maisonnée anglophones catholiques étaient-ils à la fois beaucoup plus bas que ceux des Canadiens français et substantiellement plus élevés que ceux des anglophones protestants et catholiques pris ensemble: ne savent lire: Canadiens français $48,4 \%$, anglophones 7,5\%, anglophones catholiques $14,1 \%$; ne savent écrire: Canadiens français 51,9\%, anglophones $9,6 \%$ et anglophones catholiques $16,7 \%$.

\section{TABLEAU 16}

Niveaux d'analphabétisme parmi les chefs de maisonnée âgés de 20 ans et plus selon les groupes ethniques et leur lieu de naissance à Malden et à Sandwich en 1871

(nombre et pourcentage d'analphabètes)

\begin{tabular}{|c|c|c|c|c|c|c|c|c|}
\hline \multirow[b]{2}{*}{ ne sait lire $\left(\mathrm{n}^{\text {bre }}\right)$} & \multicolumn{2}{|c|}{ Écossais Anglais } & Allem. & Irlandais & \multicolumn{3}{|c|}{$\begin{array}{l}\text { Anglo- Canadiens Noirs } \\
\text { phones français }\end{array}$} & \multirow{2}{*}{$\begin{array}{l}\text { total } \\
552\end{array}$} \\
\hline & 7 & 15 & 6 & 33 & 61 & 418 & 73 & \\
\hline$\%$ & 5,3 & 5,1 & 9,8 & 10,1 & 7,5 & 48,4 & 39,9 & 29,5 \\
\hline ne sait écrire $\left(\mathrm{n}^{\text {bre }}\right)$ & 7 & 20 & 9 & 42 & 78 & 448 & 80 & 606 \\
\hline$\%$ & 5,3 & 6,8 & 14,7 & 12,8 & 9,6 & 51,9 & 43,7 & 32,6 \\
\hline taux moyen & 5,3 & 5,9 & 12,3 & 11,5 & 8,5 & 50,2 & 41,8 & 31,1 \\
\hline \multicolumn{9}{|l|}{ nés en Ontario } \\
\hline ne sait lire ( $n^{\text {bre }}$ ) & 7 & 3 & 3 & 5 & 18 & 316 & 3 & 337 \\
\hline$\%$ & 15,9 & 4,3 & 15,0 & 8,9 & 9,5 & 48,2 & 15,8 & 39,0 \\
\hline ne sait écrire ( $n^{\text {bre }}$ ) & 7 & 3 & 4 & 6 & 20 & 341 & 4 & 385 \\
\hline$\%$ & 15,9 & 4,3 & 20,0 & 10,7 & 10,6 & 52,0 & 21,0 & 44,6 \\
\hline taux moyen & 15,9 & 4,3 & 17,5 & 9,8 & 10,0 & 50,1 & 18,4 & 41,8 \\
\hline \multicolumn{9}{|l|}{ nés ailleurs } \\
\hline ne sait lire ( $\mathrm{n}^{\text {bre }}$ ) & 0 & 12 & 3 & 28 & 43 & 102 & 70 & 215 \\
\hline$\%$ & 0 & 5,3 & 7,3 & 10,4 & 6,9 & 49,3 & 42,7 & 21,6 \\
\hline ne sait écrire $\left(\mathrm{n}^{\text {bre }}\right)$ & 0 & 17 & 5 & 36 & 58 & 107 & 76 & 241 \\
\hline$\%$ & 0 & 7,5 & 12,1 & 13,3 & 9,3 & 51,7 & 46,3 & 24,2 \\
\hline taux moyen & 0 & 6,4 & 9,7 & 11,8 & 8,1 & 50,5 & 44,5 & 22,9 \\
\hline
\end{tabular}

Source: ANC, recensement nominatif de 1871, comté d'Essex, bobines 9888-9889. 
Ces résultats confirment en gros l'analyse de Darroch et Soltow sur les différences entre les groupes ethniques à cet égard. Il est vrai que l'analphabétisme était généralement plus répandu parmi les individus les plus âgés que parmi les jeunes, mais il n'en découle pas pour autant qu'au niveau des groupes la chose était aussi tranchée. Parmi les anglophones, l'âge moyen des chefs de maisonnée était de 46,2 ans, variant entre 42 ans et 48 ans d'un groupe à l'autre. Mais, entre les Écossais et les Anglais, d'une part, et les Allemands et les Irlandais, de l'autre, le taux d'analphabétisme fluctuait du simple au double. Il existait aussi des différences substantielles entre ceux qui étaient nés en Ontario et ceux qui y avaient immigré. Excepté dans le cas des Irlandais, le niveau d'analphabétisme était plus faible chez les immigrants que chez les autres. Pourtant, l'âge moyen de ceux qui étaient nés dans les îles Britanniques, aux États-Unis ou au Québec, y était plus élevé que parmi ceux qui étaient nés en Ontario.

Le taux d'analphabétisme des Canadiens français, les pionniers de la région, était presque six fois plus considérable que celui des anglophones et presque dix fois plus que celui des Écossais. Parmi ces Canadiens français, les différences de taux et d'âges entre les natifs et ceux qui étaient venus directement du Québec ou via les États-Unis une dizaine d'années auparavant étaient à peu près nulles. On sera surpris de constater que les Noirs, qui souvent, dit Robin Wincks, faisaient face à la discrimination, au point que Ryerson «avec peine extrême et regret» avait autorisé en 1847 des écoles séparées à leur intention, affichaient de meilleures performances que les Canadiens français ${ }^{67}$. En effet, la petite minorité noire née en Ontario, dont l'âge moyen était de 34 ans, avait des taux qui se rapprochaient davantage de ceux des anglophones que de ceux des Canadiens français. Par contre, les $90 \%$ de Noirs nés aux ÉtatsUnis, dont l'âge moyen était de 57 ans, avaient des taux

${ }^{67}$ R. Wincks, The Blacks in Canada..., pp. 148, 369. 
qui se rapprochaient de ceux des Canadiens français: 44,5\% contre $50,5 \%$.

Évidemment, on ne saurait expliquer toutes ces différences sans tenir compte en plus de la polarisation traditionnelle entre catholiques et protestants. En effet, les taux d'analphabétisme parmi les fidèles qui étaient invités à s'en remettre à la parole du prêtre, en tant que seul interprète légitime et autorisé des Écritures, et parmi ceux qui avaient un accès direct à la Bible et pouvaient, en principe, en tirer des leçons pour eux-mêmes, étaient très différents: $47 \%$ pour les premiers et $14 \%$ chez les autres. Naturellement, ces taux étaient plus élevés dans les campagnes, là où le nombre d'écoles était moins élevé que dans les villes. Ainsi, chez les catholiques, ils étaient de $53 \%$ en milieu rural et de $26 \%$ en milieu urbain, alors que, parmi les protestants, ce qui incluait les Noirs, ces écarts se chiffraient à $20 \%$ en milieu rural et à $9 \%$ en ville.

\section{TABLEAU 17}

Niveaux d'analphabétisme des chefs de maisonnée selon les groupes ethniques, selon leur lieu de résidence (ville et campagne), et selon leur appartenance sociale en 1871 (en pourcentage)

\begin{tabular}{lrrrrrrr}
\hline & Écossais Anglais & Allem. Irlandais & \multicolumn{3}{c}{$\begin{array}{c}\text { Anglo-Canadiens Noirs } \\
\text { phones français }\end{array}$} \\
& & & & & & & \\
milieu rural & 5,3 & 9,3 & 30,5 & 17,6 & 13,7 & 58,3 & 63,0 \\
cultivateurs & 18,2 & 33,3 & 10,0 & 33,3 & 25,8 & 62,0 & 55,0 \\
non qualifiés & 0 & 11,8 & 0 & 0 & 4,4 & 32,9 & 100,0 \\
qualifiés & 10,0 & 0 & 4,5 & 8,3 & 31,6 & 0 & \\
h. de profession, affaires0 & 0 & 0 & 100 & 100 & 25,0 & 75,0 & 0 \\
veufs et veuves* & 5,8 & 12,0 & 20,8 & 18,2 & 14,0 & 56,9 & 64,0 \\
total & & & & & & & \\
milieu urbain & 0 & 0 & 0 & 0 & 0 & 53,8 & 14,3 \\
cultivateurs & 0 & 1,4 & 7,1 & 4,1 & 3,0 & 50,0 & 40,4 \\
non qualifiés & 7,7 & 0 & 0 & 4,0 & 3,0 & 15,4 & 12,5 \\
qualifiés & 0 & 0 & 0 & 0 & 0 & 0 & 0 \\
h. de profession, affaires & 14,3 & 0 & 0 & 0 & 2,4 & 31,2 & 41,7 \\
veufs et veuves* & 4,2 & 0,3 & 2,0 & 2,5 & 1,8 & 33,1 & 29,0 \\
total & & & & & & &
\end{tabular}

source: ANC, recensement nominatif de 1871 , comté d'Essex, bobines 9888-9889. *sans occupation déclarée. 
Pour comprendre la portée socio-économique de ces disparités énormes, il faut d'abord noter que la campagne de Malden et de Sandwich était le lieu privilégié des cultivateurs dans une proportion de $96 \%$ et que la ville était celui des gens les plus instruits $(73 \%)$, des ouvriers les plus qualifiés (64\%) et, généralement, des personnes les plus fortunées. C'était aussi en ville que se trouvait le plus grand nombre de travailleurs non qualifiés (62\%), de veufs et de veuves sans occupation déclarée (76\%). Ainsi, les institutions culturelles, les services et les entreprises commerciales et industrielles étaient davantage localisés en milieu urbain qu'à la campagne.

Vue sous cet angle, la situation avantageuse des anglophones en ce qui concerne l'analphabétisme tenait en partie non seulement à leur taux d'urbanisation plus élevé, mais à la plus grande concentration de leurs élites et de leurs travailleurs qualifiés en milieu urbain. Au contraire, les Canadiens français étaient ruraux dans une proportion de plus de $80 \%$, surreprésentés parmi les cultivateurs et les ouvriers ruraux, mais sous-représentés parmi les classes dirigeantes. En effet, $80 \%$ des membres des classes dirigeantes urbaines et $60 \%$ des membres des classes dirigeantes rurales étaient anglophones. Quant aux Noirs, ils étaient les plus urbains de tous, fortement concentrés parmi les travailleurs non qualifiés des villes et plus alphabétisés que les Canadiens français. Par contre, dans les campagnes, ils étaient les plus mal en point de tous quant à l'accès à l'école. 
TABLEAU 18

Niveaux d'alphabétisation des épouses âgées de 20 ans et plus par origine ethnique et par lieu de naissance en 1871 (en pourcentage)

\begin{tabular}{|c|c|c|c|c|c|c|c|c|}
\hline \multirow[b]{2}{*}{ ne sait lire ( ${ }^{\text {bre }}$ ) } & \multicolumn{2}{|c|}{ Écossais Anglais } & Allem. & Irlandais & \multicolumn{3}{|c|}{$\begin{array}{l}\text { Anglo- Canadiens Noirs } \\
\text { phones français }\end{array}$} & total \\
\hline & 5 & 13 & 9 & 33 & 60 & 261 & 49 & 370 \\
\hline$\%$ & 4,4 & 5,1 & 15,2 & 12,6 & 8,7 & 34,5 & 36,8 & 23,1 \\
\hline ne sait écrire ( $\mathrm{n}^{\text {bre }}$ ) & 5 & 17 & 13 & 38 & 73 & 365 & 59 & 497 \\
\hline$\%$ & 4,4 & 6,7 & 22,0 & 14,5 & 10,6 & 48,1 & 44,4 & 31,4 \\
\hline $\begin{array}{l}\text { nées en Ontario } \\
\text { ne sait lire }\left(\mathrm{n}^{\text {bre }}\right)\end{array}$ & 2 & 5 & 4 & 4 & 15 & 206 & 4 & 225 \\
\hline$\%$ & 6,4 & 5,1 & 14,3 & 4,8 & 6,3 & 34,4 & 20,0 & 26,2 \\
\hline ne sait écrire ( $\mathrm{n}^{\text {bre }}$ ) & 3 & 6 & 7 & 4 & 20 & 289 & 5 & 314 \\
\hline$\%$ & 9,7 & 6,2 & 25,0 & 4,8 & 8,4 & 48,3 & 25,0 & 36,6 \\
\hline $\begin{array}{l}\text { nées ailleurs } \\
\text { ne sait lire }\left(\mathrm{n}^{\mathrm{bre}}\right)\end{array}$ & 3 & 8 & 5 & 29 & 45 & 55 & 45 & 145 \\
\hline$\%$ & 3,6 & 5,1 & 16,1 & 16,2 & 10,0 & 34,2 & 39,8 & 20,0 \\
\hline ne sait écrire ( $\mathrm{n}^{\text {bre }}$ ) & 2 & 11 & 6 & 34 & 53 & 76 & 54 & 183 \\
\hline$\%$ & 2,4 & 7,0 & 19,3 & 19,0 & 11,8 & 47,2 & 47,8 & 25,3 \\
\hline
\end{tabular}

Source: ANC, recensement nominatif de 1871, comté d'Essex, bobines 9888-9889.

Comme celles de Hawkesbury et d'Alfred, les épouses de Malden et de Sandwich, bien que plus jeunes que leurs maris, étaient, à l'exception des Canadiennes françaises, moins alphabétisées qu'eux. Il faut dire que ces différents bagages culturels auraient été transmis presque tels quels aux enfants si la révolution scolaire opérée sous l'égide de l'État n'avait été amorcée un quart de siècle plus tôt.

En effet, avec le temps, ces taux s'étaient améliorés, puisque les adultes masculins résidant chez les chefs de maisonnée, dont l'âge moyen était de 26 ans chez les anglophones, de 23 ans parmi les Canadiens français et de 24 ans chez les Noirs, étaient moins analphabètes que leurs parents: une différence de $21 \%$ parmi ces jeunes anglophones par rapport à eux, de $27 \%$ chez les Noirs et de $47 \%$ parmi les Canadiens français. Les Écossais et les Allemands étaient les seules exceptions à la règle. 
TABLEAU 19

Niveaux d'analphabétisme des membres de la maisonnée qui, sans en être les chefs, ont déclaré des occcupations à Malden et à Sandwich en 1871

(en pourcentage des membres âgés de 21 ans et plus)

\begin{tabular}{|c|c|c|c|c|c|c|c|c|}
\hline \multirow[b]{2}{*}{ ne sait lire } & \multicolumn{2}{|c|}{ Écossais Anglais } & \multirow[t]{2}{*}{ Allem. } & \multirow[t]{2}{*}{ Irlandais } & \multicolumn{3}{|c|}{$\begin{array}{l}\text { Anglo- Canadiens Noirs } \\
\text { phones français }\end{array}$} & \multirow[t]{2}{*}{ total } \\
\hline & & & & & & & & \\
\hline analphabètes ( $n^{\text {bre }}$ ) & 4 & 0 & 4 & 8 & 16 & 64 & 10 & 90 \\
\hline m. de 21 et $+\left(n^{\text {bre }}\right)$ & 56 & 96 & 19 & 118 & 289 & 243 & 33 & 565 \\
\hline$\%$ & 7,1 & 0 & 21,0 & 6,8 & 5,5 & 26,3 & 30,3 & 9,8 \\
\hline \multicolumn{9}{|l|}{ ne sait écrire } \\
\hline analphabètes ( $n^{\text {bre }}$ ) & 5 & 3 & 6 & 9 & 23 & 65 & 10 & 98 \\
\hline$m$. de 21 et $+\left(n^{\text {bre }}\right)$ & 56 & 96 & 19 & 118 & 289 & 243 & 33 & 565 \\
\hline$\%$ & 8,9 & 3,1 & 31,6 & 7,6 & 7,9 & 26,7 & 30,3 & 10,7 \\
\hline taux moyen & 8,0 & 1,6 & 26,3 & 7,2 & 6,7 & 26,5 & 30,3 & 16,6 \\
\hline
\end{tabular}

Source: ANC, recensement nominatif de 1871 , comté d'Essex, bobines 9888-9889.

Ce mouvement de scolarisation de la masse véhiculait une vision de l'école non seulement comme un facteur de paix sociale, mais aussi comme un instrument de progrès et de promotion des individus. En effet, en 1871, la diffusion des écoles vers les campagnes avait été sérieusement engagée et la création d'un noyau d'instituteurs susceptible de soutenir les objectifs du gouvernement, accomplie. Presque $50 \%$ de ces enseignants étaient nés en Ontario et étaient âgés de 28 ans en moyenne. Ces intituteurs étaient aussi célibataires dans une proportion de $86 \%$, laïcs à $72 \%$, masculins à $55 \%$ et à grande dominance catholique $(72 \%)$. Parmi eux, il y avait 15 anglophones, dont 7 Irlandais, 13 Canadiens français et seulement un Noir. La masse des élèves se chiffrait à 2280 enfants, âgés de 7,2 ans en moyenne et issus de 1136 familles avec enfants d'âge scolaire. Ces familles représentaient $61 \%$ des maisonnées de la région. 
DisParités SOCIO-ETHNIQUES, COMTÉ D’ESSEX (1871)

TABLEAU 20

Scolarisation des enfants appartenant à des familles avec enfants d'âge scolaire à Malden et à Sandwich en 1871

\begin{tabular}{lcccc}
\hline & $\begin{array}{c}\text { élèves } \\
\left(\mathrm{n}^{\text {bre }}\right)\end{array}$ & $\begin{array}{c}\text { âge } \\
\text { moyen }\end{array}$ & $\begin{array}{c}\text { familles } \\
\left(\mathrm{n}^{\text {bre }}\right)\end{array}$ & $\begin{array}{c}\text { élèves par } \\
\text { famille }\end{array}$ \\
Écossais & 172 & 6,8 & 81 & 2,1 \\
Anglais & 395 & 7,5 & 176 & 2,2 \\
Allemands & 70 & 7,5 & 41 & 1,7 \\
Irlandais & 428 & 8,5 & 184 & 2,3 \\
Anglophones & 1063 & 7,8 & 482 & 2,2 \\
Canadiens français & 1078 & 6,4 & 557 & 1,9 \\
Noirs & 139 & 8,6 & 97 & 1,4 \\
Total & 280 & 7,2 & 1136 & 2,0 \\
\hline
\end{tabular}

Source: ANC, recensement nominatif de 1871 , comté d'Essex, bobines 9888-9889.

Ceci dit, deux groupes ethniques, les Canadiens français et les Noirs, faisaient figure, pour des raisons différentes, de communautés infériorisées par rapport aux anglophones qui étaient à peu près complètement alphabétisés.

\section{III - Hí́rarchies Sociales et hiérARchies de la terRe en 1871}

À Malden et à Sandwich, les Canadiens français étaient arrivés les premiers et ils y constituaient l'ethnie la plus nombreuse. Mais ils n'y détenaient pas pour autant le pouvoir économique et politique. La transition de la traite des pelleteries vers une économie dominée par l'agriculture n'avait pas modifié leur statut à cet égard, en dépit du fait que les principaux marchands de fourrures avaient finalement quitté les lieux. Sur ce point, il n'y avait aucune différence entre la situation des Canadiens français, soit à Malden et à Sandwich, soit à Hawkesbury et à Alfred. Aux deux endroits, sept hommes d'affaires et hommes de profession sur dix étaient anglophones, alors qu'un peu plus de quatre chefs de maisonnées sur dix étaient de même origine. La moitié des artisans était également anglophone. 
À Malden et à Sandwich, il n'y avait aucun homme d'affaires de la taille et de l'envergure des frères Hamilton de Hawkesbury. Aussi la valeur de la production artisanale et industrielle y était-elle moins de la moitié de celle de Hawkesbury et d'Alfred. Les frères Thomas y figuraient parmi les premiers. Ils exploitaient une scierie, et un moulin à grains qui produisait 7000 barils de gruau. De son côté, Hiram Walker possédait un moulin à farine et une distillerie qui produisait 1225526 gallons d'alcool, alors que celle de Burke n'en préparait que 134400 gallons. Walker exploitait en plus une ferme de 890 acres, récoltait plus de 1000 boisseaux de céréales, engrangeait 90 tonnes de foin et entrenait 90 animaux de ferme. Pour sa part, George Middledich fabriquait 500 charrues, 200 cultivators, 50 herses et 20 marmites à potasse. Les frères Rhéaume, propriétaires de moulins à farine et à carder, appartenaient à ce groupe, ainsi que l'épiscopalien John Gauthier qui se spécialisait dans la préparation et l'empaquetage des viandes. Il manipulait ainsi 200000 livres de porc et 40000 livres de jambon. Au total, ces activités étaient réalisées dans 120 établissements, dont 67 appartenaient à des anglophones et 53 à des Canadiens français: les premiers employaient 3,4 personnes en moyenne par établisssement et les seconds 1,8. La valeur moyenne de leurs produits par établissement était de $4374 \$$ chez les anglophones et de $1706 \$$ chez les Canadiens français. Ces chiffres n'incluent pas les individus, dont plusieurs d'origine afro-américaine, qui possédaient plusieurs maisons et bateaux de pêche. En ce domaine, les disparités entre francophones et anglophones étaient aussi considérables qu'au niveau de la propriété des boutiques et des manufactures. La classe dirigeante des Noirs était encore plus anémique que celle des Canadiens français: seulement $5,2 \%$ des effectifs des hommes d'affaires de la région. 
DiSPARITÉS SOCIO-ETHNIQUES, COMTÉ D'ESSEX (1871)

TABLEAU 21

La structure sociale des chefs de maisonnée

à Malden et à Sandwich en 1871 (en pourcentage)

\begin{tabular}{lrrrrrrrrr}
\hline & \multicolumn{1}{c}{ Écossais Anglais Allem. Irlandais Anglo- Canadiens Noirs } & total \\
& & & \multicolumn{5}{c}{ phones } & français \\
cultivateurs & 43,3 & 39,8 & 34,4 & 53,7 & 45,5 & 60,8 & 39,7 & 52,1 \\
affaires, professions & 18,6 & 20,4 & 18,0 & 11,8 & 16,5 & 5,4 & 5,4 & 10,2 \\
artisans & 16,4 & 17,3 & 16,4 & 11,4 & 14,8 & 12,8 & 9,2 & 13,3 \\
non qualifiés & 15,7 & 17,0 & 27,9 & 17,7 & 17,9 & 17,7 & 38,6 & 19,8 \\
veufs et veuves* & 6,0 & 5,4 & 3,3 & 5,3 & 5,3 & 3,2 & 7,1 & 4,5 \\
Total & 100 & 99,9 & 100 & 99,9 & 100 & 99,9 & 100 & 99,9 \\
\hline
\end{tabular}

Source: ANC, recensement nominatif de 1871, comté d'Essex, bobines 9888-9889. *sans occupation déclarée.

À Hawkesbury et à Alfred, là où les Canadiens français étaient arrivés les derniers dans la région et étaient devenus majoritaires, ils constituaient $80 \%$ de tous les journaliers $^{68}$, alors qu'à Malden et Sandwich, ce pourcentage n'était que de $42 \%$. Les Noirs, les derniers venus, formaient près de $20 \%$ des ouvriers non qualifiés et, parmi eux, le nombre de ces travailleurs égalait presque celui des cultivateurs. On peut dire que leur situation, en tant que groupe défavorisé, n'était pas tellement différente de celle des Canadiens français de Hawkesbury et d'Alfred.

Comme la plupart des jeunes adultes masculins qui habitaient avec leurs parents et avaient déclaré des occupations, étaient célibataires, on ne doit pas s'étonner qu'ils aient, plus souvent qu'autrement, suivi leurs traces.

\footnotetext{
${ }^{68}$ Ces journaliers canadiens-français tributaires du travail saisonnier en forêt ou sur des fermes ressemblent à ceux dont parle Jean Lamarre dans son texte intitulé: "Modèles migratoires et intégration socio-économique des Canadiens français de la vallée de la Saginaw, Michigan, 1840-1900», Labour/Le Travail,41, 1998, pp. 9-33.
} 
TABLEAU 22

Occupations des individus masculins qui, sans être chefs de maisonnée,

en étaient membres en 1871 (en pourcentage)

\begin{tabular}{lrrrrrrrrr}
\hline & \multicolumn{1}{c}{ Écossais Anglais } & \multicolumn{6}{c}{ Allem. Irlandais Anglo- Canadiens Noirs } & total \\
& & & \multicolumn{5}{c}{ phones français } \\
cultivateurs & 39,0 & 31,0 & 20,8 & 36,0 & 33,6 & 60,5 & 38,8 & 47,1 \\
affaires, professions & 16,9 & 21,5 & 16,7 & 13,7 & 17,3 & 6,5 & 6,1 & 11,4 \\
artisans & 18,6 & 18,3 & 16,7 & 8,0 & 13,9 & 8,0 & 8,2 & 10,7 \\
non qualifiés & 25,4 & 29,1 & 45,8 & 42,3 & 35,1 & 25,0 & 46,9 & 30,8 \\
Total & 99,9 & 99,9 & 100 & 100 & 99,9 & 100 & 100 & 100 \\
\hline
\end{tabular}

Source: ANC, recensement nominatif de 1871 , comté d'Essex, bobines 9888-9889.

Précisons que la plupart des individus appartenant à ce groupe étaient des membres de la famille qui travaillaient avec leurs parents sur la ferme ou dans une boutique d'artisan. Personne dans ce groupe ne possédait un lot, un emplacement ou une maison. Certains, tels les instituteurs, exerçaient leurs activités en d'autres lieux. D'autres, comme les journaliers, fils ou non de journaliers, se livraient surtout à des travaux saisonniers, hebdomadaires ou au jour le jour. On ne saurait donc, afin d'avoir une vue globale des occupations de ces jeunes adultes masculins, les ajouter aux chefs de maisonnée simplement en assumant qu'ils étaient tous des cultivateurs ou tous des journaliers. S'il faut les intégrer, la chose doit être faite à partir de l'occupation déclarée aux recenseurs. Ce qui, il faut le dire, ne modifie pas substantiellement la répartition des occupations entre les ethnies et à l'intérieur de chacune d'elles. 
DisPARITÉS SOCIO-ETHNIQUES, COMTÉ D’ESSEX (1871)

TABLEAU 23

Chefs de maisonnée et adultes résidant dans les maisonnées et ayant déclaré des occupations à Malden et Sandwich en 1871 (en pourcentage)

\begin{tabular}{|c|c|c|c|c|c|c|c|c|}
\hline \multirow[b]{2}{*}{ cultivateurs } & \multicolumn{2}{|c|}{ Écossais Anglais } & Allem. & Irlandais & \multicolumn{3}{|c|}{$\begin{array}{l}\text { Anglo- Canadiens Noirs } \\
\text { phones français }\end{array}$} & \multirow{2}{*}{$\begin{array}{l}\text { total } \\
50,5\end{array}$} \\
\hline & 42,0 & 36,7 & 30,6 & 47,9 & 41,6 & 60,7 & 39,5 & \\
\hline affaires, professions & 18,1 & 20,8 & 17,6 & 12,6 & 16,8 & 5,8 & 5,6 & 10,6 \\
\hline artisans & 17,1 & 17,7 & 16,5 & 10,4 & 14,6 & 11,1 & 9,0 & 12,5 \\
\hline non qualifiés & 18,6 & 21,2 & 32,9 & 26,7 & 23,8 & 20,2 & 40,3 & 23,5 \\
\hline veufs et veuves* & 4,1 & 3,5 & 2,3 & 2,4 & 3,1 & 2,1 & 5,6 & 2,8 \\
\hline Total & 99,9 & 99,9 & 99,9 & 100 & 99,9 & 99,9 & 100 & 99,9 \\
\hline
\end{tabular}

Source: ANC, recensement nominatif de 1871, comté d'Essex, bobines 9888-9889. *sans occupation déclarée.

À Hawkesbury et à Alfred, les anglophones étaient arrivés les premiers dans la région. Dans la mesure où leur ambition avait été de devenir cultivateurs, ils l'avaient réalisée, puisque les deux tiers d'entre eux l'étaient en 1871. Animés des mêmes désirs, mais arrivés les derniers, moins de la moitié des Canadiens français y étaient parvenus. À Malden et à Sandwich, au contraire, les Canadiens français avaient été les pionniers et c'est pourquoi, six d'entre eux sur dix cultivaient le sol et ils étaient, par une marge de $5 \%$, les plus nombreux parmi les cultivateurs de la région. Les Noirs qui avaient sans doute eu la même aspiration, mais qui, arrivés trop tard, étaient trop pauvres pour acheter une terre ou défrayer le coût d'une location de dimension suffisante, avaient été obligés de s'insérer, plus que tous les autres, dans le prolétariat. Quant aux Irlandais, les derniers venus parmi les anglophones dans les deux régions, ils avaient davantage réalisé leurs rêves aux deux endroits que le reste des habitants d'origine britannique et germanique: dans l'Est, sept Irlandais sur dix étaient cultivateurs, alors que, dans Malden et Sandwich, cette proportion s'établissait à presque la moitié.

Il est vrai que le désir de posséder un lopin de terre, autant que celui de devenir cultivateur, était plus largement répandu que réalisable, puisqu'il dépendait, entres autres, 
de l'âge du candidat, de la durée de résidence dans la région et de sa situation financière. W. L. Marr va jusqu'à présenter le cheminement de locataire à cultivateur-propriétaire comme un processus déterminé par l'âge, le lieu de naissance, le statut civil et le niveau d'alphabétisation ${ }^{69}$. Àce sujet, Darroch et Soltow écrivent:

not everyone could immediately own land at ages 20 or 21 , or upon migration to Ontario. . Second, how do we interpret the fact that the estimate includes adult sons working on their father's farm well beyond age 20 . the process of land acquisition would have involved tenancy at an early age ${ }^{70}$.

Ces remarques sont au cœur du sujet. Disons cependant que les jeunes adultes masculins de moins de 30 ans de Malden et de Sandwich avaient beaucoup d'obstacles à franchir avant de devenir propriétaires et même locataires. Leurs perspectives étaient d'autant plus limitées qu'ils appartenaient à des groupes ethniques entrés à différentes époques dans la compétition pour les emplacements et les terres. Car ces jeunes adultes masculins qui habitaient dans les maisonnées de Malden et de Sandwich étaient âgés de 23 ans en moyenne lorsqu'ils étaient nés en Ontario et de 28 ans lorsqu'ils étaient nés ailleurs. Ajoutons à cela que l'âge moyen des chefs de maisonnée nés ailleurs était, au moment de leur arrivée en Ontario, d'environ 37 ans chez les anglophones, de $34 \mathrm{chez}$ les francophones et de 50 ans chez les Noirs. Il n'est donc pas étonnant de constater que le pourcentage de locataires âgés de 20 à 29 ans ait été si peu élevé: les Canadiens français $23 \%$, les anglophones $17 \%$ et les Noirs $13 \%$. Les propriétaires de cet âge étaient, cela va de soi, encore plus rares: les Canadiens français $10 \%$, les anglophones $9 \%$ et les Noirs $5 \%$.

${ }^{69}$ W. L. Marr, op. cit., p. 54s.

${ }^{70} \mathrm{G}$. Darroch and L. Soltow, op. cit., p. 24s. 
Tout cela aide à comprendre pourquoi l'âge moyen des chefs de maisonnée, qu'ils aient été locataires ou propriétaires, était si élevé à la ville et à la campagne.

TABLEAU 24

Âge moyen des chefs de maisonnée

de Malden et Sandwich, locataires et propriétaires en 1871

\begin{tabular}{|c|c|c|c|c|c|c|c|c|}
\hline en milieu rural & \multicolumn{2}{|c|}{ Écossais Anglais } & \multicolumn{2}{|c|}{ Allem. Irlandais } & \multicolumn{3}{|c|}{$\begin{array}{l}\text { Anglo- Canadiens Noirs } \\
\text { phones français }\end{array}$} & tota \\
\hline $\begin{array}{l}\text { en milieu rural } \\
\text { locataires }\end{array}$ & 45,2 & 39,5 & 36,3 & $42, I$ & 40,8 & 39,9 & 47,3 & 41,1 \\
\hline propriétaires & 47,4 & 46,8 & 46,5 & 47,6 & 47,3 & 45,8 & 56,9 & 46,8 \\
\hline Sandwich (ville) & & & & & & & & \\
\hline locataires & 47,1 & 43,8 & 48,8 & 43,1 & 44,6 & 41,7 & 51,6 & 44,8 \\
\hline propriétaires & 53,0 & 54,8 & 45,0 & 53,0 & 53,0 & 51,3 & 50,8 & 52,1 \\
\hline
\end{tabular}

Source: ANC, recensement nominatif de 1871, comté d'Essex, bobine 98889889.

Lorsque le jeune adulte masculin né sur place ou l'immigrant fraîchement arrivé désiraient s'établir, l'accès à la propriété n'était donc pas un événement spontané à moins que le premier ait hérité d'une terre ou que le second ait eu les fonds nécessaires à un achat immédiat. Le délai encouru n'était pas le même pour tous les groupes ethniques et il variait d'un groupe à l'autre selon le lieu de résidence, selon l'âge, le statut économique, la durée de la résidence dans la province et la classe sociale. 
TABLEAU 25

Pourcentage de propriétaires parmi les chefs de maisonnée des différents groupes ethniques de Malden et de Sandwich en 1871

\begin{tabular}{|c|c|c|c|c|c|c|c|c|}
\hline \multirow{2}{*}{ en milieu rural } & \multicolumn{2}{|c|}{ Écossais Anglais } & Allem. & Irlandais & \multicolumn{3}{|c|}{$\begin{array}{l}\text { Anglo- Canadiens Noirs } \\
\text { phones français }\end{array}$} & total \\
\hline & 67,1 & 63,1 & 29,4 & 64,9 & 67,1 & 67,0 & 41,7 & 65,2 \\
\hline nés en Ontario & 80,0 & 82,1 & 43,7 & 80,3 & 75,8 & 73,8 & 28,6 & 73,7 \\
\hline $\begin{array}{l}\text { Sandwich (ville)* } \\
\text { total }\end{array}$ & 30,0 & 37,1 & 33,3 & 23,8 & 33,3 & 50,0 & 22,7 & 37,9 \\
\hline nés en Ontario & 0 & 30,8 & 0 & 33,3 & 29,2 & 56,1 & 0 & 44,1 \\
\hline par classes & & & & & & & & \\
\hline $\begin{array}{l}\text { cultivateurs } \\
\text { affaires, professions }\end{array}$ & $\begin{array}{l}78,0 \\
50,0\end{array}$ & $\begin{array}{l}72,6 \\
41,4\end{array}$ & $\begin{array}{l}57,9 \\
37,5\end{array}$ & $\begin{array}{l}86,1 \\
40,9\end{array}$ & $\begin{array}{l}79,2 \\
42,5\end{array}$ & $\begin{array}{l}80,3 \\
54,1\end{array}$ & $\begin{array}{l}45,7 \\
50,0\end{array}$ & $\begin{array}{l}76,1 \\
46,0\end{array}$ \\
\hline artisans & 60,0 & 46,4 & 12,5 & 23,1 & 49,1 & 44,8 & 25,0 & 42,3 \\
\hline non qualifiés & 15,4 & 19,3 & 0 & 0 & 11,8 & 22,7 & 18,5 & 12,3 \\
\hline veufs et veuves** & 80,0 & 44,4 & 50,0 & 57,1 & 52,2 & 61,8 & 25,0 & 55,7 \\
\hline
\end{tabular}

Source: ANC, recensement nominatif de 1871 , comté d'Essex, bobines 9888-9889. * Le document est très confus dans Amherstburg en ce qui regarde le statut des chefs de maisonnée quant à l'accès à la propriété.

** sans occupation déclarée.

Il est évident que, pour tous les groupes, il était beaucoup plus difficile d'accéder à la propriété à la ville qu'à la campagne. À cause de leur enracinement ancien, les Canadiens français avaient progressé plus sûrement que les autres sur l'ensemble du territoire. Bien qu'arrivés plus récemment dans la région et obligés d'acheter leurs terres, les anglophones avaient aussi bien réussi qu'eux en milieu rural. Mais, en milieu urbain, ils étaient loin derrière les Canadiens français, retard qui n'avait rien de comparable à celui des Noirs. En effet, en raison de leur arrivée récente dans la région, de leur grande pauvreté et, sans doute aussi, de la discrimination dont ils étaient l'objet, les Noirs se trouvaient marginalisés, particulièrement là où ils étaient les plus représentés, c'est-à-dire en milieu urbain. De tels écarts existaient aussi en ce qui regarde le lieu de naissance des individus. Ceux qui étaient nés en Ontario étant 
naturellement ceux qui y avaient vécu le plus longtemps, avaient eu un avantage marqué sur tous les autres. Pourtant, les Canadiens français ruraux, ceux qui avaient passé le plus grand nombre d'années en Ontario, avaient été devancés par les anglophones, alors que, dans la ville de Sandwich, le pourcentage des Canadiens français devenus propriétaires était de $50 \%$ contre $33 \%$ pour les anglophones.

L'accès à la terre était en plus une question de classes. Car tous les groupes sociaux et tous les groupes ethniques n'éprouvaient pas également le désir et la nécessité de devenir propriétaires. Il va de soi que c'était parmi les cultivateurs que l'intensité de ces exigences était la plus grande. Au sujet des cultivateurs irlandais, Darroch et Soltow écrivent:

farmers from Irish origin were more likely to be landowners than others, quite independant of their age and whether they were catholics or protestants ${ }^{71}$.

En effet, à Malden et à Sandwich, les cultivateurs irlandais venaient au premier rang à cet égard, suivis des Canadiens français, des Écossais, des Allemands et, finalement, des Noirs. Les taux variaient entre $86 \%$ chez les Irlandais et $46 \%$ chez les Noirs. Après les cultivateurs, c'était parmi les veufs et les veuves d'origine française sans occupation déclarée que les taux de réussite étaient les plus élevés. À leur suite, venaient les hommes d'affaires et de profession, suivis des artisans et des ouvriers non qualifiés. Des artisans aux travailleurs non qualifiés, l'écart était de $30 \%$. Tout au bas de l'échelle, se trouvaient les journaliers d'origine irlandaise et germanique.

À Hawkesbury et à Alfred en 1871, les Canadiens français, qui étaient arrivés les derniers dans la région, affichaient un retard par rapport aux anglophones en ce qui concerne la dimension de la terre. Ils comptaient $45 \%$ des cultivateurs, possédaient $40 \%$ de l'espace occupé et

${ }^{71}$ G. Darroch and L. Soltow, op. cit., p. 56. 
$29 \%$ de l'espace amélioré. Étant donné l'ancienneté de leur résidence dans Malden et Sandwich et parce qu'ils avaient eu l'occasion de choisir le lieu de leur établissement et, sans doute, de meilleurs sols, on s'attendrait à ce qu'ils aient davantage accumulé de biens fonciers agricoles que les autres. Mais les choses ne sont pas aussi simples. Car il ne faut pas oublier que, durant la seconde moitié du XVIII e siècle, un écart s'était creusé entre eux et les anglophones au moment où ceux-ci avaient progressivement établi leur domination sur la traite des pelleteries et étaient en plus devenus grands propriétaires fonciers. Cette différence avait été radicalement réduite, mais non abolie, à la suite de la vente des biens de ces grands propriétaires après 1820 . Toujours est-il qu'en 1871 les Canadiens français comptaient $56 \%$ des occupants, mais ne possédaient que $52 \%$ de l'espace occupé et $51 \%$ de l'espace amélioré. Les pourcentages pour les anglophones étaient de $38 \%, 44 \%$ et $45 \%$. Les Noirs faisaient, au contraire, figures de marginaux: $6 \%$ des cultivateurs, $6 \%$ du terroir occupé et $3 \%$ du terrain amélioré. 
DisPaRITÉS SOCIO-ETHNIQUES, COMTÉ D'ESSEX (1871)

TABLEAU 26

Répartition des occcupants de terre et de l'espace occupé selon les groupes ethniques et la dimension de la terre à Malden et à Sandwich en 1871 (en pourcentage)

\begin{tabular}{|c|c|c|c|c|c|c|c|c|}
\hline \multirow{4}{*}{$\begin{array}{l}2-49 \text { acres } \\
\text { occupants (\%) } \\
\text { acres occupées (\%) } \\
\text { étendue } \\
\text { moyenne (acres) }\end{array}$} & \multicolumn{2}{|c|}{ Écossais Anglais } & \multicolumn{2}{|c|}{ Allem. Irlandais } & \multicolumn{3}{|c|}{$\begin{array}{l}\text { Anglo- Canadiens Noirs } \\
\text { phones français }\end{array}$} & total \\
\hline & 25,0 & 22,8 & 38,5 & 19,0 & 22,0 & 40,0 & 62,0 & 34,5 \\
\hline & 9,7 & 7,1 & 11,2 & 6,0 & 7,2 & 14,4 & 35,9 & 12,0 \\
\hline & 32,6 & 27,3 & 28,0 & 27,6 & 28,4 & 26,6 & 26,5 & 27,0 \\
\hline $\begin{array}{l}50-99 \text { acres } \\
\text { occupants (\%) }\end{array}$ & 37,5 & 47,5 & 30,8 & 41,5 & 42,4 & 32,7 & 24,0 & 35,9 \\
\hline $\begin{array}{l}\text { acres occupées (\%) } \\
\text { étendue }\end{array}$ & 29,4 & 35,6 & 19,7 & 30,5 & 31,5 & 29,5 & 31,8 & 30,4 \\
\hline moyenne (acres) & 65,5 & 65,9 & 61,5 & 63,6 & 64,6 & 66,8 & 61,7 & 65,6 \\
\hline $\begin{array}{l}100 \text { acres et + } \\
\text { occupants (\%) }\end{array}$ & 37,5 & 29,7 & 30,7 & 39,4 & 35,5 & 27,2 & 14,0 & 29,6 \\
\hline $\begin{array}{l}\text { acres occupées (\%) } \\
\text { étendue }\end{array}$ & 60,8 & 57,2 & 69,0 & 63,5 & 61,2 & 56,1 & 32,9 & 58,8 \\
\hline moyenne (acres) & 135,5 & 169,0 & 214,7 & 139,4 & 149,6 & 163,0 & 109,2 & 154,2 \\
\hline $\begin{array}{l}\text { Total } \\
\text { occupants (\%) }\end{array}$ & 100 & 100 & 99,9 & 99,9 & 99,9 & 100 & 100 & 99,9 \\
\hline $\begin{array}{l}\text { acres occupées (\%) } \\
\text { étendue }\end{array}$ & 99,9 & 100 & 100 & 100 & 100 & 99,9 & 100 & 99,9 \\
\hline moyenne (acres) & 83,5 & 87,7 & 95,8 & 86,7 & 86,9 & 74,1 & 46,6 & 77,5 \\
\hline
\end{tabular}

Source: ANC, recensement nominatif de 1871, comté d'Essex, bobines 9888-9889.

Il est clair que l'inégalité ne régnait pas seulement entre les groupes ethniques, mais aussi à l'intérieur de chacun d'eux. Les cultivateurs canadiens-français et noirs étaient surreprésentés parmi les occupants de terre de leur propre origine dans la catégorie des moins de 100 acres. Parmi eux, $73 \%$ et $86 \%$, respectivement, des occupants de terre étaient regroupés dans cette catégorie. Dans la catégorie des 100 acres et plus, les cultivateurs anglophones dominaient, composant $35 \%$ des occupants de terre de leur propre groupe. Chez les Irlandais, cette proportion atteignait les $39 \%$. Les $35 \%$ d'anglophones appartenant à cette classe contrôlaient 
$61 \%$ du sol dans leur groupe, alors que les cultivateurs canadiens-français et afro-américains ne possédaient que $56 \%$ et $33 \%$ du sol occupé par leurs communautés respectives.

Dans cette région, il existait donc, si on en juge seulement par ceux qui possédaient 100 acres et plus, une classe de cultivateurs, plus nombreuse parmi les anglophones que parmi les Canadiens français et les Noirs, qui avait suffisamment de terre pour dégager des surplus encore plus substantiels pour le marché. Cette élite représentait près d'un tiers des occupants. Elle était cependant réduite de moitié si on s'en tient à la portion améliorée des biens fonciers.

\section{TABLEAU 27}

Répartition des occupants de terre et de l'espace amélioré selon les groupes ethniques et la dimension de la terre à Malden et à Sandwich en 1871

\begin{tabular}{|c|c|c|c|c|c|c|c|c|}
\hline \multirow{4}{*}{$\begin{array}{l}2-49 \text { acres } \\
\text { occupants (\%) } \\
\text { acres améliorées (\%) } \\
\text { étendue } \\
\text { moyenne (acres) }\end{array}$} & \multicolumn{2}{|c|}{ Écossais Anglais } & Allem. & Irlandais & \multicolumn{3}{|c|}{$\begin{array}{l}\text { s Anglo- Canadiens Noirs } \\
\text { phones français }\end{array}$} & total \\
\hline & 52,1 & 44,5 & 46,1 & 43,5 & 45,3 & 60,4 & 80,0 & 55,8 \\
\hline & 25,7 & 19,1 & 16,9 & 17,7 & 19,2 & 29,2 & 54,0 & 25,6 \\
\hline & 27,8 & 25,9 & 27,5 & 26,1 & 26,4 & 23,1 & 20,8 & 23,9 \\
\hline $\begin{array}{l}50-99 \text { acres } \\
\text { occupants (\%) }\end{array}$ & 35,4 & 40,6 & 30,8 & 31,3 & 34,9 & 27,4 & 16,0 & 29,6 \\
\hline $\begin{array}{l}\text { acres améliorées (\%) } \\
\text { étendue }\end{array}$ & 42,2 & 43,5 & 23,1 & 30,7 & 36,0 & 37,3 & 33,0 & 36,6 \\
\hline moyenne (acres) & 67,0 & 64,9 & 56,2 & 63,0 & 64,2 & 64,9 & 63,5 & 64,5 \\
\hline $\begin{array}{l}100 \text { acres et }+ \\
\text { occupants (\%) }\end{array}$ & 12,4 & 14,8 & 23,1 & 23,2 & 19,7 & 12,2 & 4,0 & 14,5 \\
\hline $\begin{array}{l}\text { acres améliorées (\%) } \\
\text { étendue }\end{array}$ & 32,1 & 37,4 & 59,9 & 51,5 & 44,7 & 33,5 & 12,9 & 37,8 \\
\hline moyenne (acres) & 144,3 & 152,7 & 194,7 & 131,4 & 141,0 & 125,7 & 100,0 & 125,7 \\
\hline $\begin{array}{l}\text { Total } \\
\text { occupants (\%) }\end{array}$ & 99,9 & 99,9 & 100 & 100 & 99,9 & 100 & 100 & 99,9 \\
\hline $\begin{array}{l}\text { acres améliorées (\%) } \\
\text { étendue }\end{array}$ & 100 & 100 & 99,9 & 99,9 & 100 & 100 & 99,9 & 100 \\
\hline moyenne (acres) & 56,2 & 60,6 & 74,9 & 64,5 & 62,2 & 47,7 & 30,8 & 52,3 \\
\hline
\end{tabular}

Source: ANC, recensement nominatif de 1871, comté d'Essex, bobines 9888-9889. 
DisPaRITÉS SOCIO-ETHNIQUES, COMTÉ D'ESSEX (1871)

TABLEAU 28

Les producteurs de Malden et de Sandwich classés selon le niveau de production de céréales, de pommes de terre et de navets, ainsi que de l'étendue occupée et améliorée de la terre en 1871

\begin{tabular}{|c|c|c|c|c|c|c|c|c|}
\hline \multirow{2}{*}{ 100-399 boisseaux } & \multicolumn{2}{|c|}{ Écossais Anglais } & s Allem. & Irlandais & \multicolumn{3}{|c|}{$\begin{array}{l}\text { is Anglo- Canadiens Noirs } \\
\text { phones français }\end{array}$} & total \\
\hline & 29,4 & 28,8 & 35,7 & 38,5 & 33,6 & 37,1 & 58,8 & 37,1 \\
\hline espace occupé (acres) & 61,0 & 60,0 & 60,0 & 57,1 & 58,6 & 42,3 & 36,8 & 47,3 \\
\hline espace amélioré (acres) & 30,1 & 33,3 & 30,0 & 38,8 & 35,6 & 25,0 & 18,9 & 28,0 \\
\hline $\begin{array}{l}\text { 400-999 boisseaux } \\
\text { producteurs (\%) }\end{array}$ & 58,8 & 54,8 & 42,8 & 48,9 & 52,2 & 49,8 & 41,2 & 50,2 \\
\hline espace occupé (acres) & 82,5 & 67,4 & 123,0 & 109,5 & 90.3 & 73,7 & 50,4 & 79,1 \\
\hline espace amélioré (acres) & 58,1 & 52,1 & 106,3 & 74,9 & 65,0 & 53,3 & 41,8 & 57,8 \\
\hline $\begin{array}{l}1000 \text { boisseaux et }+ \\
\text { producteurs (\%) }\end{array}$ & 11,8 & 16,3 & 21,4 & 12,6 & 14,1 & 13,1 & 0 & 12,7 \\
\hline espace occupé (acres) & 128,8 & 189,3 & 160,7 & 143,1 & 160,2 & 152,8 & 0 & 155,9 \\
\hline espace amélioré (acres) & 92,7 & 125,9 & 119,3 & 115,8 & 117,4 & 94,8 & 0 & 104,3 \\
\hline $\begin{array}{l}\text { Total } \\
\text { producteurs (\%) }\end{array}$ & 100 & 99,9 & 99,9 & 100 & 99,9 & 100 & 100 & 100 \\
\hline espace occupé (acres) & 81,6 & 85,2 & 108,6 & 93,6 & 89,5 & 72,4 & 42,4 & 77,0 \\
\hline espace amélioré (acres) & 54,4 & 58,7 & 81,8 & 66,1 & 62,5 & 48,7 & 28,3 & 52,7 \\
\hline
\end{tabular}

Source: ANC, recensement nominatif de 1871, comté d'Essex, bobines 9888-9889.

Même si, comme la chose se produisait fréquemment, le niveau de la production des céréales, des pommes de terre et des navets n'était pas exactement le reflet de la dimension de la terre et de sa portion améliorée, il existait néanmoins une relation assez étroite entre ces deux variables. Une fois que les producteurs de moins de 100 boisseaux de céréales, de pommes de terre et de navets, soit environ $13 \%$ des anglophones et des Canadiens français et 30\% des Noirs, sont exclus de l'équation, trois types de fermes apparaissent. Celles où cette récolte se situe entre 100 à 399 boisseaux sont surtout axées sur la subsistance. Les fermes, dont le niveau de la production s'échelonne entre 400 et 999 boisseaux, dégagent des surplus de plus en plus importants pour le marché. Enfin, celles où les récoltes 
atteignent 1000 boisseaux et plus sont surtout orientées vers la production pour le marché. Comme le démontre le Tableau 29, ces niveaux de production ont leurs équivalents en termes d'acres occupées et améliorées.

À Hawkesbury et à Alfred, les pionniers anglophones occupaient des terres de 118 acres en moyenne, dont 57 acres améliorées. De leur côté, les Canadiens français, arrivés les derniers, ne disposaient que de 64 acres, dont 29 améliorées. Cependant, à Malden et à Sandwich, les pionniers canadiens-français étaient, à ces deux points de vue, au deuxième rang, les anglophones au premier et les Noirs au troisième.

Les Canadiens français, légèrement, et les Noirs, très largement, étaient surreprésentés parmi les cultivateurs dont les fermes étaient principalement centrées sur la subsistance de la famille. Celles-ci étaient de plus grande dimension chez les anglophones ( 59 acres en moyenne) que chez les Canadiens français ( 42 acres) et les Noirs ( 37 acres). Elles étaient également plus intensément cultivées par rapport à leur étendue. Dans la mesure où ces exploitations avaient un contact minimal avec le marché, elles étaient surtout possédées par les anglophones. En effet, le pourcentage d'animaux tués pour fins de consommation familiale ou pour vente était de $36 \%$ parmi les anglophones, de $24 \%$ parmi les francophones et de $20 \%$ parmi les Noirs. Aussi les troupeaux des Canadiens français étaient-ils plus petits, particulièrement quant au nombre de bêtes à cornes, et leur récolte de foin était la moitié de celle des anglophones. Ils fabriquaient trois fois et demie moins de beurre et aucun fromage. Ils produisaient moins de laine et $25 \%$ moins de flanelle. Les Noirs étaient les plus désavantagés de tous en ce qui concerne la nourriture des animaux, la production laitière, la laine et les tissus. 
TABLEAU 29

Le profil de la ferme de niveau 1 (100-399 boisseaux de céréales, de pommes de terre et de navets) selon les groupes ethniques

à Malden et à Sandwich en 1871

\begin{tabular}{|c|c|c|c|c|c|c|c|c|}
\hline & \multicolumn{2}{|c|}{ Écossais Anglais } & Allem. & \multicolumn{4}{|c|}{$\begin{array}{c}\text { Irlandais Anglo- Canadiens Noirs } \\
\text { phones français }\end{array}$} & \multirow[t]{2}{*}{ total } \\
\hline \multicolumn{8}{|c|}{ céréales, pommes de terre et navets (boisseaux par ferme) } & \\
\hline blé & 18,3 & 12,1 & 31,4 & 11,4 & 13,5 & 16,4 & 15,6 & 15,4 \\
\hline avoine & 69,5 & 66,5 & 56,0 & 60,1 & 63,1 & 69,7 & 36,3 & 64,2 \\
\hline pois & 0 & 1,4 & 0 & 4,5 & 2,7 & 1,7 & 0,4 & 1,9 \\
\hline pomm & 34,6 & 51,1 & 42,0 & 55,5 & 50,6 & 40,0 & 28,3 & 42,5 \\
\hline autre & 102,3 & 122,0 & 162,6 & 131,8 & 126,2 & 131,3 & 144,5 & 130,9 \\
\hline toté & 224,7 & 253,1 & 292,0 & 263,3 & 256,3 & 259,2 & 225,1 & 254,8 \\
\hline foin (tonnes) & 4,8 & 5,5 & 5,2 & 5,8 & 5,5 & 2,8 & 1,8 & 3,7 \\
\hline \multicolumn{9}{|c|}{ animaux par ferme (nombre) } \\
\hline chevaux & 2,7 & 2,9 & 2,5 & 3,0 & 2,8 & 3 , & 2,6 & 3,0 \\
\hline bêtes & 3,5 & 6,3 & 4,2 & 5,6 & 5,4 & 3,0 & 3,4 & 3,9 \\
\hline moutor & 4,6 & 9,0 & 4,7 & 3 & & 4,8 & 1 , & 4,6 \\
\hline porcs & 4,9 & 5,5 & 2,0 & 6 & & & 6,0 & 6,0 \\
\hline total & 15,7 & 23,6 & 13,0 & 18,8 & 19,3 & 17,2 & 13.6 & 17,5 \\
\hline tués ou vendus* & 6,2 & 8,4 & 3,2 & 6,7 & 6,9 & 4,2 & 2,7 & 5,0 \\
\hline \multicolumn{9}{|c|}{ produits de la ferme } \\
\hline & 111,6 & 224,1 & 150,0 & 168,4 & 173,9 & 48,7 & 56,8 & 92,4 \\
\hline from & 0 & 2,1 & 0 & 0 & 0,6 & 0 & 0 & 0,2 \\
\hline & 16,5 & 26,0 & 17,0 & 11,2 & 16,3 & 13,6 & 4,7 & 13,7 \\
\hline flanelle (verges) & 6,4 & 3,1 & 6,5 & 5,6 & 5,0 & 4,2 & 2,0 & 4,2 \\
\hline
\end{tabular}

Source: ANC, recensement nominatif de 1871, comté d'Essex, bobines 9888-9889. * tués pour consommation familiale ou pour vente; ou, encore, vendus vivants pour être exportés.

Dans la deuxième catégorie de fermes, les différences entre les Canadiens français et les autres étaient peu considérables en ce qui concerne la production des céréales, des pommes de terre et des navets par ferme: 632 boisseaux dans le cas des anglophones, 611 dans celui des Canadiens français et 604 dans celui des Noirs. Mais il en était autrement pour les autres aspects de l'activité agricole. Leur déficit par rapport aux anglophones pour la production de foin était de $35 \%$. Il était de $16 \%$ pour le nombre total des animaux de la ferme, de $41 \%$ pour les 
bêtes à cornes, de $65 \%$ pour le beurre, de $27 \%$ pour le fromage et, finalement, de $32 \%$ et de $11 \%$ respectivement pour la laine et la flanelle. Les Noirs étaient encore plus désavantagés qu'eux à ces égards, excepté pour la fabrication du beurre. Le pourcentage d'animaux tués ou vendus était de $41 \%$ sur les fermes gérées par les anglophones, de $24 \%$ sur les fermes possédées par des Canadiens français et de $30 \%$ sur celles appartenant à des Noirs.

\section{TABLEAU 30}

Le profil de la ferme intermédiaire (400-999 boisseaux de céréales, de pommes de terre et de navets) selon les groupes ethniques à Malden et à Sandwich en 1871

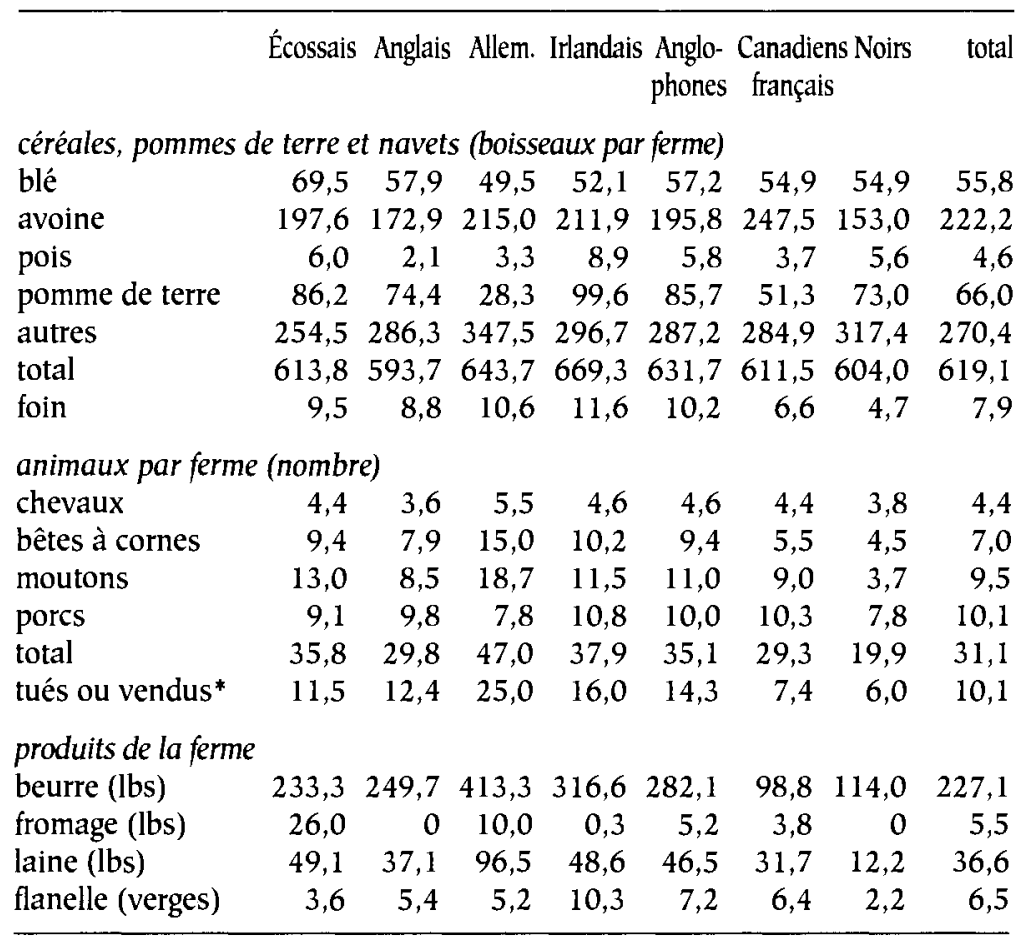

Source: ANC, recensement nominatif de 1871, comté d'Essex, bobines 9888-9889. *tués pour consommation familiale ou pour vente; ou, encore, vendus vivants pour être exportés. 
À Malden et à Sandwich, il y avait donc une élite agricole canadienne-française qui s'était constituée sur place pendant plusieurs générations. Ceux qui en faisaient partie étaient à peine différents par leur âge de ceux qui produisaient moins: 48 ans contre 45 ans. Ils l'étaient davantage par la durée de leur résidence en Ontario: $96 \%$ d'entre eux étaient nés dans la province, alors que l'ensemble des cultivateurs de même origine ne l'étaient que dans une proportion de $84 \%$. Ils avaient aussi 1,4 enfants de plus que les autres, ce qui ne veut pas dire qu'ils n'avaient pas eu recours à une main-d'œuvre extérieure. Sur les six chefs de maisonnée canadiens-français de religion protestante, trois appartenaient à cette catégorie de producteurs.

Au contraire, l'élite anglophone était plutôt récente puisqu'elle était née du processus migratoire, sans doute d'immigrants plus fortunés que les autres. Seulement $24 \%$ d'entre eux ( $30 \%$ pour l'ensemble des cultivateurs anglophones) étaient nés dans la province, ce qui veut dire que la grande majorité de ces producteurs y résidait depuis une dizaine d'années seulement. Ils étaient aussi plus âgés que l'ensemble des cultivateurs de même origine: 51 ans en moyenne contre 47 . Ils avaient également plus d'enfants que les autres anglophones, mais moins que les Canadiens français: 3,8 enfants contre 5,4 . Constituant $31 \%$ des effectifs de ce groupe, les catholiques s'y trouvaient adéquatement représentés.

Entre cette élite canadienne-française qui se chiffrait à $13 \%$ des producteurs, et les autres producteurs de même origine, les écarts étaient plus considérables qu'entre l'élite anglophone et le reste du peloton anglophone. En effet, ces Canadiens français produisaient $32 \%$ des céréales, des pommes de terre et des navets, $33 \%$ du foin, élevaient $25 \%$ des animaux, en tuaient ou vendaient $25 \%$, fabriquaient $29 \%$ du beurre, $4 \%$ du fromage, $27 \%$ de la laine et $14 \%$ de la flanelle. De son côté, l'élite anglophone regroupait $14 \%$ 
des producteurs de même origine, récoltait $31 \%$ des céréales, des pommes de terre et des navets, coupait $28 \%$ du foin, entretenait $23 \%$ des animaux, en tuait ou vendait $23 \%$, fabriquait $24 \%$ du beurre, $87 \%$ du fromage, $23 \%$ de la laine et $15 \%$ de la flanelle. Dans chacune des communautés anglophones, comme dans la communauté canadiennefrançaise, il existait de substantielles inégalités au niveau des performances et des statuts économiques. Même si les Noirs n'étaient pas représentés parmi ces producteurs de 1000 boisseaux et plus, leur communauté était loin d'être homogène. Car les producteurs dans la catégorie des 400 à 999 boisseaux qui regroupaient $41 \%$ de leurs effectifs, récoltaient $65 \%$ des céréales, des pommes de terre et des navets, engrangeaient $64 \%$ du foin, gardaient $48 \%$ des animaux, en éliminaient $58 \%$ pour consommation familiale ou pour vente, fabriquaient $56 \%$ du beurre, $62 \%$ de la laine et $42 \%$ de la flanelle.

Des inégalités similaires se retrouvaient entre les Canadiens français et les anglophones. Le cultivateur d'origine française récoltait $6 \%$ plus de céréales, de pommes de terre et de navets que l'anglophone, mais il était à égalité avec lui en ce qui concerne le nombre d'animaux sur la ferme. Par contre, il coupait $17 \%$ moins de foin que lui, tuait $35 \%$ moins d'animaux pour consommation domestique et pour vente, et il préparait $56 \%$ moins de beurre, $99 \%$ moins de fromage, $4 \%$ moins de laine et $14 \%$ moins de flanelle. 
TABLEAU 31

Le profil de la ferme axée sur le marché

( 1000 boisseaux de céréales, de pommes de terre et de navets)

à Malden et à Sandwich en 1871

Écossais Anglais Allem. Irlandais Anglo- Canadiens Noirs total phones français

céréales, pommes de terre et navets (boisseaux par ferme)

$\begin{array}{lrrrrrrrr}\text { blé } & 127,3 & 167,9 & 133,7 & 107,2 & 135,2 & 158,3 & 0 & 148,6 \\ \text { avoine } & 385,8 & 287,6 & 310,0 & 501,9 & 390,2 & 505,4 & 0 & 456,7 \\ \text { pois } & 6,0 & 10,9 & 6,7 & 15,3 & 11,7 & 6,0 & 0 & 8,4 \\ \text { p. de terre* } & 127,7 & 141,1 & 276,7 & 259,0 & 196,6 & 146,0 & 0 & 167,4 \\ \text { autres } & 636,3 & 692,9 & 520,7 & 544,6 & 612,8 & 615,9 & 0 & 614,5 \\ \text { total } & 1283,2 & 1300,5 & 1247,7 & 1427,7 & 1346,6 & 1431,4 & 0 & 395,5 \\ \text { foin } & 22,3 & 20,0 & 16,3 & 19,5 & 19,9 & 16,6 & 0 & 18,0\end{array}$

animaux de la ferme (nombre)

\begin{tabular}{lrrrrrrrr} 
chevaux & 5,3 & 7,8 & 4,0 & 5,4 & 6,2 & 7,4 & 0 & 6,9 \\
bêtes à cornes & 18,5 & 18,5 & 3,5 & 13,8 & 15,9 & 10,5 & 0 & 12,8 \\
moutons & 9,5 & 18,9 & 14,0 & 14,5 & 15,5 & 18,2 & 0 & 17,1 \\
porcs & 14,2 & 16,9 & 4,0 & 17,4 & 16,1 & 17,5 & 0 & 16,9 \\
total & 47,8 & 62,0 & 25,5 & 51,2 & 53,8 & 53,6 & 0 & 53,7 \\
tués ou vendus** & 15,3 & 20,9 & 22,5 & 21,9 & 20,6 & 13,4 & 0 & 16,5 \\
produits de la ferme & & & & & & & & \\
beurre (lbs) & 823,7 & 393,5 & 305,0 & 461,1 & 477,7 & 210,0 & 0 & 321,8 \\
fromage (lbs) & 175,0 & 0 & 0 & 283,3 & 143,0 & 0,7 & 0 & 60,1 \\
laine (lbs) & 14,2 & 87,0 & 50,0 & 56.0 & 62,1 & 59,5 & 0 & 60,6 \\
flanelle (vgs) & 0 & 8,6 & 0 & 8,7 & 7,0 & 6,0 & 0 & 6,4 \\
\hline
\end{tabular}

Source: ANC, recensement nominatif de 1871, comté d'Essex, bobines 98889889. ${ }^{*}$ pommes de terre. ${ }^{* *}$ tués pour consommation familiale ou pour vente; ou, encore, vendus vivants pour exportation.

Au total, cependant, la condition des Canadiens français était fort différente de ce qu'elle était à Hawkesbury et à Alfred. Car, à ces endroits, leur production moyenne de céréales, de pommes de terre et de navets par cultivateur était inférieure à celle des anglophones par une marge de $60 \%$. À Malden et à Sandwich, au contraire, leur agriculture était aussi surtout centrée sur la production des céréales, des pommes de terre et des navets, mais leur niveau de production par ferme était deux fois plus élevé qu'à Hawkesbury et à Alfred et il égalait celui des anglophones 
qui les entouraient. Mais cette égalité ne s'étendait pas au reste de l'activité agricole. Par rapport au cultivateur anglophone, ils étaient en déficit de $35 \%$ pour la récolte de foin, de $14 \%$ pour le nombre d'animaux, de $45 \%$ pour le nombre d'animaux tués ou vendus, de $65 \%$ pour la fabrication du beurre, de $91 \%$ pour celle du fromage, de $26 \%$ et de $15 \%$ pour celle de la laine et de la flanelle. Il est vrai que certaines productions, comme celle du fromage domestique, étaient peu répandues, surtout parmi les Canadiens français et les Noirs. Mais, même parmi les anglophones, cette industrie était très concentrée. Les deux frères Atkins produisaient $72 \%$ du fromage fabriqué dans ces deux cantons. C'est un phénomène que nous avons observé à Hawkesbury et à Alfred où $82 \%$ de la production avait été réalisée par sept cultivateurs d'origine britannique.

Les Canadiens français étaient les pionniers de la région, mais ils se situaient au second rang pour les performances agricoles. Comme ils étaient surreprésentés parmi les petits producteurs, ils dépendaient plus que les anglophones du travail saisonnier. Au troisième rang venaient les Noirs arrivés les derniers dans la région et fortement défavorisés en ce qui concerne l'accès à la terre. Leur niveau de production de céréales, de pommes de terre et de navets était de $28 \%$ plus élevé que celui des Canadiens français de Hawkesbury et d'Alfred. Cependant, à Malden et à Sandwich, ils récoltaient $35 \%$ moins de céréales, de pommes de terre et de navets que les Canadiens français, coupaient $54 \%$ moins de foin, gardaient $42 \%$ moins d'animaux, en tuaient ou en vendaient $57 \%$ de moins, fabriquaient $17 \%$ et $100 \%$ moins de beurre et de fromage, $73 \%$ moins de laine et $100 \%$ moins de flanelle qu'eux. Comme ces Noirs étaient fortement surreprésentés parmi les producteurs de moins de 100 boisseaux et parmi ceux qui récoltaient entre 100 et 499 boisseaux, ils dépendaient plus que tous les autres du travail saisonnier ou au 
jour le jour. D'une façon générale, leur statut économique, en tant qu'agriculteurs, ressemblait à celui des Canadiens français de Hawkesbury et d'Alfred.

\section{TABLEAU 32}

Le profil toutes catégories de la ferme de Malden et de Sandwich en 1871

Écossais Anglais Allem. Irlandais Anglo- Canadiens Noirs total phones français

céréales, pommes de terre et navets (boisseaux)

\begin{tabular}{lrrrrrrrr} 
blé & 61,3 & 60,9 & 61,1 & 43,4 & 52,9 & 54,2 & 31,8 & 52,3 \\
avoine & 182,1 & 161,0 & 178,6 & 190,0 & 178,5 & 215,3 & 84,4 & 193,2 \\
pois & 4,2 & 3,3 & 2,8 & 8,0 & 5,6 & 3,3 & 2,5 & 27,7 \\
p. de terre* & 75,9 & 48,1 & 86,4 & 102,7 & 89,5 & 61,7 & 46,7 & 71,3 \\
autres & 254,7 & 305,0 & 318,6 & 264,5 & 278,9 & 255,9 & 215,7 & 262,0 \\
total & 578,1 & 611,0 & 647,5 & 608,6 & 606,2 & 588,2 & 381,1 & 582,1 \\
foin (tonnes) & 9,6 & 9,7 & 9,7 & 10,4 & 10,0 & 6,5 & 3,0 & 7,6 \\
animaux de la ferme & & (nombre) & & & & & & \\
chevaux & 4,0 & 4,1 & 5,1 & 4,4 & 4,3 & 4,3 & 3,1 & 4,2 \\
bêtes à cornes & 8,7 & 9,2 & 11,4 & 8,9 & 9,1 & 5,3 & 3,9 & 6,6 \\
moutons & 10,1 & 10,4 & 15,9 & 8,8 & 9,8 & 6,8 & 2,4 & 8,7 \\
porcs & 8,5 & 9,7 & 6,3 & 10,0 & 9,5 & 9,7 & 6,7 & 9,5 \\
total & 31,2 & 33,4 & 38,7 & 32,2 & 32,7 & 28,0 & 16,1 & 29,0 \\
tués ou vendus** & 19,4 & 12,6 & 20,8 & 13,2 & 12,8 & 7,0 & 4,0 & 9,0 \\
produits de la ferme & & & & & & & & \\
beurre (lbs) & 267,7 & 266,1 & 369,0 & 277,8 & 275,2 & 94,8 & 78,8 & 161,3 \\
fromage (lbs) & 36,1 & 0,6 & 6,0 & 35,8 & 23,1 & 2,0 & 0 & 9,8 \\
laine (lbs) & 35,3 & 42,1 & 74,7 & 35,1 & 38,8 & 28,6 & 7,6 & 31,1 \\
flanelle (verges) & 4,0 & 5,2 & 5,7 & 8,3 & 6,5 & 5,5 & 2,1 & 5,7 \\
\hline
\end{tabular}

Source: ANC, recensement nominatif de 1871, comté d'Essex, bobines 9888-9889. ${ }^{*}$ pommes de terre. ${ }^{* *}$ tués pour consommation familiale ou pour vente; ou encore, vendus vivants pour être exportés. 


\section{Conclusion}

Ainsi, l'idée de l'existence d'une paysannerie égalitaire au sein des sociétés en voie de se structurer dans le bassin du Saint-Laurent sous l'aile vigilante d'une métropole, aussi hiérarchisée que la France l'était à l'époque, relève beaucoup plus du mythe que de la réalité. Car non seulement l'inégalité gisait-elle au cœur des institutions implantées en Nouvelle-France, mais elle habitait aussi l'esprit de ceux qui, à tous les niveaux, intervenaient dans leur fonctionnement. La distribution inégale des seigneuries aux classes dirigeantes et des censives aux paysans, selon le mode seigneurial, illustre d'autant mieux la force de cette orientation initiale qu'il existait alors une grande abondance de terres et peu de personnes pour les occuper.

Cette tendance se manifesta de plus en plus à mesure que la prise de possession du sol progressa et qu'au XIX ${ }^{e}$ siècle les pressions démographiques se généralisèrent sur le territoire seigneurial. C'est ce que démontre le dépouillement des aveux et dénombrements et des terriers. Ces documents font état des moindres parcelles possédées par chaque individu, alors que les recensements, tout en étant plus riches en informations diverses sur l'activité des individus, n'indiquent que la dimension totale de la terre louée ou possédée par les chefs de maisonnée et ne mentionnent à propos des seigneurs que les lots qu'ils exploitaient euxmêmes. En effet, parmi les artisans de l'inégalité et ceux qui la subissaient, il n'y avait pas que les agents de l'État et les seigneurs (nobles, ecclésiastiques et bourgeois), mais les roturiers eux-mêmes qui, dans leurs transactions au jour le jour, faites d'achats, de ventes, d'échanges, de legs et de donations-partages, agissaient dans le même sens. Ainsi, la transmission des biens s'opérait-elle à l'intérieur d'un système juridique qui, d'une part, encourageait le partage égal de la terre entre les descendants et, de l'autre, justifiait des pratiques qui consistaient à confier le patri- 
moine foncier à l'un des fils et à prévoir des compensations équitables pour les autres enfants. En temps d'abondance des terres, il était peut-être plus facile, théoriquement parlant, d'opter pour la solution qui évitait le morcellement excessif des avoirs fonciers. Par contre, en phase de saturation du territoire et de difficultés économiques, la situation incitait d'autant plus au partage égal de la terre que le système des compensations se trouvait lui-même menacé. De toute façon, en pareille conjoncture, aucune des deux méthodes ne pouvait prévenir, à la longue, la multiplication des individus sans terres, des dépendants du travail saisonnier et, éventuellement, des migrants intérieurs et extérieurs.

Ainsi, dans la seigneurie de Laprairie, $51 \%$ des 1515 parcelles de terre décrites dans le Terrier de 1837-1841, provenaient d'un partage égal de la terre entre les héritiers masculins et féminins. Comme, pour un grand nombre de propriétaires, les parcelles ainsi acquises s'ajoutaient à des avoirs fonciers existants et que plusieurs autres, pour des raisons de prestige et de profit, ou en vue de l'établissement des enfants, désiraient plus de terre que leurs voisins, il est évident qu'un nouvel équilibre foncier, toujours érigé sur l'inégalité, était sans cesse en construction. Nous avons la conviction que, même si l'aveu et dénombrement commencé en 1723 ne mentionne pas les partages de terres entre les descendants, cette façon d'agir avait toujours joué un rôle variable dans les mouvements de la propriété foncière, non seulement dans Laprairie, mais aussi ailleurs. Étant donné que les inégalités font partie du tissu social, il serait donc excessif de les définir uniquement en termes d'accès à la terre, à la propriété et de performances agricoles. Car l'accroissement des disparités à l'intérieur de la communauté canadienne-française et de la classe paysanne se déroulait aussi dans une société strictement divisée, d'une part, entre des classes dirigeantes instruites 
et des milieux populaires à peu près analphabètes et, d'autre part, entre des urbains plus alphabétisés et des ruraux peu touchés par l'école avant les années 1830-1850.

Ces dichotomies furent accentuées après 1760 par l'entrée en scène d'immigrants britanniques et majoritairement protestants qui, dans un premier temps, se concentrèrent surtout dans les villes, et, plus tard, se dirigèrent en plus grand nombre vers les campagnes seigneuriales et, surtout, cantonales. Leur présence dominante dans l'économie s'exprima non seulement dans le commerce, les finances et l'industrie, mais en plus par l'acquisition, en tout ou en partie, d'un grand nombre de seigneuries et de cantons. Puis, à mesure que les immigrants anglophones se recrutèrent davantage dans les milieux populaires, leur intérêt pour la petite propriété foncière, aussi bien dans les villes que dans les campagnes, s'accrut. Dans les zones seigneuriales, ils furent cependant limités dans leur progression par le fait que les Canadiens français étaient les premiers occupants du sol. Dès lors, la question de l'inégalité se posa dans le cadre d'une population multiethnique et multiconfessionnelle dont les éléments étaient inégalement répartis sur le territoire. Dans toutes les catégories sociales, les Britanniques, eux-mêmes divisés sur les plans ethnique et confessionnel, étaient beaucoup plus alphabétisés que la population canadienne-française. Les disparités entre les Canadiens français et les Britanniques étaient d'autant plus substantielles à cet égard que ces derniers étaient plus urbains et relativement plus présents dans les classes dirigeantes que dans les milieux populaires.

La société qui se forma après 1701 autour du fort et du poste de traite de Détroit était aussi constituée de militaires, de commerçants de pelleteries, d'esclaves et d'engagés pour la traite. Bientôt, grâce à l'aide de l'État colonial, une paysannerie presque égalitaire, faite d'éléments venus des campagnes de la Nouvelle-France, s'y était ajoutée. Après 1760 , les commandants militaires britanniques tentèrent 
d'abord de préserver l'équilibre agraire existant, mais, bientôt, les Amérindiens distribuèrent en signe d'amitié de grandes quantités de terre à des commerçants de pelleteries et à des officiers militaires, surtout à des Britanniques. La hiérarchie de la terre, ainsi étendue à l'ouest de Montréal, fut renforcée par la suite avec l'arrivée des Loyalistes, le licenciement des militaires, dont la plupart étaient des Britanniques, et la création du Haut-Canada en 1791. Elle fut même confirmée par les transactions quotidiennes des individus.

Le système du franc et commun soccage alors introduit dans les régions non divisées en seigneuries du Haut et du Bas-Canada fut utilisé, non pas pour procéder à une distribution égale des terres, mais pour reconnaître par la dimension des concessions les services rendus, les mérites, la stature et l'utilité sociales des candidats. Et cela, avec l'idée d'assurer les bases d'une aristocratie foncière. Ainsi, le simple soldat, le Loyaliste ordinaire et l'immigrant hautcanadien moyen étaient peut-être exempts des servitudes seigneuriales, mais ils se trouvaient quand même dans une société qui distribuait le sol d'une manière fort inégale. À la fin du XVIII ${ }^{\mathrm{e}}$ siècle, à Malden et à Sandwich (Essex), l'inégalité foncière régnait non seulement entre les différentes couches sociales, mais aussi entre les groupes ethniques et à l'intérieur de chacun d'eux. Les Canadiens français, arrivés les premiers, mais moins alphabétisés, moins élevés socialement et plus pauvres que les Britanniques, se situaient au deuxième rang et les Noirs, plus désavantagés qu'eux sur les plans économique et social, étaient au dernier rang. Disons, cependant, que la classe des grands propriétaires fonciers, édifiée grâce au commerce des pelleteries et aux circonstances créées par l'indépendance américaine, était appelée à disparaître de la région. Car, à mesure que déclina le commerce des fourrures et que l'immigration s'accrut dans le Haut-Canada, ces personnages mirent leurs terres en vente et quittèrent la 
région. De la sorte, tel que l'indique le recensement de 1871, à Malden et à Sandwich, comme à Hawkesbury et à Alfred, la terre se trouvait, par le simple jeu des achats, des ventes et des pratiques successorales, surtout répartie, quoiqu'inégalement, entre ceux dont le rôle était de cultiver le sol.

La répartition inégale des terres dans la société et la paysannerie, comme le démontrent l'évolution du Québec ainsi que celle de Malden et de Sandwich avant 1871, n'était qu'un aspect de la prolifération des inégalités socioéconomiques et socioculturelles à tous les niveaux. Étant donné que les apports migratoires successifs avaient été le fait non seulement de couples mariés et d'individus, mais aussi de groupes ethniques et religieux, les inégalités socioéconomiques avaient acquis une intensité différente d'un groupe ethnique et religieux à un autre.

Parmi les facteurs qui, à part les antécédents socioculturels, avaient contribué à ces disparités, telles qu'elles ressortent du recensement de 1871, le moment de l'arrivée de chaque groupe dans la région avait été très important, particulièrement pour les Canadiens français. C'est ce qu'une comparaison des chefs de maisonnée de Hawkesbury et d'Alfred avec ceux de Malden et de Sandwich fait ressortir. En effet, les Canadiens français de Hawkesbury et d'Alfred y étaient arrivés bien après les Anglais et les Écossais, même après les Irlandais. Ils étaient venus en si grand nombre durant les années 1850-1860 qu'en 1871 ils comptaient pour plus de la moitié des chefs de maisonnée de l'endroit. Aussi, seulement $14 \%$ d'entre eux étaient nés en Ontario. Pauvres et analphabètes aux trois quarts, ces migrants s'étaient trouvés plongés dans une société multiethnique, multiculturelle, à peu près alphabétisée, qui avait un pressant besoin de main-d'œuvre à bon marché. Pas étonnant que leurs classes dirigeantes aient été encore peu développées et que leur contribution à la valeur de la production, dite industrielle, n'ait été que de $4 \%$ de 
celle de la région, même si leur classe artisanale y était adéquatement représentée. L'ampleur de leur présence parmi les travailleurs non qualifiés, dont ils constituaient $80 \%$ des effectifs régionaux, était encore plus manifeste. Pourtant, leur rêve était de devenir propriétaires de terres et cultivateurs. Mais seulement $51 \%$ et $47 \%$ d'entre eux l'avaient réalisé. Il est vrai que, dans leur propre communauté, les cultivateurs constituaient le groupe le plus nombreux, mais les trois quarts d'entre eux appartenaient à la catégorie des agriculteurs qui, pour joindre les deux bouts, dépendaient du travail saisonnier en forêt et ailleurs. Pour tout dire, dans la hiérarchie sociale et la hiérarchie de la terre, les Canadiens français se situaient au dernier rang par rapport aux divers groupes anglophones.

À Malden et à Sandwich, au contraire, où leurs ancêtres avaient été les pionniers et s'étaient maintenus de génération en génération, leur communauté avait eu le temps d'acquérir une plus grande maturité que celle de Hawkesbury et d'Alfred. Là aussi, ils étaient devenus majoritaires. Étant là depuis plus longtemps, ils étaient plus alphabétisés qu'ils ne l'étaient dans l'est de la province et leur contribution à la valeur de la production, dite industrielle, s'élevait à $28 \%$. Ils égalaient presque les anglophones en ce qui concerne l'accès à la propriété foncière. Enfin, ils étaient surreprésentés parmi les cultivateurs au point que leur communauté surpassait toutes les autres par son caractère rural et agricole. Ajoutons qu'ils n'étaient pas inférieurs aux anglophones en ce qui a trait à la récolte de céréales, de pommes de terre et de navets. Pourtant, comme à Hawkesbury et à Alfred, ils étaient derrière eux pour la superficie des fermes et loin derrière eux pour la production de foin et les productions animales. Au total, bien que plus dépendants du travail saisonnier que les anglophones, ils se trouvaient, par une marge considérable, dans une meilleure situation à cet égard que leurs compatriotes d'origine française de Hawkesbury et d'Alfred. 
Par contre, entre les divers groupes d'anglophones des deux régions, les différences, bien que réelles, n'étaient pas considérables, même si ceux de l'Est avaient été les premiers arrivants et ceux du Sud-Ouest étaient venus après les Canadiens français. S'il fallait établir une hiérarchie à ces égards, il faudrait sans doute classer les Anglais au sommet, suivis de près par les Écossais et les Irlandais: les premiers dominant davantage parmi les classes dirigeantes, les deuxièmes s'illustrant davantage par leurs performances au plan de l'alphabétisation et les Irlandais par leur grande contribution aux activités agricoles.

Quant aux Noirs, dont certains descendaient de ceux qui habitaient la région de Malden et de Sandwich depuis l'époque française, ils avaient connu en cours de route tant d'aléas qu'à la veille de la guerre de Sécession, ils ne formaient toujours qu'une fragile minorité. En 1871, leurs effectifs, également répartis entre les deux cantons, s'étaient accrus au point de surpasser en nombre les Écossais et les habitants d'origine germanique. Aussi, seulement un d'entre eux sur dix était né en Ontario et les autres aux ÉtatsUnis, alors que les Canadiens français l'étaient dans une proportion de $76 \%$ et les anglophones de $23 \%$. Ils étaient plus pauvres que les autres, plus concentrés qu'eux dans les villes et leurs filles, pour trouver des maris, étaient à toutes fins utiles limitées à leur propre race. Leurs classes dirigeantes étaient à peine développées et leurs journaliers étaient presque aussi nombreux que leurs cultivateurs. Bien que beaucoup plus alphabétisés que les Canadiens français de Hawkesbury et d'Alfred et, même un peu plus que ceux de Malden et de Sandwich, les Afro-Américains se rapprochaient des Canadiens français de l'Est. Car ils étaient fortement sous-représentés parmi les propriétaires et les cultivateurs. Leurs terres étaient petites par rapport à celles des autres groupes, leur production faible, mais pas autant que celle des Canadiens français de l'Est, et leurs 
familles agricoles dépendaient des emplois saisonniers dans une proportion d'au moins $60 \%$.

Le moment de l'arrivée des individus et des groupes dans une région eut, certes, des effets significatifs et plus ou moins durables sur le développement des inégalités entre les communautés et à l'intérieur de chacune d'elles, y compris dans la paysannerie. Mais il n'était pas le seul facteur en cause. Pour estimer les inégalités en Ontario, Gordon Darroch et Lee Soltow insistent non seulement sur l'ethnicité, l'âge et le lieu d'origine des individus et des groupes, mais en plus sur la religion et l'alphabétisation. Avec raison, d'ailleurs, puisque la religion, avec toutes ses ramifications, était à la fois, au même titre que l'ethnicité, un facteur de solidarité et de division.

En effet, les Canadiens français se distinguaient de tous les autres par l'unique intensité de leur attachement à une seule religion, le catholicisme. À Malden et à Sandwich, ainsi qu'à Hawkesbury et à Alfred, $98 \%$ de leurs chefs de maisonnée s'en réclamaient. Aussi constituaient-ils dans les deux régions près de $80 \%$ des catholiques, eux-mêmes étant responsables en grande partie du fait que les catholiques y étaient aux deux tiers majoritaires. Comme ils étaient les plus nombreux et les plus ruraux de tous, rien, sur le plan démographique, si ce n'est la forte demande de filles à marier dans les autres groupes moins nombreux, ne les incitait à contracter des mariages mixtes. À Malden et à Sandwich, dans tous les groupes excepté chez les Noirs, les plus urbains de tous, ces unions étaient plus nombreuses en milieu urbain que dans les campagnes. L'ethnicité était, bien sûr, un obstacle important, à tel point qu'un seul couple sur 1447 anglophones et francophones incluait une partenaire noire. Par contre, six maris afroaméricains sur dix engagés dans ces unions avaient pu choisir leurs épouses dans les autres groupes ethniques. Au total, moins de $5 \%$ des couples canadiens-français, 
$33 \%$ des anglophones et $17 \%$ des Afro-Américains étaient formés de conjoints différents par l'origine ethnique. Comme l'appartenance religieuse constituait un obstacle plus considérable à ces mariages que l'ethnicité, seulement $1 \%$ des époux canadiens-français, $16 \%$ des anglophones et $16 \%$ des Noirs avaient épousé des personnes d'une religion différente.

À cause de ses liens presque exclusifs avec la religion catholique, de son sens d'une identité en péril, de son caractère linguistique et, tout autant par sa longue tradition d'analphabétisme, la communauté canadiennefrançaise, comparée aux autres, s'en distinguait fortement. En effet, à Sandwich et à Malden, comme à Hawkesbury et à Alfred, comme au Québec, il existait un énorme contraste entre eux et les anglophones en ce qui concerne le savoir lire et écrire. Leur taux d'analphabétisme dans ces deux cantons du Sud-Ouest ontarien était, quant au savoir lire, plus de quatre fois plus élevé que celui des anglophones catholiques et plus de six fois plus élevé que celui des anglophones. Il était même supérieur à celui des Noirs qui, pourtant, avaient connu l'esclavage. Évidemment, ces disparités doivent être tempérées par le fait qu'ils étaient plus ruraux que les autres et qu'ils étaient surreprésentés parmi les cultivateurs. Mais les Noirs, quoique plus urbains, étaient surreprésentés parmi les ouvriers non qualifiés et ils éprouvaient de très grandes difficultés d'accès à l'école dans les campagnes, au point d'y avoir les plus hauts taux d'analphabétisme de tous. Même si les épouses canadiennesfrançaises étaient les seules à être plus alphabétisées que leurs maris, les écarts entre elles et les épouses anglophones étaient à peine moins considérables que ceux qui séparaient leurs époux. Il est évident que cette longue tradition d'analphabétisme qui pesait encore sur eux avait eu des effets négatifs sur leur développement socioculturel et socioéconomique. Ceci dit, ils avaient quand même bénéficié de la révolution scolaire puisque leurs enfants adultes étaient 
plus alphabétisés qu'eux et que leurs enfants d'âge scolaire fréquentaient l'école en nombre croissant.

Dernier point, à Malden et à Sandwich, les rapports ville-campagne avaient toujours été très importants. La création des villes d'Amherstburg et de Sandwich à la fin du XVIII ${ }^{e}$ siècle pour remplacer Détroit, bien que dictée par des considérations politico-militaires, n'avait pas été un geste artificiel. Autant Détroit avait été une ville de relais pour la traite des pelleteries, autant ces deux villes avaient été des centres pour le trafic des produits agricoles. Là, comme ailleurs, la diversification des occupations et la progression des inégalités s'était accomplie, depuis le début du siècle, en symbiose entre des activités agricoles dominantes et des activités forestières et maritimes secondaires. Il est vrai que ces villes étaient le lieu privilégié des bourgeois, des artisans, des marins, des pêcheurs, des journaliers, des veufs et des veuves sans occupation déclarée. C'était aussi un endroit où l'accès à l'école était plus facile et où plus de six chefs de maisonnée sur dix étaient des locataires. Mais Amherstburg et Sandwich ne possédaient aucune exclusivité à ces points de vue. Au point que la campagne, bien que le domaine presque exclusif de la paysannerie, avait, en plus de sa bourgeoisie, ses classes populaires dont le revenu reposait, le plus souvent, sur le salariat. Notons aussi que c'était là que le poids de la présence française s'affirmait davantage, non seulement par la suprématie numérique de sa paysannerie, mais aussi par le fait que sa bourgeoisie, ses artisans et surtout ses travailleurs non qualifiés y étaient surreprésentés. La concentration en ces lieux des veufs et des veuves sans occupations déclarées laisse peut-être supposer l'existence de pratiques successorales bien spécifiques aux Canadiens français. 
TABLEAU 33

Pourcentage des chefs de maisonnée ruraux selon leurs occupations par rapport à l'ensemble des chefs de maisonnée dans chaque groupe occupationnel dans les cantons de Malden et de Sandwich en 1871

\begin{tabular}{lcccr}
\hline & Anglo- & Canadiens & & \\
& phones & français & Noirs & Total \\
cultivateurs (nombre) & 359 & 516 & 66 & 935 \\
$\%$ & 95,7 & 97,5 & 90,4 & 96,3 \\
affaires et professions (nombre) & 31 & 30 & 4 & 52 \\
$\%$ & 23,1 & 36,2 & 40,0 & 27,2 \\
artisans (nombre) & 43 & 44 & 1 & 88 \\
$\%$ & 35,8 & 39,6 & 5,9 & 35,5 \\
travailleurs non qualifiés (nombre) & 43 & 100 & 19 & 162 \\
$\%$ & 29,6 & 64,9 & 26,8 & 37,7 \\
veufs et veuves* (nombre) & 3 & 16 & 1 & 20 \\
$\%$ & 7,0 & 57,1 & 7,7 & 23,8 \\
total (nombre) & 473 & 693 & 91 & 1253 \\
$\%$ & 58,3 & 79,8 & 49,4 & 67,4 \\
\hline
\end{tabular}

Source: ANC, recensement nominatif de 1871, comté d'Essex, bobines 9888-9889. *sans occupation déclarée.

Il est clair que la campagne était bien structurée socialement. Au point qu'il est difficile de distinguer la bourgeoisie rurale de sa contrepartie urbaine puisque leurs activités principales étaient toutes polarisées par l'agriculture et la forêt. C'étaient souvent les mêmes individus qui exploitaient, les uns en ville et les autres à la campagne, à la fois des moulins à scie, à farine, à gruau et à carder. Il en était ainsi des distilleurs et des brasseurs qui convertissaient en alcool et en bière le plus gros des surplus de grains des cultivateurs. Par contre, les hommes d'affaires qui se livraient à l'empaquetage des viandes, à la fabrication des équipements agricoles et aux travaux d'imprimerie, résidaient en ville.

Cette classe moyenne rurale et urbaine disposait aux deux endroits d'une main-d'œuvre saisonnière abondante et à bon marché qui se recrutait non seulement parmi les ouvriers non qualifiés, mais aussi dans les familles de cultivateurs, dont le niveau de production se situait entre 
zéro et 399 boisseaux de céréales, de pommes de terre et de navets. Ces derniers représentaient $42 \%$ des cultivateurs chez les anglophones, $45 \% \mathrm{chez}$ les francophones et $71 \%$ chez les Noirs. Ce qui pourrait vouloir dire que la bourgeoisie rurale et urbaine avait son support et, jusqu'à un certain point, son prolongement parmi les cultivateurs qui généraient des surplus agricoles substantiels. Mesurée par la dimension de la terre, soit 100 acres et plus, cette catégorie de propriétaires agricoles, estimée à $35 \%$ des occupants chez les anglophones, à $27 \%$ parmi les Canadiens français et à $14 \%$ chez les Noirs, contrôlait $61 \%$ du sol chez les premiers, $56 \%$ du sol chez les seconds et $33 \%$ du sol parmi les derniers. L'étendue moyenne de ces terres était de 109 acres chez les Noirs et d'environ 150 parmi les deux autres groupes. Évidemment, il s'agissait de cultivateurs pour qui la main-d'œuvre familiale et l'équipement d'autrefois ne pouvaient suffire à la tâche.

Mesurée en termes de performances agricoles qui allaient au-delà de la stricte subsistance, soit de ceux qui récoltaient plus de 399 boisseaux de grains et de racines, l'élite des producteurs était cependant plus répandue et moins richement pourvue en terre que celle définie par la possession de 100 acres et plus de terre. C'est sans doute à ce groupe que Gordon Darroch se réfère lorsqu'il parle de «farm-based, middle-class social formation ${ }^{72}$ ».

${ }^{72}$ Gordon Darroch, «Scanty Fortunes and Rural Middle-Class Formation in Nineteenth Century Central Ontario", Canadian Historical Review, 79, 1998, p. 656. 


\section{TABLEAU 34}

Le profil des producteurs de céréales, de pommes de terre et de navets de 400 boisseaux et plus

à Malden et à Sandwich en 1871

\begin{tabular}{|c|c|c|c|c|}
\hline & $\begin{array}{l}\text { Anglo- } \\
\text { phones }\end{array}$ & $\begin{array}{c}\text { Canadiens } \\
\text { français }\end{array}$ & Noirs & Total \\
\hline $\mathrm{n}^{\text {bre }}$ de cultivateurs (\%) & 58,0 & 55,0 & 29,0 & 54,0 \\
\hline superficie moyenne & & & & \\
\hline $\begin{array}{l}\text { occupée (acres) } \\
\text { superficie movenne }\end{array}$ & 105 & 90 & 50 & 95 \\
\hline $\begin{array}{l}\text { améliorée (acres) } \\
\text { céréales, pommes de } \\
\text { terre, navets par }\end{array}$ & 81 & 63 & 42 & 67 \\
\hline producteur (bois.) & 784 & 782 & 604 & 776 \\
\hline foin par producteur (tonnes) & 12,2 & 8,7 & 4,7 & 9,8 \\
\hline animaux par ferme $\left(\mathrm{n}^{\text {bre }}\right)$ & 38,3 & 34,4 & 19,0 & 35,3 \\
\hline animaux tués ou vendus ( $\mathrm{n}^{\text {bre }}$ ) & 15,3 & 8,7 & 5,7 & 11,2 \\
\hline beurre par ferme (lbs) & 317 & 122 & 108 & 200 \\
\hline fromage par ferme (lbs) & 34 & 3 & 0 & 15 \\
\hline laine par ferme (lbs) & 49 & 37 & 12 & 41 \\
\hline flanelle par ferme (vgs) & 7 & 6 & 2 & 6 \\
\hline
\end{tabular}

Source: ANC, recensement nominatif de 1871, comté d'Essex, bobines 9888-9889.

Mais, pour vraiment parler de capitalisme agraire, il faudrait sans doute réduire ce groupe à ceux qui récoltaient 1000 boisseaux et plus de céréales, de pommes de terre et de navets. Ces individus qui n'avaient pas leur équivalent parmi les Noirs, constituaient $11 \%$ des producteurs parmi les anglophones et les Canadiens français, et ils possédaient un tiers de la terre, récoltaient la même proportion de céréales, de pommes de terre et de navets et coupaient un tiers du foin. Ici, comme cela s'était souvent produit ailleurs sous l'égide des entrepreneurs forestiers, le capitalisme agraire avait fait ses premiers pas. À Hull, il s'agissait de Philemon Wright, au Saguenay-Lac-Saint-Jean de William Price et, à Hawkesbury, des frères Hamilton. À Malden et à Sandwich, il s'agissait de Hiram Walker, le plus gros distilleur de la place, qui, avec ses 1000 boisseaux de céréales, de pommes de terre et de navets, ses 900 acres de terre, ses 90 animaux de ferme et ses 90 
DisPARITÉS SOCIO-ETHNIQUES, COMTÉ D'EsSEX (1871)

tonnes de foin coupées, était le chef de file de l'endroit. Ce qui démontre la grande difficulté de réduire la réalité à un seul concept qui engloberait tous les aspects de ce qu'on nomme la Middling-class ou Middle-class rurale. 